\title{
THE EVOLUTIONARY ORIGIN AND BIOLOGICAL UTILITY OF SUPERNATURAL EXPERTISE
}

\author{
By
}

Andrew Neil Mahoney

\author{
A thesis \\ submitted to Victoria University of Wellington \\ in fulfilment of the requirements for the degree of \\ Doctor of Philosophy \\ in Religious Studies
}

Victoria University of Wellington 


\begin{abstract}
Recent psychological and cognitive research has explored the evolutionary origins of human religiosity. In this thesis, I explore the historical origin and social function of supernatural expertise. I define supernatural expertise as the act of acquiring and expressing supernatural knowledge. I critique several recent theories from evolutionary psychology and cognitive science by assessing the extent to which they can explain supernatural expertise.
\end{abstract}

Costly signalling theory is the view that religious costs are adaptations that signal the cooperative intent of individuals. This theory cannot account for supernatural expertise as expressions of supernatural knowledge are typically linguistic, and one can verbally misrepresent one's supernatural beliefs.

Sexual selection theory explains how physiological or psychological traits can become exaggerated over time if they are preferred by mating partners. Sexual selection can explain an increase in the cognitive capacities necessary for the acquisition of supernatural knowledge. However, it cannot account for the complex nature of supernatural information.

Cognitively optimal theory predicts that the religious information which persists within human populations should be easily transferred and recalled. The theory cannot account for any supernatural information which requires considerable effort to acquire. 
The modes theory explains religion in terms of memory systems and the social arrangements that humans have developed to mediate the exchange of religious ideas. These result in two modes of religiosity. The doctrinal mode of religiosity explains why supernatural experts exist, but not how supernatural expertise originated.

I conclude by arguing for an innovative theory for supernatural expertise. I employ cognitively optimal theory to explain why some supernatural concepts are difficult to recall. I explain the signalling function of supernatural expertise in terms of the costly effort invested in the acquisition of supernatural information. I propose that sexual selection for the cognitive capacities to acquire supernatural knowledge has enhanced the ability to acquire such information; this necessitates an increase in the complexity of supernatural information which ensures cooperative commitment remains a predominant motivation for the acquisition of supernatural knowledge, in spite of enhanced cognitive ability. I discuss several social conditions that result from the doctrinal mode of religiosity and how they solve cooperation problems in dense populations. 


\section{Acknowledgements}

To my dearest Pollyanna, "the whole wide world could not mean more than a friend whose heart I'd adore." You were right, I am smart! I guess we're living in the alternate universe after all, where anything is possible. :) Thank you for looking after mе. Ты моя бабочка, моя радуга, и мой лебедь. Я люблю тебя, моя лапочка.

Thank you to Joseph Bulbulia, my supervisor. Joseph went beyond the call of duty on many occasions, even appointing me guest lecturer of his 2009 Religion and Biology paper at my own request. In truth, without his mentoring, encouragement, and friendship, I would never have completed my Honours degree, let alone this thesis.

I thank the Bright Futures scheme for funding my $\mathrm{PhD}$ candidacy with a Top Achiever Doctoral scholarship.

Writing a $\mathrm{PhD}$ is a very difficult task, and many a $\mathrm{PhD}$ student has seriously contemplated giving up. I myself gave up one day. This thesis is dedicated to the two Jehovah's Witnesses who knocked on my door the following day, and who, after a most perplexing conversation, motivated me to continue. 


\section{Contents}

Abstract

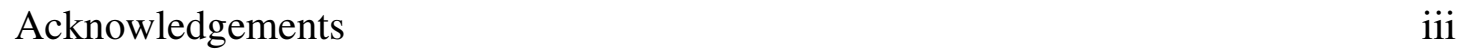

Contents iv

Chapter 1. Supernatural expertise and the evolutionary paradigm 1

1.1 Introduction 1

$\begin{array}{ll}\text { 1.2 The evolutionary paradigm } & 3\end{array}$

1.3 Evolutionary biology

1.4 Cognitive science $\quad 8$

$\begin{array}{ll}1.5 \text { Evolutionary psychology } & 10\end{array}$

$\begin{array}{ll}1.6 \text { Religious studies } & 12\end{array}$

$\begin{array}{ll}\text { 1.7 Cognitive science and religion } & 14\end{array}$

$\begin{array}{ll}1.8 \text { Evolutionary psychology of religion } & 16\end{array}$

$\begin{array}{lr}1.9 \text { Supernatural expertise } & 18\end{array}$

1.10 The evolutionary paradigm does not predict supernatural expertise 24

1.11 Chapter overview 26

$\begin{array}{ll}\text { 1.12 Scope and objections } & 28\end{array}$

1.13 Conclusion 32

$\begin{array}{ll}\text { Chapter 2. Adaptationism } & 33\end{array}$

2.1 Introduction 33

2.2 Costly signalling theory 35

2.2.1 Pan-human religion $\quad 35$

2.2.2 Cooperation dilemmas $\quad 36$

2.2.3 Altruism and secular punishment 38 
2.2.4 The handicap principle

2.2.5 Costly signalling in humans

2.2.6 Supernatural causality

2.2.7 Religious signalling

2.2.8 Religious signalling strategies $\quad 51$

2.2.9 Supernatural expertise as a handicap $\quad 55$

$\begin{array}{ll}\text { 2.2.10 Conclusion } & 57\end{array}$

$\begin{array}{ll}2.3 \text { Sexual Selection } & 58\end{array}$

$\begin{array}{ll}\text { 2.3.1 Evolution by sexual selection } & 58\end{array}$

2.3.2 Sexual selection for cultural phenomena and supernatural

$\begin{array}{ll}\text { expertise } & 62\end{array}$

$\begin{array}{ll}\text { 2.3.3 The ratchet effect } & 64\end{array}$

$\begin{array}{ll}\text { 2.3.4 The ratchet effect and supernatural expertise } & 67\end{array}$

$\begin{array}{ll}\text { 2.3.5 Conclusion } & 69\end{array}$

$\begin{array}{ll}\text { Chapter 3. Spandrelism } & 71\end{array}$

$\begin{array}{ll}3.1 \text { Introduction } & 71\end{array}$

3.2 Cognitively optimal theory 72

$\begin{array}{ll}\text { 3.2.1 Evolved intuitions } & 72\end{array}$

$\begin{array}{ll}\text { 3.2.2 Counter intuitive information } & 77\end{array}$

$\begin{array}{ll}\text { 3.2.3 Supernatural knowledge as cognitively optimal } & 79\end{array}$

3.2.4 Conclusion $\quad 82$

$\begin{array}{ll}3.3 \text { The modes theory } & 82\end{array}$

$\begin{array}{ll}\text { 3.3.1 The doctrinal mode of religiosity } & 84\end{array}$

$\begin{array}{ll}\text { 3.3.2 Discussion of the doctrinal mode } & 87\end{array}$

$\begin{array}{lr}\text { 3.3.3 Conclusion } & 90\end{array}$ 
Chapter 4. Towards a reconciliation of the adaptationist and spandrelist paradigms

4.1 Introduction

4.2 The cost of complex supernatural knowledge

4.3 Sexual selection for the cognitive capacities necessary for

supernatural expertise

98

4.4 The functionality of the doctrinal mode

101

4.5 Conclusion

109

Bibliography

114 


\section{Chapter 1. Supernatural expertise and the evolutionary paradigm}

\subsection{Introduction}

I open this thesis with the same question that I proposed in the first lecture of a third year Religious Studies class at the beginning of 2009, "Why do people have religion?" The history of sociology is riddled with attempts to answer to this question. For David Hume, religion resulted from a "passion for surprise and wonder" (1776). For Karl Marx, religion is an oppressive tool concocted by a conspiracy of a ruling class (Marx \& Engels 1888/1976). For Edward Tylor, religion is a product of intellectual curiosity (1871). For Sigmund Freud, religion is a psychological tool enabling the repression of guilt $(1913 / 1938,1927 / 1964)$. For Emile Durkheim, religion is the objectification of social order through a network of symbols (1915/1995).

This thesis approaches this question, not from any of the above perspectives, but from a biological perspective. I open by overviewing Charles Darwin's theory of evolution (1859/1968). I define the evolutionary paradigm as the method of studying biology, psychology and sociology from a Darwinian perspective. To clarify, human physiology and psychology are the product of evolution, as is the human brain. The process of evolution has endowed the human brain with the ability to experience consciousness, and this consciousness enables us to engage in complex social behaviour and to practice religion. Thus the theory of evolution can help to foster a better understanding of human psychology, sociality, religiosity and other aspects of human nature. 
Research has been conducted examining many aspects of religion from an evolutionary point of view, including ritual (Sosis 2003; Whitehouse 2004), religious emotion (Bulbulia 2004a), belief (Boyer 2001), and doctrine (Whitehouse 2004), as well as consideration of whether religion can be sexually attractive (Miller 2001). This thesis focuses on one aspect of religion, specifically, the acquisition and expression of complex knowledge regarding the gods and other supernatural beings or forces. Throughout this thesis, I call this behaviour supernatural expertise, and I define a supernatural expert as a person who possesses such expertise. That is, a person who engages in the acquisition and expression of complex supernatural knowledge. Supernatural expertise is interesting from an evolutionary perspective because unlike other human needs such as the desire to eat, sleep, have sex, etc., the desire to acquire supernatural knowledge does not appear to be explainable in terms of biological impulses.

After explaining the evolutionary paradigm, this chapter continues with a brief introduction to the fields of evolutionary biology, cognitive science, evolutionary psychology and religious studies. I then define supernatural expertise in more detail and explain the necessity of studying supernatural expertise from an evolutionary perspective. The chapter proceeds by considering common objections to the evolutionary study of religion, and concludes with an overview of the chapters to come. 


\subsection{The evolutionary paradigm}

Few would dispute that life is one of the most interesting properties of the universe. Not only for its peculiarity in comparison to more common celestial phenomena, such as inter-galactic void or stellar bodies, but also for the ability of life to evolve, adapt, and ultimately survive in a diverse variety of terrestrial environments and ecological niches. Mountain tops, city dumps, animal excretions, and even your intestines, are all rich environments in which complex ecologies exist. Ironically, this great triumph is surpassed only by the monumental failure of the vast majority of living forms to survive and reproduce. A single sunfish can lay up to 300 million eggs at once, a giant puffball will produce 7 trillion spores in its lifetime, and a human male will ejaculate 200 million sperm during a single copulation. The vast majority of these forms will fail to mature and those that do mature will likely fail to survive to adulthood and successfully reproduce. Even within our own species, for which recent technologies have made it possible for most children to survive to adulthood in some geographical locations, those fortunate enough to be born in these locations can only survive at the expense of the lives of countless other organisms. Given that almost all life seems to be exceptionally good at dying, the tiny iota of forms that do survive must be the greatest experts at living.

The $19^{\text {th }}$ century naturalist Charles Darwin developed the theory of natural selection (1859/1968) to account for similar observations. Darwin identified three mechanisms of natural selection. First, variation is the principle that most living things differ from each other in some manner. Second, the mechanism of competition states that living things will constantly be struggling with one another to survive. Third, inheritance is 
the observation that offspring inherit the vast majority of their parents' traits. From these three mechanisms Darwin deduced the theory of natural selection, which states that those few organisms that are uniquely skilled to survive the competition for existence will pass the variations that enabled them to do so onto subsequent generations. This results in a gradual accumulation of infinitesimally small variations, which the theory maintains is responsible for the significant changes to species over vast geological epochs.

Darwin himself overviewed his theory in his book entitled The Origin of Species $(1859 / 1968)$, and the theory is sometimes thought of as serving no purpose other than to explain the origins of life, with little application to the contemporary world. However, I suggest that an evolutionary study of human psychology is relevant. Darwin himself understood that his theory had wide ranging applications. He wrote, "in the distant future I see open fields for far more important researches. Psychology will be based on a new foundation, that of the necessary acquirement of each mental power by gradation" (Darwin 1859/1968). To clarify his point, life can be explained as the product of both chance and a universal set of laws (Edis 2002; Edis 2004; Monod 1971). To illustrate, in evolutionary terms we understand life to be the product of natural selection acting upon random variations. We can likewise understand human intelligence to be the product of laws and chance (Edis 2004). Thus, a better understanding of human culture, religion, and behaviour will be gained when we understand the nature of the laws governing the origins of the human mind, as well as the limits of randomness to which these laws are subject. 


\subsection{Evolutionary biology}

In brief, natural selection is the process during which intergenerational change occurs via the differential survival ability of varying replicators. Although the process can be summarised in a single sentence, it has lead to as many different outcomes as there are individual organisms in the world. Each replicator in existence, whether it be an organism, a replicating cell in an organism, or a self replicating group of organisms (such as an ant colony) represents a different outcome of the evolutionary process. In biology, genetically similar organisms are grouped into species, genus and other levels of taxonomical classifications (Mayr 2001).

Many traits possessed by species can be explained in reference to an evolutionary trend, that is, an identifiable process of development which occurs when natural selection interacts with particular variations in a certain manner. Examples of evolutionary trends include the handicap principle and the ratchet effect. These theories are analysed in chapter 2. Other evolutionary trends include coevolution, where two species evolve side by side (such as a predator and its prey), or genetic drift, where change occurs without conveying an advantage or disadvantage to the changing organism (such as varying eye shapes in different human racial groups) (Richerson \& Boyd 2005).

Further, almost all physiological and psychological traits can be classified as either an adaptation or a spandrel. If we think of natural selection as a process that generates apparent design, an adaptation would be a purposeful component of that design, whereas a spandrel would be a side effect of a purposeful or group of purposeful 
components. For a trait to be considered an adaptation, two conditions must be met. First, a biological adaptation must be an emergent property from physiological and/or psychological systems (Andrews, Gangestad, \& Matthews 2002). Second, the adaptation should be able to function with a reasonable level of efficiency (Williams 1966). An example of an adaptation in our own species would be our tendency to prefer environments or homes that offer visibility and privacy (Appleton 1975). Since we evolved in a competitive predator rich landscape, these environments would have endowed our ancestors with a strong survival advantage, thus selection targeted this preference. It should also be noted that adaptations are not limited to individual organisms but can likewise be possessed by a group of individuals (Wilson 2002). That is, no individual within the group can be said to possess the adaptation and the adaptation belongs to the group as a whole, such as the pollen processing function of a beehive. No individual bee can manufacture honey alone; the adaptation belongs to the group.

A spandrel is an accidental byproduct of an adaptation, named after spandrels in cathedrals which are typically decorated with beautiful artwork. An architectural lay person may conclude that the spandrel was placed in the cathedral deliberately for an artistic purpose. However, she would be mistaken. A spandrel may appear to be part of the design, but in reality it is the effect created when two archways are placed side by side. A spandrel is the side effect of an archway. In biology, a spandrel is a trait that may appear to be a part of an organism's design, but in fact has not been targeted by natural selection (Gould \& Lewontin 1979). Spandrels can be either advantageous, disadvantageous, or neither. An example of a positive spandrel would be literacy. Literacy is, at best, a four thousand year old technology. Human brains were not 
designed to be literate, but it seems that almost all human beings can become literate after several years of training. Literacy is a spandrel (a side effect) of the human ability to use language and recognise symbols. An example of a disadvantageous spandrel would be ingrown toenails. Toenails are an adaptation designed to protect toes. They are not designed to become ingrown. Ingrown toe nails are a spandrel of the particular way in which toenails are adapted to grow.

I now turn to examples of the manner in which evolutionary theory has been applied to understand human origins and human nature and the relevance of these examples to this thesis. Due to the many observable differences between human beings and other animals, humans have occasionally been considered as being separate from the primate order (Strier 2002) and animal kingdoms. However, we share many traits with other animals (Foley 1995), indicating common descent with the animals with which we share traits. For example, we share a number of habits with apes (Dunbar 2004), such as social culture (Sapolsky 2006). Human culture accumulates through the human ability of imitation, an ability that we share with chimpanzees (Tomasello $\&$ Carpenter 2005). Further, it is not only the great apes with whom humans share traits, for example it is known that some other animals experience rudimentary emotions (Lazarus 1991; Maynard Smith \& Harper 2003). In section 2.2.5, I discuss the relationship between emotions and morality. Notably, evolutionary theory has been applied to show how morality can evolve to prevent violence (de Waal 1996), and how human violence had its origins in a primate context (Wrangham \& Peterson 1996). 


\subsection{Cognitive science}

The study of human cognition is referred to frequently throughout this thesis.

According to cognitive science, the human brain performs a computational function (Tooby \& Cosmides 2005), which accepts input in the form of sensory information and processes that information to produce output in the form of behaviour (Pinker 1995). Cognitive capacities are embedded in the human brain (Whitehouse 2000) and are utilised in the processing of this information.

The human brain develops with age, with different components of the brain maturing at different stages of development. For example, the temporal cortices of the brain attain maximum volume at age 16 (Giedd, Blumenthal, Jeffries, Catellanos, Liu, Zijdenbos, et al. 1999). As the different parts of the brain develop, the manner in which the brain processes environmental information also develops (Kolb, Forgie, Gibb, Gorney, \& Rontree 1998), until the brain attains maximum volume at age 17 (Giedd, Blumenthal, Jeffries, Catellanos, Liu, Zijdenbos, et al. 1999). For example, during the adolescent stage of the brain's development, people will display stronger reactions to environmental stimuli. For instance, social interest heightens and symbolic reasoning increases. This may be due to specific brain components which grow during adolescence, such as the amygdala (Spear 2000). This suggests a strong connection between the biological composition of the brain and human behaviour.

Our behaviour is produced by nearly universal innate cognitive capacities embedded in the human brain. For instance, people hearing the same music typically share the same heart rate, respiration rate, and emotions (Harrar \& Harrar 1977). This suggests 
that different brains possess a similar cognitive capacity to respond to music. The only reason I do not claim that all human cognitive capacities are completely universal is because the brains of some severely mentally handicapped persons operate differently, for example the brain's limbic system functions differently in psychotic patients (Hare 1999; Kapur 2003). Examples of cognitive capacities which emerge from the brain's biological composition include an awareness of space and time (Levinson 2003), the ability to acquire language (Pinker \& Bloom 1990), knowledge of predator/prey interaction (Barrett 2005) which was essential information during our species' evolution, and the ability to experience emotion (Damasio 1999). Although the role of emotion is sometimes neglected in psychological theories of religion (Hill 1995; Watts 1996; Watts \& Williams 1988), I discuss it in sections 2.2 .5 and 2.2.8 because of a close link between emotion and cognition (Epstein 1994) which affects behaviour. For example, certain emotions function to temporarily enhance awareness (Hattfield, Cacioppo, \& Rapson, 1994; Levenson 1999).

The cognitive capacities of the human brain are implemented within the brain's physical and chemical structure. For example, certain chemicals, such as dopamine and endorphins, have been shown to alter behaviour by elevating attention and emotion (Damasio 1999). Also, people are known to respond strongly to pain, hunger and sexual desire, in part, because of our dopamine reaction to these states (Berridge \& Robinson 1998; Horvitz 2000). Sensory inputs can also alter the brain's chemical state, with stress and some forms of pain such as dehydration and exposure to extreme hot or cold, leading to an increase of endorphins (Henry 1982; Prince 1982). 
As per the convention in cognitive science, throughout this thesis I treat the human brain as an information processing device. This device interacts with body and culture to process sensory input and produce behavioural output. All human brains share a similar design. This design is the product of natural selection, a topic I turn to in the next section.

\subsection{Evolutionary psychology}

The hominid genus has evolved gradually over the past two million years, with homo sapiens emerging around 150,000 years ago. The environment in which our species evolved is known as the environment of evolutionary adaptation, or EEA for short. During this time, natural selection has been acting upon human psychological traits and cognitive capacities. For this reason, we can treat all human psychological traits as being an emergent property of cognitive capacities that evolved during the EEA (Barrett 2004b; Mithen 1996).

A number of predictions can be made from this observation. Our brains are designed to promote survival within the set of environments in which our ancestors lived during the past two million years (Lazarus 1991). For this reason, our brains are adapted to make rational decisions regarding our most basic survival needs (Bulbulia 2004a), such as the sourcing of food, shelter, warmth, etc. The human brain therefore possesses a preference for information that promotes the likelihood of one's survival (Tooby \& Cosmides 1992). 
One example of a cognitive adaptation which promotes our chances of survival are our environmental preferences. As discussed earlier, humans prefer environments that offer visibility and privacy (Appleton 1975). This preference, along with other environmental preferences, is common to many different human cultures (Herzog, Herbert, Kaplan, \& Crooks 2000). Environmental preferences are often unconscious (Korpela, Klemettila, \& Hietanen, 2002; Ulrich 1983; Zajonc 1980), and these unconscious preferences have been targeted by natural selection (Kaplan 1992; Orians, \& Heerwagen 1992; Silverman \& Choi 2005). There is also evidence to suggest that humans are cognitively adapted to adopt specific survival strategies in certain environments (Kaplan \& Kaplan 1989).

The manner in which the brain responds to environmental inputs is determined by specific psychological mechanisms (Kenrick, Maner, Butner, Li, Beker, \& Schaller, 2002; Rozin, Kurzer, \& Cohen 2002; Tooby \& Cosmides 1990). The cognitive capacities of the human brain are modular (Mithen 1996), that is, they are divided into specific mechanisms, each of which is designed to perform a certain task. These psychological mechanisms evolved during the EEA (Boyer 2001) to help solve environmental problems that our ancestors had to cope with. One example of a psychological mechanism unique to human evolution is our ability to use fire without being afraid of it. This mechanism is separate from another mechanism common to other animals which endows us with a fear of uncontrollable fire (Fessler 2006). This thesis follows the recent practice of explaining human behaviour in terms of psychological mechanisms which evolved during the EEA. 


\subsection{Religious studies}

Although we can understand behaviour as being determined by a Pleistocenedesigned human brain, the cultural context in which a person exists is also relevant as cultural information constitutes an environmental input which the brain must process. There is much literature stressing the importance of taking culture into consideration when studying humans (Clark 1997; Clark \& Chalmers 1998; Deacon 1997; Hutchins 1995; Richerson \& Boyd 2005; Rowlands 2003; Tomasello 1999; West-Eberhand 2003). The prominent aspect of human culture examined within this thesis is religion. Religions are, of course, a very diverse phenomenon and have been classified as assuming a number of different forms, such as individualistic, shamanic, communal, and ecclesiastical (Wallace 1966). There are however some elements common to many religions, such as a focus on salvation (Weber 1923/1978).

Since the concept of religion is sometimes regarded as being a western political construct (Smith 1982), any discussion of religion requires a definition of what is meant by the term religion. Indeed, it is not uncommon for people in the western world to have opinions, sometimes strong opinions, about what religion is or what it ought to be. For purposes of this thesis, I set aside such folk definitions and instead employ Justin Barrett's definition of religion as "a shared system of beliefs and actions regarding supernatural agency" (2000). Much scholarship concerns itself with methodologies to help understand the origin of religion, such as the view that an understanding of this origin can be gained through the study of ancestral cultures (Harrison 1909) or the view that religion results from emotionally charged symbols (Tooby \& Cosmides 2001). These views are helpful. However, accounting for all 
religion with a single explanation is problematic when we consider the multiplicity of religious experience. Research concerning the scope of the diversity of religious experience (Hill \& Hood, Eds. 1999a; Hill \& Pargament 2003) justifies the view that a variety of explanations for religiosity are necessary. Further, some people explicitly choose a belief in religion (James 1907/2003) and would not consider themselves to believe for reasons such as those previously mentioned. Nevertheless, in the tradition of cognitive science and evolutionary psychology, we can treat religion as a cognitive capacity, or the product of a set of cognitive capacities, that have evolved during our species' evolutionary history. Religion can be considered separate from the many forms which it assumes (Tiele 1897), and the essence of religious forms that I am concerned with in this thesis is the psychological mechanism or set of mechanisms which, by design or accident, produce the many forms of religiosity.

Despite the many diverse forms that religion assumes in different societies, there is evidence demonstrating that systems of belief regarding supernatural agency are universal to all human cultures (Brown 1991; Murdock 1965). According to the many criteria that must be met before claiming that a behaviour or trait is universal (Brown 1991; Norenzayan \& Heine 2005), shared systems of belief can be considered a human universal for many reasons. For instance, in a study of 186 human societies, shared supernatural beliefs were found to be present in every one (Johnson 2005; Murdock \& White 1969). Additionally, religious practices motivated by shared supernatural beliefs have been found to be common, with $70 \%$ of cultures practising rites of passage for adolescents (Lutkehaus \& Roscoe, Eds. 1995). The evidence demonstrates that a belief in supernatural agents is common to all cultures (Bering 2006a; Tremlin 2006), and possibly to all individuals, with those professing no belief 
in the supernatural devoting themselves to quasi-magical abstractions (Bulbulia 2004a).

\subsection{Cognitive science and religion}

Given the universality of religiosity, the origin or cause of religious concepts and practices is of great interest. The search for this cause is the focus of the cognitive science of religion (Barrett 2000). Given the pan-human design of the brain, there is evidence showing that religion draws on specific cognitive systems built into the brain (Persinger 1987), and that the brain produces representations of supernatural agents and forces (Boyer 2001). Cognitive science concerns itself with how these understandings are being produced. To utilise the understanding of the brain as a computer, our brains are sourcing certain information from the environment as input, processing that information to generate belief, and producing religious behaviour as an output. Accordingly, the cognitive science of religion concerns itself with explaining religiosity in computational terms (Gibson 2005).

There is much evidence to show that there is a relationship between religion and the brain. One study argued that a dedicated system within the temporal cortex enables persons to experience the presence of God (Persinger 1987). Additionally, several experiments have been conducted in which religious participants have engaged in religious practice while neural images of their brain patterns were observed (Azari, Nichel, Wunderlich, Niedeggan, Hefter, Tellmann, et al. 2001; Beauregard \& Paquette 2006). These experiments show that multiple areas of the brain are utilised during mystical experiences, (Beauregard \& Paquette 2006) and that the brain's 
dorsolateral prefrontal cortices are activated during the recitation of scriptural passages (Azari, Nichel, Wunderlich, Niedeggan, Hefter, Tellmann, et al. 2001). These neural activities function to stimulate certain emotional responses (Newberg \& d'Aquili 1998). Further, where emotional states are accompanied by a release of endorphins, this creates an experience which can sometimes be attributed to supernatural influence (Frecska \& Kulscar 1989), cementing religious belief. We observe that religious practice activates specific systems in the brain, which invoke specific emotional responses which can strengthen a belief in religiosity, motivating repeat religious behaviour.

There is likewise evidence to demonstrate a relationship between the brain's chemical structure and religiosity. It has been shown that certain drugs, which can either enhance or reduce levels of dopamine in the brain, can also increase or decrease levels of religiosity (Nichols \& Chemel 2006). Further the DRD4 gene, which is known to be related to dopamine levels within the brain, likewise corresponds to a higher level of religiosity (Comings, Gonzales, Saucier, Johnson, \& MacMurray 2000). It is also interesting to note that people suffering from Parkinson's disease display lower levels of religiosity (McNamara, Durso, Brown, \& Harris 2006), which may be related to the fact that dopamine levels in Parkinson's sufferers are $40 \%$ lower than those of nonsufferers (Agid, Jovoy-Agid, \& Ruberg 1987).

Cognitive science has had many useful applications and has helped to gain a better understanding of specific religious behaviours. For example, cognitive science has been used to demonstrate that the psychological states which the brain experiences during firewalking are the same as those experienced at rave parties, and further that 
these states can be drug induced (Greenfield 2000). It has also been applied to studies involving meditation by monks (Newberg, Alavi, Baime, Pourdehnad, Santanna, \& d'Aquili 2001), and the prayer of nuns (Beauregard \& Paquette 2006). The knowledge that religious belief is produced in the human brain has proved practical, which is my reason for utilising such research throughout this thesis.

\subsection{Evolutionary psychology of religion}

Just as cognitive science concerns itself with how the brain generates religious belief and behaviour, the study of the evolutionary psychology of religion concerns itself with why the brain produces religion. Or more specifically, why the brain has evolved the particular structure discussed that is responsible for religiosity. Despite attempts to abandon evolutionary approaches to cultural and sociological studies (Sharpe 1986), the theory of evolution has influenced the scientific study of religion for a long time (Harrison 1909). So much so that without Darwin's theory, a scientific understanding of religion would be impossible (Marett 1912; Sharpe 1986). A number of publications overviewing the variety of research conducted within this field are available (see Atran 2006; Barrett 2000; Bering 2006b; Boyer 2003; Bulbulia 2004b, 2007; Dow 2006; Sosis \& Alcorta 2003).

Utilising this approach, the study of the origin of religion need no longer concern itself with the religions of ancestral cultures (a view expressed by Harrison 1909), but instead with the evolution of religious cognition (Marett 1909). I define religious cognition as the brain's tendency to produce religious belief and output religious behaviour in response to the environmental stimuli that the brain encounters. In order 
to consider whether this trait can evolve in a Darwinian sense, we must identify whether the three mechanisms of Darwinian evolution, being variation, competition, and inheritance, apply to religion. First, it has been shown that there are differences in the religious attitudes and behaviours of different individuals (Koenig \& Bouchard 2006). Second, there is evidence to support the hypothesis that belief and worldview can provide advantages in competitive contexts (Covey, Merrill, \& Merrill 1994; Waitley 1979; Wind, Crook, \& Gunther 2005). Two examples include the stress relief that can be gained from meditation (Benson 1976; Lazar, Bush, Gollub, Fricchoine, Khalsa, \& Benson 2000), or the relationship between spirituality and mental health (Hill \& Pargament 2003). There is also evidence supporting the hypothesis that religiosity is inheritable (D’Onofrio, Eaves, Murrelle, Maes, \& Spilka 1999; Koenig \& Bouchard 2006). There are two conclusions that can be drawn from these facts. One is that any differences in religious behaviour which provide a competitive advantage will be inherited by subsequent generations, allowing the Darwinian evolution of religious cognition to take place; this is an adaptationist perspective. Another is that religious cognition is a side effect of another cognitive trait (Boyer 1994), and that any inheritable differences in religious cognition are a byproduct of the inheritable differences of the trait that produces it; this is a spandrelist account.

However, as discussed earlier, it is difficult to justify a single explanation for religiosity given the diverse scope of religious behaviour and experience. For this reason, the dissection of religion into constituent components for the purposes of studying the evolutionary history of each one is possible (Bering 2005). Therefore, the study of the evolutionary psychology of religion has identified a number of 
different evolutionary processes for the purposes of explaining different aspects of religion (Alcorta \& Sosis 2005). Several publications present a system of classification for the variety of different evolutionary accounts of religion (see Atran \& Norenzayan 2004; Dennett 2006; Wilson 2005), some of which are identified in section 1.11. As with any good scientific field, these hypotheses are empirically testable (Atran \& Norenzayan 2004; Wilson 2005). Both theoretical and empirical research has lead to a generally accepted hypothesis concerning the origin of religion (see Atran 2002; Boyer 2001; Dawkins 2006; Dennett 2006; Mithen 1996).

\subsection{Supernatural expertise}

I define supernatural expertise as the acquisition and expression of complex knowledge regarding the gods and other supernatural beings or forces, and I define a supernatural expert as a person who possesses such expertise. I treat the acquisition and expression of supernatural knowledge as a practice or ritual that some religious persons engage in. Supernatural reality may include beings or forces such as Amida, Krishna, God, Zeus, karma, Christ and num. Thus a lama, shaman, psychic and most other religious elites would be considered a supernatural expert according to this definition. In this regard, expert supernatural discourse differs from other religious discourse in that other religious discourse is not dependent upon expertise. My definition of supernatural expertise does not include rational discussions of the supernatural beliefs of others; for example, a buddhologist explaining the nature of Avalokiteshvara in Tibetan Buddhism is expressing sociological and anthropological knowledge regarding the beliefs of Buddhists; but this knowledge is not necessarily a part of her personal supernatural beliefs. 
In previous publications I referred to supernatural expertise as theology, which I defined in a manner identical to the definition of supernatural expertise presented here (Bulbulia \& Mahoney 2008; Mahoney 2008). A recent body of literature which references one of my publications (Mahoney 2008) also uses the term theology in this manner (see Bulbulia 2009; Bulbulia \& Mahoney 2008; Bubulia \& Frean, in press; Chesswas, unpublished). This has caused some confusion given that theology is ordinarily understood as "an historical body of systematic reflection on religious and spiritual matters by an elite group of specifically trained scholars” (Morris 2010, personal communication). This thesis does identify specific cognitive and opportunity costs that supernatural experts must incur during the acquisition of complex supernatural knowledge, costs which may or may not occur during formal training. It also explains how systematic reflection on religious and spiritual matters can generate increasingly more complex supernatural information. However, although I maintain that the conventional definition of theology is compatible with my definition of supernatural expertise, I recognise that centuries of use has endowed the word theology with numerous connotations. Therefore, throughout this thesis I have elected to replace the term theology from my previous work with the new term supernatural expertise, to avoid the problems that arise from invoking these connotations. However, for purposes of compatibility, whenever the term supernatural expertise is invoked herein it should be regarded as interchangeable with the manner in which the term theology has been applied in my previous publications.

Although supernatural expertise is not universal, the vast majority of human beings, both contemporarily, historically, and even traditionally, have believed in the 
existence of supernatural beings or forces (Boyer 2001; Tremlin 2006). Those who claim otherwise are often devoted to quasi-magical abstractions such as "freedom", “justice", or "progress" (Bulbulia 2004a). Belief in such entities typically entails an interest in numerous supernatural questions, such as: "Who are the gods?", "What is the nature of the gods?", "What is my relationship with the gods?", "How do I alter this relationship?", etc. The fact that almost everyone wonders about these questions, sustains a body of religious elites who acquire an expert level of supernatural knowledge. This thesis addresses the issue of why shared systems of supernatural beliefs are elaborated upon by complex bodies of supernatural knowledge. It does not attempt to account for the near universal human interest in supernatural questions, rather it accounts for the few individuals whose desire to acquire supernatural knowledge motivates them to successfully emerge as supernatural experts. Given that supernatural experts are not present in every society, this thesis only concerns itself with the phenomenon of supernatural expertise, where it occurs.

Despite the near universal human interest in supernatural questions, it is perplexing that answers to such questions are typically portrayed in esoteric language that appears to be finely configured in such a way so as to be incomprehensible to most and understandable only to an elite few. Although the scope and extent of supernatural commitment is not the topic of this thesis, I illustrate this point with two examples. First, consider the following quotation: "The second Guardian of the Faith has faithfully appointed his successor and the Guardianship continues to exist as a living Institution ... with the assurance that the highest institutions of the ... Administrative Order have been preserved intact and uncorrupted in their divinely-

\footnotetext{
${ }^{1}$ I use the word "god" to refer to any supernatural being or force.
} 
conceived perfection and glory for both the believers of this day and for future generations ... in the ages to come of the [current] Dispensation" (Marangella 1998).

This quotation was written by Joel Marangella, the leader of a religious sect he founded in the late 1960s called the Orthodox Bahá'í Faith. This statement is impossible to understand without contextual knowledge of the phrases: "second Guardian of the Faith”, “Guardianship", "living Institution”, "highest institutions”, “Administrative Order", "intact and uncorrupted”, "divinely-conceived perfection and glory", "ages to come", and "[current] Dispensation". Furthermore, a member of the mainstream Bahá'í World Faith would likely struggle to contextually comprehend the first, third, and sixth of these phrases, unless they were familiar with the supernatural beliefs of this particular sect. Most, if not all, Orthodox Bahá'ís would be familiar with this terminology and thus able to accurately recognise this quote as evidence for Joel Marangella's claim to be God's current representative; as for the rest of us, the quotation is nonsensical.

Second, I presented another example from a very different religious tradition in a recent paper (Mahoney 2008), in which I challenged my reader to "try to decipher the following quotation from a Gnostic Christian gospel: 'All natures, starting from the revelation of chaos, are in the light that shines without shadow, and in joy that cannot be described, and in unutterable jubilation. They ever delight themselves on account of their unchanging glory and the immeasurable rest, which cannot be described among all the aeons that came to be afterward, and all their powers.' (Soph. Jes. Chr. 113.19-114.8, Robinson 1990). 
"This quotation is typical of the language employed in a scripture called The Sophia of Jesus Christ. As this scripture was unearthed in Egypt 62 years ago, ${ }^{2}$ having been buried since the fourth century (Robinson 1990), any theological baggage implicit in the discourses of groups that recognised this scripture has been long forgotten. I therefore suggest that no living person could justifiably claim to fully understand all of the theology in this text" (Mahoney 2008). It seems that wherever there is supernatural information, there is also terminology and metaphor that can only be understood by a select group of people.

Contrast supernatural rhetoric with a more rational statement, ${ }^{3}$ such as the fact that there is an axe murderer standing behind you. This is an example of what I would call biologically strategic information. By this I mean information that can help you survive and ultimately reproduce in the real world.

What is even more perplexing is that there is evidence to show that many people who learn complex supernatural concepts and explicitly claim to believe in them, do not implicitly believe in them (Slone 2004). That is, they will claim to hold beliefs but their actions will speak differently. This has been confirmed by experiments involving the use of implicit association tests (IATs), (for examples see Gibson 2005) in which participants' reaction times are measured to assess the speed at which they cognitively process information; these tests are an alternative to self-report measures,

\footnotetext{
${ }^{2}$ Note that I am quoting from a paper that I wrote in 2007, it would now be accurate to say that the scripture was unearthed 66 years ago.

${ }^{3}$ I define rationality as self correcting domains of reason based upon empirical foundations. The example given, of an axe murderer standing behind you, is empirically testable; whereas the claim that an incorporeal demon is present in the room with you is not. For this reason, this thesis does not examine theories which maintain that religion is an intellectual response to one's environment. Indeed, these theories have been superseded by more current theories (for an example, see Foster \& Kokko 2009).
} 
in which participants are asked to state explicitly what they believe (Gibson 2006). Despite arguments that self-report measures are reliable (Hill 2005), IAT results often differ from the results of self-report measures (Gibson 2006).

One experiment confirming a conflict between explicit and implicit belief involved questioning participants about God's characteristics then requiring them to recall a narrative about God to assess whether they implicitly thought of God as possessing the characteristics that they attributed to Him (Barrett \& Keil 1996). The experiment showed a difference in the attributes people believed God to possess and the manner in which they talked about God. For example, participants who described God as being capable of performing multiple tasks at once, typically talked about Him as if He was performing specific tasks sequentially. Further, control conditions for this experiment indicated that participants were capable of conceiving of God in nonanthropomorphic terms, but did not do so.

There are several other examples distinguishing explicit from implicit belief. One includes the fact that many non-theist Theravada Buddhists, who claim not to believe in a personal god, will worship and pray to Buddha as if he is a god (Slone 2004). Second, some persons who claim to deny a belief in luck and magic will often act as if they do believe in magic (Slone 2004; Subbotsky \& Quinteros 2005). Lastly, Calvinists who claim to believe that all fate is predestined by God, typically act as if they have the ability to influence their own future (Slone 2004). These examples show that people can hold theologically incorrect beliefs (Slone 2004), even though they may deny such a claim. 
Supernatural expertise is perplexing for two reasons. One, the acquisition of biologically non-strategic information is useless in an evolutionary context. Two, many supernatural experts don't act or think in accordance with the supernatural information that they acquire.

\subsection{The evolutionary paradigm does not predict supernatural expertise}

Contemplate the implications that the evolutionary paradigm bears upon our species. Natural selection has operated for two hundred thousand years of homo sapiens' evolution, two million years of hominid evolution, one hundred and sixty million years of mammalian evolution, and eight hundred million years of animal evolution, out of a total three and a half billion years of evolutionary history; during which, at every generation, our ancestors flourished in spite of whatever difficulties plagued them at the time, and did so while countless others failed. One could predict that, by inheriting the survival expertise of many millions of years of successful reproducers, the primary governing principle by which all human beings operate should be the biologically rational strategy of maximising individual reproductive potential at all costs.

Indeed, there is a lot of evidence to suggest that our species is biologically conditioned to survive (Balling \& Falk 1982), particularly as regards the kinds of information that humans are interested in. People possess a cognitive bias toward information that they perceive as relevant (Sperber 1985, 1996; Sperber \& Wilson 1986). This makes good evolutionary sense as good information allows people to make better judgements, which can endow persons with a competitive advantage over 
others (Waitley 1979; Wind, Crook, \& Gunther 2005). For this reason, humans are adapted to prefer information that promotes the likelihood of their survival (Tooby \& Cosmides 1992).

Yet few people would consider themselves to be biologically rational. However, for the sake of conjecture, let us try to imagine how a biologically rational agent might behave. Such an agent would only be interested in biologically strategic information that could enhance their reproductive potential. This information might include: where the cleanest water holes are, what berries are safe to eat, which weapons are best for hunting megamammals, the cooperative reputations of potential exchange partners, the reproductive history of possible mates, etc.

Against the evolutionary backdrop, the acquisition of supernatural knowledge is mystifying. Given that the human mind is designed to source relevant information from the environment (Sperber 1985, 1996; Sperber \& Wilson 1986), for the purpose of obtaining benefits within the natural material world (Stark 1999; Stark \& Bainbridge 1987), one would not expect a biologically rational agent to be interested in: how reincarnation works, memorising the entire Qur'an, how to reconcile the doctrines of anatta and rebirth, which mantras invoke which deities, how to read an extinct language, the nature of the trinity, etc. Nevertheless, there are those who devote their lives to the acquisition of this knowledge.

If the evolutionary paradigm is taken at face value we could conclude that agents prone to gossiping about non-utilitarian information should be selected out in favour of strictly rational agents adapted to focussing all time, effort and resource on 
studying biologically strategic information. Just as our bodies are adapted to resist invasion by dangerous organisms, our minds should be adapted to resist the invasion of ideas which would distract us form our biological interests; yet these predictions of the evolutionary paradigm do not conform to some of the most basic observations about the supernatural information that humans are interested in. Either the theory of evolution requires refinement or supernatural expertise is not what it seems, or perhaps both.

\subsection{Chapter overview}

The first chapter of this thesis introduces the field of evolutionary psychology and identifies that supernatural expertise, as a feature of human behaviour, does not correspond to the behaviours that we might expect to observe given the evolutionary paradigm. Subsequent chapters of this thesis will examine specific evolutionary theories of religion. Although there are a variety of adaptationist and spandrelist theories of religion, I focus only on those which are necessary to support the model of supernatural expertise that I argue for in my final chapter. I will test the accuracy of each theory discussed by assessing the extent to which it can account for supernatural expertise.

The second chapter will examine two adaptationist theories of religion. These theories argue that religion is a biological adaptation. First, I will examine costly signalling theory (Bulbulia 2004a, Sosis 2003), which maintains that religious tendencies were selected because they, at least prehistorically, enhanced cooperation between individuals. Second, I will assess whether supernatural expertise can be 
explained in terms of sexual selection (Miller 2001), an evolutionary mechanism which preserves traits, not because they are necessarily environmentally adaptive, but because they are appealing to mates.

The third chapter will examine two spandrelist theories of religion. These theories maintain that religion is not an adaptation, but a byproduct of cognitive systems which evolved to perform functions unrelated to religion. First, the chapter will examine cognitively optimal theory (Boyer 2001), the view that religion consists of ideas which are configured in such an appealing manner that religion propagates itself on the basis of this appeal. Second, I will examine the modes theory of religion (Whitehouse 2004). This theory maintains that human cognition has evolved in such a way so as to cause some concepts and experiences to be more memorable than others. This results in certain social arrangements developing around the exchange of certain information. The theory holds that religion is the collection of these ideas and arrangements.

In the final chapter I draw upon my assessment of these theories in an attempt to construct a coherent and complete explanation for supernatural expertise. The theory I argue for is controversial in that it incorporates elements form both adaptationist and spandrelist theories of religion, approaches that have previously been considered incompatible. I demonstrate how cognitively optimal theory can be applied to identify the precise manner in which the acquisition of complex supernatural concepts is costly. I employ elements of both costly signalling theory and sexual selection theory to account for the emerging complexity of the content of supernatural belief 
systems. I conclude by arguing that my theory resolves a number of questions that are left unanswered by the modes theory of religion.

\subsection{Scope and objections}

At this point it is necessary for me to clarify the scope of this thesis and respond to some possible objections to my methodology. There are three areas in which the scope of this thesis requires clarification. First, this thesis focuses on the acquisition and expression of supernatural information, as this information stands in clear contrast to the kind of perceptually accurate information that biologically rational agents should be interested in. I accept that some information can be based upon perceptually accurate observations yet still appear to be biologically non-strategic. Examples of such information include sports statistics, Star Trek trivia, and evolutionary psychology. However, regardless of whether such interests have biological bases, I focus solely on supernatural information.

Second, this thesis does not present a complete theory of social dominance. Although I examine the manner in which supernatural experts acquire social prestige, I accept that social prestige is earned via numerous other methods and that many supernatural experts have acquired their elite positions via multiple means, of which the expression of their complex supernatural knowledge was only one. However, my treatment of prestige will focus solely on the manner in which it is earned via supernatural expertise. 
Third, as supernatural knowledge is primarily expressed through spoken and written language, this thesis will address issues relevant to linguistic communication. However, it follows from the second point above that this thesis does not present a complete theory of the relationship between language and prestige. Further, it follows from the first point, that I will not examine the relationship between prestige and nonsupernatural discourse.

I also wish to respond to four objections. First, given that the most popular and developed approaches to religious studies are sociological, anthropological and political in nature; the evolutionary approach may seem perplexing and inefficient. For this reason, this thesis examines several evolutionary theories of religion for the purpose of determining the efficiency of the evolutionary approach. However, I respond to this objection by highlighting the facts that evolutionary theory has proved effective in understanding the nature of many other organisms and human animals are equally as much the product of natural selection as all other species. In my view, the suggestion that our species is somehow special in that evolutionary scrutiny doesn't or shouldn't apply to us is a dangerous error. The presumption that humans are somehow separate from the very natural processes that brought us into existence could be used as a means to justify the false belief that humans are above, independent of, or outside of nature. Thus, I encourage my reader to share my pride in this attempt to understand supernatural expertise in terms of evolutionary dynamics.

Second, given that non-evolutionary approaches to religious studies are typically riddled with specific examples in the form of case studies to illustrate an argument, 
my reader may further object that evolutionary approaches are not ordinarily illustrated with examples. Instead, evolutionary approaches to religious studies typically argue for models which account for general observations about religious behaviour in terms of evolutionary dynamics. Indeed, the evolutionary model constructed in this thesis is argued for in reference to scientific developments within the evolutionary psychology of religion, but not by illustration with specific instances of supernatural belief.

My reader should note that the usefulness of evolutionary models is not in their application to specific observations, rather their value is in providing "thoughtprovoking scenarios that illustrate a general problem that would be easy to miss in more complicated scenarios, despite being present there too" (Kokko 2008a). Testing general evolutionary models by comparing them with specific observations is highly problematic given that one could be accused of using only the special examples which confirm the model, while neglecting to discuss disconfirming examples (Wilson 2005).

Evolutionary models need not be applied to any specific examples to be of value (Maynard Smith 1982). Indeed, this thesis would have been of little value had it presented a discussion of certain varieties of supernatural belief, as the possibility of bias in the selection of these cases would significantly confound the thesis. The value of this thesis is in its critique of the body of literature within the evolutionary psychology of religion for purposes of developing a general model to account for the acquisition and expression of complex supernatural knowledge. One need not understand how to play a symphony by Tchaikovsky to appreciate the complexity of 
doing so; likewise I suggest that one need not be made to understand a specific example of complex supernatural knowledge to appreciate that acquiring such knowledge is a difficult task, requiring considerable opportunity costs with no obvious utility. For these reasons I conclude that it is not necessary to include specific case studies of supernatural experts or examples of supernatural belief in this thesis. Indeed, selected examples and cases should not be included, as this would confound the thesis.

Third, some may object that my method is reductionist as it may appear to imply the possibility of a single biological explanation for a diverse variety of complex phenomena. In my view, this objection is based upon a flawed understanding of the evolutionary paradigm which foremost stipulates the mechanism of variation; a principle that renders obsolete universal explanations for behaviour, as these explanations must by definition ignore variations between individuals. Furthermore, having read my chapter overview section, my reader will realise that my thesis does not argue for a universal explanation, but examines a collection of conflicting theories.

Fourth, my reader may presume that my method will naturally result in the conclusion that all supernatural belief is false or even foolish. To this I respond that I am aware that the only reason I have the ability to experience romantic love is because my thalamus and paraventricular nucleaus secretes the chemical oxytocin, yet I do not believe that the experience of romantic love is less meaningful for me than it is for a person who is ignorant of this fact. Biological explanations for powerful emotions do not in any way invalidate emotional experiences. Correspondingly, I see no reason to 
recognise any association between biological explanations for supernatural knowledge and the validity, or necessity, of supernatural speculation.

\subsection{Conclusion}

Confronted with the evolutionary paradigm, the supernatural interests that so many members of our species possess are perplexing. This is not a trivial problem. On one hand we have the theory of evolution, which is the predominant scientific explanation for the origin of our species. On the other hand we have some of the most basic observations that can be made about the kinds of information that humans are interested in. Our theory does not predict our observations. Either the theory of evolution is wrong or we are observing the world incorrectly. Both of these possibilities constitute a serious error. To date, there has been no evolutionary theory of religion developed which specifically focuses on supernatural expertise. Therefore, this thesis critiques a variety of theories within the field of the evolutionary psychology of religion in an attempt to reconcile this discrepancy between the theory of evolution and our observations of human behaviour. 


\section{Chapter 2. Adaptationism}

\subsection{Introduction}

This chapter examines a collection of theories which argue that religiosity is a component of the brain's design. The theories differ in regard to the evolutionary process that has given rise to religiosity, and the biological function that religiosity evolved to perform. Regardless of the nature of this function, we know that for a trait to be considered an adaptation it must perform its purpose with a high level of efficiency (Williams 1966). For this reason, adaptationist theories of religion maintain that the many religions accomplish the same goals, albeit perhaps in slightly different ways (Wilson 2002). Adaptationism predicts that these goals should be implemented by way of universals inherent in the design of religiosity. The requirements for claiming that a human trait is universal are well documented (Brown 1991; Norenzayan \& Heine 2005), and there is evidence to suggest that religious universals are biologically advantages (Reynolds \& Tanner 1985). Religion is presented as an adaptation in a variety of literature (for examples see Bering 2006a; Bloom 2004). One view is that religion is designed to benefit the individual (Reynolds \& Tanner 1985), and another is that religion performs social functions to benefit a group (Wilson 2002). Other views maintain that only some components of religiosity are adaptive, such as ritual (Macalister 1882).

There are a number of facts supporting the hypothesis that religion is a component of our biological design. One example is the fact that there are genes which appear to increase religiosity (Hamer 2004). Second, people are motivated to minimise any 
doubts they may experience as regards their religion (Hill \& Hood 1999b). Lastly, religiosity appears to improve health (Paloutzian \& Kirkpatrick, Eds. 1995). Even if religion is disadvantages in some circumstances, it can still be considered an adaptation. To illustrate, schizophrenia could have been selected if the genetic alleles which cause schizophrenia are beneficial to family members in which schizophrenic symptoms are not manifest (Shaner, Miller, \& Mintz 2004). So it is still possible for religion to be an adaptation even if it benefits only a small number of persons.

One example of an adaptationist theory of religion is the view that religion evolved to help people cope with anxiety (Atran 2002; Atran \& Norenzayan 2004). There is some empirical evidence to support this theory. Specifically, an experiment in which participants were asked to rate the power of God. The group of participants who had been primed with a story about the death of a child rated God as being more powerful than the control group (Atran \& Norenzayan 2004). This suggests that people adopt stronger mental images of the supernatural when dealing with sad and high anxiety events.

Returning to the topic of this thesis, supernatural expertise is difficult to understand from an adaptationist perspective. This is because the human mind is designed to source information that improves one's chances of survival (Tooby \& Cosmides 1992) in the material and natural environment (Stark \& Bainbridge 1987; Stark 1999). Information regarding who the gods are and what the gods are doing does not appear helpful in an ancestral context. Therefore this chapter seeks to test a variety of adaptationist theories regarding the origin of religion by examining the extent to which they can explain supernatural expertise. 


\subsection{Costly signalling theory}

Costly signalling theory (Bulbulia 2004a; Sosis 2003) maintains that human religiosity is a biological adaptation selected for the purpose of securing cooperation (Bulbulia 2004a, 2004b; Cronk 1994). This section opens by identifying aspects of human religiosity that appear to be universal across religions and cultures.

Specifically, I examine belief in supernatural reality and the ritual behaviours that are adopted relevant to these beliefs. I then overview relevant aspects of game theory and the biology of animal signalling, before relating these to religious universals in order to demonstrate how these universals can secure cooperation. I conclude with an evaluation of the extent to which costly signalling theory explains supernatural expertise.

\subsubsection{Pan-human religion}

Belief in supernatural agents can be considered a human universal (Atran \& Norenzayan 2004; Tremlin 2006), according to the criteria for documenting universals (Brown 1991; Norenzayan \& Heine 2005). But, perhaps no aspect of human behaviour contradicts predictions of the evolutionary paradigm more so than our religions. My cat appears to respond only to tangible and material objects, plants, and animals; whereas my sister spends a great deal of her time interacting not only with these, but also with invisible beings that I've never seen. Other predators conserve energy to stalk prey but humans often prostrate frequently before symbols and iconography, burning calories which are essential for predation. Consider also 
fasting, celibacy, female circumcision, etc. We observe that wherever there is religion, there are behaviours which contradict our biological interests.

A second apparent universal feature of religiosity is a belief in some kind of supernatural consequence linked to social behaviour. Among the Abrahamic religions, this manifests as a belief in heaven and hell. God is believed to be a judge who will send the deceased to one of these realms based upon how good or evil they were while alive. ${ }^{4}$ Among the eastern religions, this manifests as a belief in karma, the view that good persons will be rewarded in their next life by being born as a king or a god, whereas bad people will be punished by being born as a goat or a blade of grass. In some ancient religions, such as that of the ancient Israelites, good and bad deeds were believed to be rewarded and punished before death. Again, wherever there is religion, there is belief in supernatural causation.

Costly signalling theory maintains that these universals are biologically beneficial (Reynolds \& Tanner 1985). This would suggest that natural selection has targeted a tendency for humans to believe and act in these ways. If true, the hypothesis indicates that religion is part of our pan-human design.

\subsubsection{Cooperation dilemmas}

Given that the second mechanism of evolution is competition, which states that varying individuals must be in competition with each other for natural selection to

\footnotetext{
${ }^{4}$ The reader may object that in Protestant Christianity, salvation is attained via faith and not through good works. I note that among Protestants, good deeds are seen to be indicative of faith (few Christians, if any, would maintain that Adolf Hitler's never renounced Catholic faith was sufficient to save him).
} 
occur, explaining the evolution of altruism is problematic. Humans have evolved violent tendencies (Wrangham \& Peterson 1996), though most of us do a very good job of controlling them. Although aggression can be biologically beneficial in that it is helpful in securing resources necessary for survival and reproduction (Tooby \& Cosmides 1988), it is often considered unacceptable. This is true among foraging cultures (Boehm 2000; Brown 1991), as well as modern societies. Somewhat ironically, it is this tendency toward non-cooperative behaviour that may have lead to the evolution of altruism (de Waal 1996).

To illustrate, the benefits of paying our taxes are bridges, tap water, and hospitals. However, we each stand to benefit more by using these goods without paying; but if all fail to pay, the goods secured by cooperation disappear.

This is an example of a prisoner's dilemma situation, a hypothetical scenario designed to illustrate typical cooperation dilemmas. The situation is as follows. Two criminals are arrested for being accomplices in a crime that carries a penalty of ten years. However, prosecutors only have sufficient evidence to jail each of them for one year, so the prosecutors visit each prisoner separately and offer them the same deal: "If you privately testify against your accomplice, which will provide sufficient evidence to jail your accomplice for the full ten years, you will receive a one year reduction on your own sentence." A testifying prisoner will always receive their one year reduction, regardless of whether or not their accomplice also chooses to testify.

Assume both prisoners are only interested in minimising their personal sentence without regard for their accomplice, their preferred option would be to testify (defect 
against their accomplice). They will then each receive nine years, this being the full ten year sentence less their one year reduction. Whereas, if both prisoners had remained silent (cooperated with their accomplice), the prosecutors only had sufficient evidence to jail them for one year each. An alternative scenario would be for one prisoner to testify and the other to remain silent, in which case the defector would go free whilst the cooperator would serve ten years; this is either the best or the worst scenario depending on which prisoner you happen to be.

These examples illustrate the dilemmas faced during most cooperative endeavours. We benefit by participating in them but gain more by cheating them. Thus evolution must secure cooperation.

\subsubsection{Altruism and secular punishment}

Human societies function because of the cooperative commitments of individuals (Nesse 2001). These commitments are advantageous to the societies in which they're adopted because these societies will be more successful than those in which cooperative strategies are less prevalent (Richerson \& Boyd 2005). Even Darwin himself observed that a group of altruistic animals will dominate a group of nonaltruistic animals (Darwin 1871). Individuals within cooperative societies also benefit (Schelling 1960), not only by being a member of a successful collective, but also by reaping the personal benefits which result from a long term altruistic regard for others (Post 2007), such as a return of one's altruistic sentiments and a positive outlook on life. 
There are two forms of cooperation that are necessary for a society to function effectively. The first is kinship cooperation which is universal to all societies (Steadman \& Palmer 1995), that is, cooperation between members of the same immediate family. The second is large scale cooperation between persons who are not close relatives (Richerson \& Boyd 2005). The social skills necessary to include those outside of one's immediate family in one's peer group are acquired by humans and other mammals around the time of puberty (Sachser, Durschlag, \& Hirzel 1998). We observe that humans have evolved to cooperate with the social group to which they belong and to refrain from cooperation with the social groups that their group is in competition with (Sosis 2003). I proceed with a discussion of how altruism evolved.

Jeffrey Schloss (2008) outlines the manner in which the universal beliefs and behaviours identified in section 2.2.1 function to resolve cooperation dilemmas. Throughout this section I explain Schloss's model using taxation as my example.

Suppose Dave Henderson ${ }^{5}$ refuses to pay his taxes. He benefits by using the goods that are secured through taxation, without contributing to their production. In this scenario, Henderson is a cooperation free rider or a first order defector. An agent from the Inland Revenue Department (IRD) can audit Henderson and force him to pay via the court system, threatening him with imprisonment unless he cooperates. Thus cooperation free riding can be resolved via social punishment.

\footnotetext{
${ }^{5}$ Dave Henderson is the author of the 1999 book Be very afraid: One man's stand against the IRD, which inspired the 2007 movie We're here to help. In the book he recounts his four year battle with New Zealand's Inland Revenue Department, during which he was audited 27 times and sued for $\$ 924,341$.
} 
Punishment has been shown to be an effective method of social control (Boyd \& Richerson 1992). It has also been shown to be more powerful than offering rewards as a means to motivate behaviour (Johnson \& Bering 2006). Further, despite the personal cost often associated with the act of punishing others, people will often engage in punishing behaviour (Fehr \& Gachter 2002).

However, suppose that Henderson's IRD agent chooses not to incur the time costs associated with auditing Henderson. The IRD officer will be paid regardless, and since all of her colleagues are hard working, they will function as a sufficient deterrent to prevent cooperation free riders. However, if every case officer behaved this way, Henderson could successfully evade taxation. In this scenario, Henderson's case officer is a punishment free rider or a second order defector (Hauert, Traulsen, Brandt, Nowak, \& Sigmund 2007).

One solution would be for another IRD representative to supervise the work of Henderson's IRD agent. The supervisor could then punish Henderson's agent, perhaps by issuing written warnings of dismissal if she is not performing her duties correctly. This solution could work, unless the supervisor is also a punishment free rider, in which case he would also require supervision. This line of reasoning becomes somewhat ridiculous, as it leads to an infinite regress (Colman 2006). If we punish those who do not punish, then we may have to punish those who do not punish those who do not punish, and so on. A body of literature examines possible solutions to the problems of punishing (see Boyd, Gintis, Bowles, \& Richerson 2003; Fowler 2005; Henrich \& Boyd 2001; Panchanathan \& Boyd 2004). I now turn to a discussion of one biological tool that can be used to overcome this difficulty. 


\subsubsection{The handicap principle}

The theory of evolution appears to predict that natural selection should universally minimise cost and maximise gain. To illustrate, imagine two organisms in competition, all things being equal, the creature capable of surviving whilst incurring the smallest cost to its reproductive fitness will have the highest probability of parenting the next generation.

However, supernatural expertise and altruism are not the only examples of behaviours that contradict this prediction. One classic textbook example is that of stotting. When a herd of gazelles are being stalked by a predator, we could intuit that the gazelles' most biologically rational option would be to run or hide. However, it is common for the gazelles to advertise their location to the predator by stotting, the action of exhausting oneself by leaping frequently into the air. This behaviour could be interpreted as an act of altruism; if one gazelle martyrs themselves by drawing the attention of a pack of predators, they're group as a whole will incur less damage than if all the gazelles were to remain stationary. However, this hypothesis is inconsistent with the observation that predators rarely chase stotting gazelles.

The biologically rational strategy for the predator is to chase those who are so weak that they must preserve all of their energy for the impending chase. A predator is able to identify these individuals as they will not stot, instead they may immediately flee or conceal themselves underneath vegetation in an attempt to avoid predation. Thus our initial intuition concerning a gazelle's biologically rational strategy was incorrect; it is 
in the gazelles' biological interests to stot if they are able. Even though stotting gazelles are ordinarily capable of escaping predators, it is better to stot and not be chased than not to stot and be chased.

This evolutionary anomaly is known as the handicap principle (Grafen 1990; Zahavi 1975; Zahavi \& Zahavi 1997). This principle states that biologically costly traits and behaviours can evolve for the purpose of signalling specific qualities of the signaller (Gintis, Smith, \& Bowles 2001; Grafen 1990; Zahavi \& Zahavi 1997). In the above example, by stotting a gazelle signals its ability to evade predation, preventing predators from pursuing it. I call these traits Zahavian handicaps, after the two people who theorised the principle.

Three criteria are required to be met before a trait can be considered a Zahavian handicap (Zahavi \& Zahavi 1997). Here I explain these criteria using stotting as an example. First, the signal must be costly; stotting is costly to gazelles in that it prohibits hiding as an option and depletes energy reserves that are required for escaping. Second, the cost must be contextually linked to the quality it signals; stotting cannot be performed unless a gazelle is in a fit condition and possesses strong and well-built leg muscles, the very traits necessary to evade a predator giving chase. Third, the cost must burden a dishonest communicator more so than an honest one; hypothetically if an unfit gazelle stotted, its chance of escaping a predator, should its stotting action be ignored, would be exceptionally lower than if it had not stotted, whereas a fit gazelle would be able to escape a predator regardless. 
Before the third criterion can be met, a signal's cost to an honest communicator must be lower than the benefit they stand to gain by producing the signal, resulting in a net gain; whereas the cost to a dishonest communicator should be greater than that benefit, resulting in a net loss. This ensures that signals can be preformed by honest communicators, but still remain reliable by preventing dishonest communicators from imitating them. For example, the benefit a fit gazelle gains from stotting is that predators wisely choose not to chase them. However, the cost associated with stotting is relative. By stotting, gazelles capable of outrunning a predator lose little.

However, if gazelles incapable of outrunning were to stot, they would quickly tire and their fatigue would be apparent to predators in the corresponding deterioration of their stotting performance. Predators would be able to judge that an unfit gazelle is attempting to falsely imitate the behaviour of a fit gazelle, enabling the predator to identify and chase the unfit gazelle. We see that the net gain to a fit stotting gazelle is substantial; whereas the risk to an unfit stotting gazelle is too great, resulting in a net loss.

An example of a handicap in human beings is hair length. Humans have much longer hair than other primates, which is not only an inconvenience but it can become very dirty and unclean. Most of us spend a great deal of time and resources grooming ourselves daily to prevent this. Occasionally we may encounter a person who does not self-groom, such as a homeless person who likely does not possess the resources necessary to allow thorough grooming. When we encounter these people, their poorly groomed state allows us to immediately recognise their situation and we may pity them or develop a low opinion of them. Even though hair length is an inconvenience, 
it is a handicap that allows us to immediately acquire sometimes very detailed information about another person (Zahavi \& Zahavi 1997).

It should be noted that every species of animal possesses a variety of strategic handicaps used for communication (Maynard Smith \& Harper 1995; Gintis, Smith, \& Bowles 2001; Grafen 1990). While each of these handicaps may exist to communicate different information, in some animals, such as some species of bird and humans, the overall effect for these handicaps is accumulative. Organisms that can perform a variety of handicaps well, acquire a high level of prestige, with those failing to do so acquiring a low level of prestige. This can lead to conflicts for status (Zahavi \& Zahavi 1997). During these conflicts organisms may compete by consciously handicapping themselves (Cronk 1994).

\subsubsection{Costly signalling in humans}

In order to secure the cooperation of others, humans signal intent to a given set of moral norms (Alexander 1987). These signals involve both voluntary and involuntary handicaps. One example of a voluntary handicap includes bodily scarring. People may tattoo or pierce their bodies, and in some cases remove body parts such as the foreskin, to signal commitment to their group (Boehm 1999). These markings sometimes foster in-group commitments that are so strong they can lead to warfare against groups that do not possess the same markings (Sosis, Kress, \& Boster 2007). Another manner in which the quality of a signal to moral norms can be voluntarily enhanced is by signalling to a large group of people. If the signaller does not adhere to their moral commitments, they lose prestige by exposing themselves as a fraud and 
arouse suspicion among all those who witnessed their signal. Signalling to a group is stronger because of the higher risk involved (Zahavi \& Zahavi 1997).

Among the most reliable involuntary signals are emotions (Frank 1988, 2001). Used by humans and some other animals (Lazarus 1991; Maynard Smith \& Harper 2003), emotions are effective in signalling commitment (Frank 1988; Hirschleifer 1987) as they are processed outside the brain's neocortex (Ramachandran 1997) and are hard to fake (Frank 1988). For this reason, empathy plays a role in human communication (Escalas \& Stern 2003; Wispe 1986) and is important in the coordination of cooperative endeavours (Levinson 2003).

Emotions, desires and goals influence the manner in which the brain processes information (Kunda 1999). This enables emotions to influence the quality of a signal by identifying the precommitments of the signaller (Darwin 1872/1965; Frank 1988, 2001). For example, emotions such as guilt can be detectable when a person attempts to lie. For this reason, the most effective liars are those who believe that they're telling the truth (Hirstein 2005; Trivers 1971). The most efficient means to deceive somebody else is to first deceive oneself in the same manner (Trivers 1971). Thus people often attribute negative events to external agents as opposed to themselves (Morewedge 2009). By not holding oneself responsible when bad things happen, a person can develop a high opinion of themselves, which is useful when persuading others that they're reliable.

This presents a problem in which emotions act as involuntary signals which persons subconsciously attempt to overcome through self-deception. This results in the need 
to track reputation (see Leary 1999). Humans constantly try to predict the behaviours of other people (Leslie, German, \& Polizzi 2005; Wellman \& Miller 2006) and knowledge of a person's past behaviours can increase the accuracy of these predictions. For example, after a person has cheated you once, you will remember this and you'll be less likely to cooperate with her in the future. For this reason, humans are constantly searching for other agents and their behaviours (Wegner 2005). We all possess a need to know about other people and this is illustrated by the practice of divination techniques (Dennett 2006), and the results of ink blot tests (Wood, Nezworski, \& Garb 2003).

The benefit of our ability to track reputation is enhanced by psychological mechanisms which allow us to recognise faces. Facial recognition mechanisms are linked to emotional systems (Gobbini, Leibenluft, Santiago, \& Haxby 2004; Paller, Ranganth, Gonsalves, LaBar, Parrish, Gitelman, et al. 2003; Shah, Marshall, Zafaris, Schwab, Zilles, Markowitsch, et al. 2001). Therefore, certain emotional responses can be invoked when we identify certain persons. For instance, if you see someone who has cheated you in the past, you may feel upset or angry. Negative emotions such as these stimulate alertness (Hattfield, Cacioppo, \& Rapson 1994; Levenson 1999), thus we are more likely to notice counter-cooperative behaviour from those to whom we attribute a bad reputation. An example of reputation mechanisms in action was observed in an experiment in which participants were asked to wear a jumper that they were told had been worn by an immoral person. Most participants refused to wear the jumper (Frazer 1994). This demonstrates that people actively try not to associate themselves with the negative reputations of others. 


\subsubsection{Supernatural causality}

In religious studies and evolutionary psychology, costly signalling theory is the hypothesis that religion is an adaptation that evolved as a hard to fake signal of cooperation (Alexander 1987; Bulbulia 2004a; Cronk 1994; Irons 1996a, 2001; Roes \& Raymond 2003; Schloss 2004, 2005; Sosis 2000, 2003, 2005; Sosis \& Bressler 2003; Sosis \& Ruffle 2003). It is a part of a wider body of investigation which argues that religion functions to promote altruism and social cohesion (see Atran \& Norenzayan 2004; Johnson 2005; Johnson \& Bering 2006; Johnson \& Kruger 2004; Wilson 2002, 2005). Costly signalling theory is supported by data collected in several recent empirical experiments (Bubulia \& Mahoney 2008; Sosis 2000; Sosis \& Alcorta 2003; Sosis \& Ruffle 2004), such as an experiment in which participants primed with supernatural agent concepts were observed to behave more altruistically (Shariff \& Norenzayam 2007).

It has been shown that belief can provide an individual with a competitive advantage (Waitley 1979; Wind, Crook, \& Gunther 2005). Central to the advantage of religion is the belief in deities or forces that monitor the manner in which humans beings interact and that require fair cooperation between persons (Bering 2005). This is arguably a pan-human religious universal. These supernatural sanctions reinforce the power of one's moral conscience (Bering \& Johnson 2005; Johnson \& Bering 2006). The fact that some supernatural beings are assumed to be omnipotent heightens their moralising effect (Johnson 2005). Data supporting the view that a belief in supernatural beings promotes cooperation was collected in one experiment in which participants who were primed with the idea of a ghost were less likely to cheat when 
playing a competitive game (Bering, McLeod, \& Shackelford 2005). We observe that a belief in supernatural sanctions is a good solution to cooperation dilemmas (Johnson \& Kruger 2004; Roes \& Raymond 2003; Wilson 2002).

The exact nature of the supernatural agents that a society believes in differs depending upon the type of society. One example of a supernatural agent concept is ancestor representations. For example, in small tribal societies where most individuals are related, ancestor worship is common, as this promotes cooperation among kin (Steadman, Palmer, \& Tilley 1996). In larger societies consisting of non-kin, gods that perform a more explicit moralising function are revered (Roes \& Raymond 2003). One example is the judgemental nature of the Christian God, a concept which strongly emphasises reward and punishment (Malley 2004). These god concepts perform the advantageous social function of restricting negative social behaviours. For instance, many deities impose heavy sanctions on incestuous practices (Durham 1991). For this reason, humans have evolved cognitive mechanisms to prevent us from doubting the existence of the gods that our religious group believes in (Bulbulia 2004a).

Let us now return to the hypothetical example of Dave Henderson and his IRD audit. Costly signalling theory predicts that an effective solution to both cooperation and punishment free riders is a belief in supernatural causation. If the IRD officer is convinced that he will reap unfavourable consequences in the afterlife by defecting, he will be motivated to audit Henderson. 
In fact if everyone held these beliefs, then everyone would pay their taxes, and the auditing process could be eliminated as it would be unnecessary. However, suppose that Henderson is the only person who doesn't believe in an afterlife. All of his peers would be paying their taxes, but he wouldn't. In this scenario, Henderson is an unbeliever or a third order defector. The issue of unbelief can be resolved if believers are required to signal their commitment. Suppose all those who believe were to communicate their beliefs to one another. The IRD could then be re-established with the charter to audit unbelievers only.

However, Henderson can overcome this safeguard by falsely identifying himself as a believer, thus avoiding an audit. In this scenario, Henderson is a hypocrite or a fourth order defector. Costly signalling theory maintains that this problem can be solved via another religious universal, specifically the many religious behaviours which conflict with our biological interests. Committed afterlife enthusiasts could engage in a variety of signals to indicate their commitment, such as prayer, fasting, monogamy, etc. I now turn to a discussion of this solution.

\subsubsection{Religious signalling}

Religious behaviour typically involves the performance of a number of biologically costly rituals (see Atran 2002). There has, historically, been some theological speculation as to the relationship between ritual displays and religious commitment (Edwards 1741/2007; Edwards 1746/1982; Wesley 1766/2006; Wilberforce 1997). More recently, in evolutionary psychology, a distinction is being drawn between what is practical and what is adaptive (Wilson 2002). Something which seems impractical 
may be adaptive. This can help to explain religious rituals and sacrifice. According to costly signalling theory, religious costs function as signals of both solidarity (Bulbulia 2004a; Irons 1996a, 1996b) and commitment (Frank 1988; Sosis 2003; Sosis \& Ruffle 2003) to a belief in supernatural causality, so as to prevent cooperative defectors from entering a group (Sosis 2004). This hypothesis is supported by evidence that group rituals are essential to both the construction and preservation of social connections (Durkheim 1915/1995).

However, for religious signals to be reliable they must be Zahavian handicaps; that is, they must be configured in such a way so as to prevent non-believers from mimicking them. By applying the three criteria identified by the handicap principle, we can assess whether religious signalling is reliable. First, the signals are costly; for example, prostrating and fasting contradicts our biological interest to preserve energy. Second, these costs are contextually linked to an afterlife belief in that believers hold that prayer and monogamy will be rewarded in the afterlife along with cooperation. Third, these signals must be perceived as more costly by the non-believing Henderson than by his believing peers. However, whether or not this is the case as regards religious costs is difficult to determine.

To illustrate, the Islamic practice of zakat, the annual act of giving $2.5 \%$ of one's wealth to the poor, costs committed Muslims just as much as it would cost somebody pretending to be a Muslim. However, Richard Sosis (2003) has argued that there is a perceptual difference in the manner in which both believers and sceptics assess the severity of religious costs. A committed afterlife enthusiast may perceive $2.5 \%$ as a small price to pay for an eternity in heaven, performing zakat clearly results in a net 
gain from this perspective. Failing to perform zakat will result in a substantial loss if the sinner will be punished in hell. Thus, a believer's interest is to pay the tax with enthusiasm. On the other hand, a person pretending to be a Muslim without possessing the relevant beliefs will recognise only the immediate utilitarian gains and losses. Zakat is clearly a loss from this perspective so the interests of a sceptic would be to avoid paying if he can. I suggest that these interests manifest in the quality of religious activity. A believer pays with enthusiasm, a sceptic may still pay but will do so with more hesitation. In this regard, the additional cost that Henderson perceives religious activity to carry enables his believing peers to assess his degree of commitment.

Bulbulia (2004a) has demonstrated that these conditions are true for religious emotional displays, just as Sosis (2003) has demonstrated that these conditions are true for religious rituals. Schloss (2008) has shown how costly pan-human religious universals solve the problem of cooperation dilemmas. First, a belief in supernatural causation prompts religious persons to misunderstand the payoffs of a prisoner's dilemma situation, in that cooperating is understood to be the most beneficial option. Second, a tendency to engage in costly actions contextually linked to this belief enables cooperators to accurately identify each other. Thus, religious communities comprised of persons who are conditioned to cooperate can easily be formed.

\subsubsection{Religious signalling strategies}

The costly signalling model explains religious behaviours as public displays which enable religionists to assess the extent of each other's group commitment. The model 
does not explain private religious activities which one's fellow religionists will never witness. Sosis (2003) has argued that private rituals function to enhance public displays. For example, prayer is a common religious activity practiced in both public and private. Prayer requires both a degree of creativity and uniformity in the phrases that are spoken and in specific bodily postures that must be adopted at very precise moments whilst a certain emotional composure is induced. Further, the manner in which prayer is mandated differs between religious groups. An evangelical Christian may be required to bow their head, creatively mix and match a variety of supernatural phrases, whilst smiling or occasionally even laughing. A Muslim will be required to prostrate in a very specific manner, recite very specific words, whilst adopting a calm, devotional and submissive mindset. Prayer is a very difficult task.

Prayer must be performed accurately in public for one's fellow religionists to reliably assess one's commitment. However, given the difficulty associated with the performance of prayer, significant quantities of practice are required before accurate public performance can occur. Truly, practice makes perfect. In this regard, we can observe that although private rituals are not religious signals in themselves, they do function as preparatory measures for the performance of those signals. This model predicts that private rituals impact upon the quality of the performance of public rituals in some manner.

Although individuals may buy into religious belief and practice for a number of reasons, such as to avoid punishments imposed by their group for not doing so (Johnson 2005), religion brings a number of advantages to both individuals and the group as a whole. Specifically, the expression of religious belief provides a 
mechanism by which members of a group can monitor commitment (Iannaccone 1994; Irons 2001; Sosis 2003). This mechanism is significant as religious ritual is more effective at securing cooperation than secular ritual (Irons 2001; Sosis 2004). Once considerable energy has been invested into signalling commitment to one's group and monitoring the signals of group members, suspicion of other groups whose signals have not been monitored follows (Bulbulia 2004a). This helps to explain why religious commitment increases during war (Boyer 2001), why societies which engage in war more frequently also engage in more costly rituals, and why those societies often practice more intense rites of passage among adolescents (Sosis, Kress, \& Boster 2007).

The reason why religiosity may increase during times of warfare is because of greater threats to fitness and resource shortages during war. To illustrate, it has been shown that there is a relationship between the cost of religious ritual and both threats to the fitness of a religious group (Boyer \& Lienard 2006) and the pressure on individuals within the group to defect from cooperative endeavours (Sosis, Kress, \& Boster 2007). When the pressure to defect increases, perhaps because of a resource shortage, the cost of religious rituals increase (Boyer 2005). For example, it is known that religiosity increases in response to terrorist attacks (Schuster, Stein, Jaycox, Collins, Marshall, Elliot, et al. 2001; Sosis 2007). For this reason, religious groups that impose strict rules on their members generate higher levels of cooperation among those members (Iannaccone 1994).

One interesting signalling strategy used in most religious groups is the expression of emotion. It is known that there is a relationship between emotion and religion 
(Pyysiäinen 2001, 2003, 2004a), as neurofunctional activities in the brain during religious experience are associated with emotional effects (Newberg \& d'Aquili 1998). According to costly signalling theory, religious emotion signals commitment, in the same manner as costly ritual (Alcorta \& Sosis 2005; Bulbulia 2004a).

The main reason that emotional signalling is used is because emotions are generated outside of conscious control, thus they are both hard to fake and cheap to produce. Displaying emotions does not incur the same cost to fitness as lengthy rituals. In other words, emotions generate a reliable signal at a low cost (Chen 2003). The same emotions are often experienced during a religious ritual by participants. This helps to create a strong sense of group identity and cohesion (Durkheim 1915/1995; Turner 1990). This view is supported by evidence collected during an experiment in which participants reported a higher level of fondness toward persons with whom they believed they shared a subjective experience than toward persons with whom they believed they did not (Pinel, Long, Landau, Alexander, \& Pyszczynski 2006). Rituals transform our emotions (Sosis 2003; Sosis \& Alcorta 2003) to make us fond of each other. Emotion also functions to enforce cooperation through guilt (Shariff \& Norenzayam 2007). Guilt is a disadvantage associated with defection (Bulbulia 2004a) and falsifying religious commitments (Pargament, Koenig, Tarakeshwar, \& Hahn 2001), further ensuring that religiosity functions to secure cooperation.

There is much evidence supporting the view that ritual signals solidarity (Sosis 2000; Sosis \& Bressler 2003; Sosis \& Ruffle 2003). One example is the fact that trust among Pentecostal communities, in which strong emotions are frequently experienced during collective ritual, is stronger than other neighbouring religious communities 
(Pew 2006). One well known series of studies which support costly signalling theory focused on Israeli kibbutz. Members of religious kibbutz have been found to be more cooperative than members of secular kibbutz (Sosis \& Ruffle 2003). This explains why secular communes do not last as long as religious communes which impose more rituals and taboos on their members (Sosis \& Bressler 2003).

Although there is evidence that religion is supportive of morality (Norenzayan \& Shariff 2008; Sosis 2003), it should be noted that costly signalling theory does not imply that all religious people will be saints. The existence of paedophile priests and some dishonest televangelists testify to this. The notion that religion is an adaptation which secures cooperation merely indicates that throughout the evolutionary history of our species, religion has more often than not been successful at the task it was selected to achieve. Costly signalling theory does not predict that in the modern world all religious persons will behave in a highly altruistic manner (Cronk 1994).

\subsubsection{Supernatural expertise as a handicap}

To determine whether costly signalling theory is sufficient to explain the discrepancy between supernatural interests and the evolutionary paradigm, we must examine supernatural expertise in terms of the three criteria characteristic of Zahavian handicaps. Unfortunately, expressions of complex supernatural knowledge do not appear to conform to the first criterion as they are not hard to fake signals in and of themselves. If a Buddhist were to state: "I believe that the current Dalai Lama is the thirteenth human incarnation of Avalokitesvara", the act of articulating this claim does not entail any fitness or opportunity costs beyond the few seconds it takes to 
pronounce this sentence. This statement is insufficient to prove cooperative intent, as a fourth order defector can easily make this claim. We observe that personal expressions of religiosity are easier to cheat than tangible costly displays (Trivers 2000). In this regard Zahavi and Zahavi (1997), the initial proponents of the handicap principle, have concluded that "verbal language does not contain any component that ensures reliability in signalling." Henderson's claim to be religious does not prove that he is religious any more than his claim to be an honest tax payer proves that he is an honest tax payer. It follows that verbal assertions of supernatural commitment can neither conform to the second nor third Zahavian criteria as these foremost require that there be a cost. Nevertheless, it is interesting that often more time and investment is dedicated to the expression of supernatural belief, than is invested in believing the beliefs (Dennett 2006).

It is worthwhile to note that in Tibetan Buddhism the current Dalai Lama is actually believed to be the fourteenth human incarnation of Avalokitesvara, and not the thirteenth as was suggested above. Thus a Buddhist listening to the above statement would be able to determine that the speaker is not very familiar with Buddhist beliefs. Systems of supernatural belief can be complex, thus they require a significant investment of time to memorise. It is this investment that entails opportunity costs. The expression of accurate supernatural knowledge, although not costly in itself, signals a history of prior investment undertaken in public or private. In this regard, the private acquisition of supernatural knowledge can be understood as preparatory behaviour for its public expression. 
However, it seems that some statements of supernatural belief require a greater investment than others if they are to be understood accurately. Compare the children's Sunday school song lyric: "Jesus loves me, this I know, for the Bible tells me so", with the opening verse to the gospel of John: "In the beginning was the Word, and the Word was with God, and the Word was God." This latter statement is derived from a greater number of supernatural speculations, and therefore requires a greater degree of investment before its canonical interpretation can be expressed.

From this perspective, we see that expressions of supernatural knowledge conform to the first criterion. The acquisition of complex supernatural knowledge entails numerous opportunity costs in terms of the sheer time and effort that it takes to acquire this knowledge. Supernatural expertise likewise conforms to the second criterion in that there is a contextual association between religious commitment and the expression of complex knowledge surrounding that commitment. However, whether or not supernatural expertise conforms to the third criterion remains to be identified. It seems just as easy for a gentile to learn Biblical Hebrew as it is for a Jew. Thus a comprehensive theory of supernatural expertise must account for the manner in which specific units of supernatural information are difficult to acquire, so that any difference in acquisition difficulty between believers and non-believers can be determined.

\subsubsection{Conclusion}

Costly signalling theory can explain supernatural expertise when the acquisition of complex supernatural knowledge is understood as a private ritual that is necessary for 
the public expression of that knowledge. However, the theory can only explain supernatural expertise in terms of its cost and the contextual association between that expertise and supernatural commitment. Costly signalling theory falls short of explaining the manner in which the costs of supernatural expertise burden a fourth order defector more so than a genuine religionist.

\subsection{Sexual selection}

Sexual selection theory attempts to account for evolutionary phenomena that are produced as a product of sexual reproduction. Below I describe sexual selection before discussing the manner in which it may have impacted upon the evolution of cognitive capacities necessary for supernatural expertise. I proceed to explain the ratchet effect, an evolutionary process that can enhance sexual selection to the point of producing highly bizarre non-utilitarian traits. I examine the ratchet effect in context of both the sexual selection and costly signalling theories of supernatural expertise.

\subsubsection{Evolution by sexual selection}

In The Origin of Species Darwin (1859/1968) contrasted natural selection with human selection. The human selection of domesticated animals for breeding purposes was a process that was known to produce observable evolutionary change. With this analogy, Darwin described natural selection as the selective processes that occur arbitrarily in nature. The fittest animals survive and pass their genes onto the next generation. 
This form of natural selection is not the only process that drives evolutionary change. Sexual reproduction causes some interesting phenomena which result from an animal's choice of mate. It is useful to analyse sexual selection as a separate phenomenon than natural selection due to the mechanical differences between the conventional understanding of natural selection as the survival of the fittest, and the sometimes highly non-utilitarian traits that develop through sexual selection.

Sexual selection is known to occur as variations in the mating strategies of a given group of animals have been shown to impact the animals' social ecology (Crook \& Crook 1988; Orians 1969). The importance of sexual partners as a resource may explain why mate poaching is common during war (Buss 2002; Goldstein 2003). Further, sexual selection theory is useful as it is known to be empirically testable (Miller 2007).

One example of a trait that has been produced via sexual selection is the peacock's tail. Peacocks have very long tails. The tail is so big and bulky that it cannot help the peacock to balance, as the short and nimble tails of many mammals do. A peacock's tail adds unnecessary weight to the peacock's body, slowing the peacock and making it hard for him to manoeuvre. Further, a predator can easily grab hold of the tail, immobilising the peacock. Surely a peacock would have a better chance of survival without a tail. The tail appears to serve no utilitarian function. If natural selection, as understood in the conventional sense, had been the only factor influencing peacocks' evolution, they would not have evolved long tails. 
It is even more perplexing that peacocks appear to show pride in their non-utilitarian appendage by frequently lifting their bulky tails off the ground and spreading them wide. This behaviour in itself is highly costly as it wastes vital energy reserves. However, it is worthwhile noting that if as few as five of the 150 features in a peacock's tail are removed, the peacock will noticeably attract fewer mates.

Peahens will prefer not to mate with peacocks that have damaged tails, as this damage is likely to have resulted during a close call with a predator. A peahen has an interest in giving birth to offspring that will be able to evade predation. For this reason, peahens historically chose to mate with peacocks that displayed perfect tails. Peacocks without tails did not win any mates as they had no way of signalling their ability to steer well clear of predators. Those peacocks that did not display their tails also did not win any mates, as no peahen could know for sure what the state of their tail was. In this regard, we can see how peacocks' characteristic of growing and displaying tails evolved via the necessity for peahens to choose mates with good genes (Kokko, Brooks, \& Jennions 2003; Kokko, Jennions, \& Brooks 2006; Kotiaho, Simmons, \& Tomkins 2001; Miller 2000; Tomkins, Radwan, Kotiaho, \& Tregenza, 2004). This is evolution by sexual selection.

However, it should be noted that a tail of a few centimetres in length would suffice as a reliable signal. A tail of over a meter in length increases a peacock's susceptibility to predation much more than is necessary to signal their ability to evade predation. It is possible that this cost of being more susceptible to predation outweighs the benefit of producing a small signal of fitness. Somehow during evolutionary history, the peacock's tail grew to the point that the cost associated with maintaining the signal 
may not justify the signal's use. The manner in which a sexually selected trait can gradually become exaggerated beyond utilitarian necessity is examined below in section 2.3.3.

Sexual selection has been shown to have impacted on human evolution. For instance, females are known to invest more heavily in offspring than males. Because of this, women are adapted to seek men with strong family values, that is, men who have a strong interest in raising children (Buss 2003). Women are able to assess a man's commitment by observing his moral behaviours, as moral values signal the presence of genes that code for particular mental traits (Miller 2000). Women generally have a stronger theory of mind than men, meaning they are more empathic and better able to understand the intentions of others (Baron-Cohen 2003) (for a full description of theory of mind, see section 3.2.1). This allows them to better assess the moral behaviours of potential mates. This has lead to a level paternal investment by human males, which is greater than that of other mammals. Interestingly, the characteristics to which a woman is attracted will change depending upon her stage of development, with women near peak fertility preferring creative partners as opposed to wealthy partners (Haselton \& Miller 2006). This ensures their offspring inherit the good genes which code for favourable mental traits. Even mental traits which are disadvantages can be preserved by sexual selection. For example, schizophrenia can be selected if the genes which cause schizophrenia in some people increase the courtship potential of others (Shaner, Miller, \& Mintz 2004). 


\subsubsection{Sexual selection for cultural phenomena and supernatural expertise}

There are many cultural phenomena that may result from sexual selection. Here I discuss three cultural examples, before considering supernatural expertise. One example is music (Miller 2000). Music may be sexually attractive as musical ability signals good hearing and voice control skills, as well as a good sense of timing and the patience to practice musical rhythms. This may explain why music is so popular among teenagers (Olsen 2006).

A second example is human moral traits. Human children are dependant on their parents for up to two or more decades. Thus it is in the interest of a parent to find a mate who will remain with the children long term. Moral behaviours such as kindness, loyalty, and fairness can function as reliable signals of a potential mate's intent to invest heavily in their offspring. The reason that humans are adapted to find these traits sexually attractive is because people who select partners possessing these traits gain a substantial reproductive benefit. Moral values signal genes that code for moral traits (Miller 2001, 2007). People possessing these genes are therefore more likely to find a partner, thus they will have more children who will inherit those genes.

Finally, a third example is religion (Dennett 2006). Participation within a religious group is a useful way to find a mating partner (Irons 2001). Indeed, men who out compete their peers in religious rituals, in terms of performing the rituals more precisely or in a more costly fashion, may have greater reproductive success (Miller 2001). This is due to the fact that ritual behaviours result from the sexual selection of 
costly displays (Miller 2000). Further, it may be the case that the frequency of male initiation rituals is positively correlated to the presence of inter-group conflict or warfare (Sosis, Kress, \& Boster 2007).

I now discuss whether the human capacity to acquire complex supernatural knowledge may be the result of sexual selection. Supernatural experts must possess a high degree of intelligence. Further, the acquisition of vast quantities of supernatural knowledge requires an excellent memory. Additionally, the ability to resolve supernatural dilemmas requires strong problem solving skills. These are traits that humans not only desire in their offspring but also find attractive in a partner. The expression of complex supernatural knowledge may signal these capacities, making supernatural experts more attractive to the opposite sex. Supernatural experts would therefore have had more descendents who would have inherited the genes that code for the cognitive capacities necessary for supernatural expertise.

However, the fact that many supernatural experts claim to be celibate presents a problem for this particular application of sexual selection theory. Within the broader scope of our species' evolution, celibacy may be a very recent phenomenon. However, I note that there is little to no evidence for the authenticity of celibacy claims. Indeed, there are supernatural experts who claim to be able to levitate or perform spontaneous healings and other miraculous feats, but there is very little evidence for the authenticity of these claims either.

What matters, from an evolutionary perspective, is not the number of immediate children you have, but rather the number of descendants that you have throughout 
history. Religionists who identify as celibate may have fewer children on average than other religionists, but this wouldn't constitute a net cost to their inclusive fitness unless celibate religionists have on average fewer descendents than non-celibate religionists. Further, although there may be genuinely celibate religionists, this would only present a problem for a sexual selectionist account of supernatural expertise if it could be shown that, on average, supernatural experts have less inclusive fitness than lay people.

\subsubsection{The ratchet effect}

A ratchet is a mechanical tool that allows linear motion to occur in one direction only. In an evolutionary sense, the ratchet effect is the process by which a trait continually increases in intensity. When applied to religion, the ratchet effect is known as the bower bird hypothesis (Dennett 2006). Below I explain how traits preferred by mating partners can become more elaborate (Kokko, Brooks, \& Jennions 2003; Kokko, Jennions, \& Brooks 2006; Kotiaho, Simmons, \& Tomkins 2001).

Male bowerbirds exhibit an extraordinary mating behaviour. In order to attract females, they build highly elaborate structures of sticks and leaves, often with a raised structure in the centre shaped like a walkway or a hut. The bird then collects and decorates this bower with blue objects such as shells, feathers, flowers, berries, and stones. In human settlements, the birds will also add blue glass, bottle tops, pegs, and other plastic objects. Once complete, the male will dance in his bower. Females will study the available bowers and observe the mating dances, before selecting the most 
elaborate bower and mating with its creator. Aside from attracting mates, a bower serves no utilitarian purpose.

Interestingly, the degree of elaboration of a bower is inversely proportionate to the brightness of the plumage of the species to which the bird that built it belongs. The most elaborate bowers are created by birds belonging to a species that have a dull plumage, whereas the least elaborate bowers are created by birds with a bright plumage. It almost seems that by building a bower, a bird is trying to compensate for poor plumage. This being the case, it is hard to imagine how the tendency to build bowers evolved.

Evidently, this trait is the product of sexual selection. Females select males that build the most elaborate bowers and their male offspring inherit the genes that condition the behaviour of bower building. If we imagine a primordial species of bower bird that did not build bowers, the females may have had a tendency to mate with the males that displayed the brightest plumage; such individuals would have stood out from the crowd, and thus could have been selected as mating partners arbitrarily. A male lacking in this area may have been able to create the illusion that his plumage was brighter by placing a small blue object in his nest. If the bird was successful in his deception, he would have won many mates and the resulting offspring would inherit the genes that conditioned that behaviour. Thus, our figurative evolutionary ratchet has turned one notch. At the second generation, the birds have a slightly duller plumage as well of the tendency to adorn their nest with a small blue object. Again, a bird with duller plumage than his peers could attract a female by adorning his nest with two objects, making himself look brighter than his peers who are only using one 
object. If successful, the third generation will again be duller, but carry the genes for slightly more elaborate bower building. Our figurative ratchet has moved two notches. After several thousand generations, the ratchet has moved to the point of the highly elaborate bowers we observe today. This hypothetical scenario accounts both for the evolutionary origin of bower building behaviour as well as the inverse relationship between bower elaboration and plumage quality.

The ratchet effect can also help to explain peacocks' enormous tails. A tail of a few centimetres long is sufficient to signal a peacock's ability to evade predation. However, longer tales will be more visible to a peahen, giving peacocks with slightly longer appendages an advantage in attracting a mate. As the evolutionary ratchet turns, peacocks evolve longer and longer tails. The tails may become so long that they unnecessarily increase a peacock's susceptibility to predation, imposing a huge biological cost on the peacock. However, once peahens have evolved an attraction to long tailed peacocks, the mating benefit gained by long tailed peacocks outweighs this increased susceptibility. We see how the ratchet effect can gradually increase the intensity of both adaptive and arbitrarily non-utilitarian traits.

There are examples of the ratchet effect occurring within our own species. One example is brain size, which has been increasing gradually in hominids over the past two million years, despite the fact that brains require very high energy costs. There is evidence to suggest that the invention of cooking was the catalyst which prompted the ratchet effect to act on brain size, as cooking reduced the amount of energy required for digestion, freeing more energy for brain development (Aiello \& Wheeler 1995; Wrangham, Jones, Laden, Pilbeam, \& Conklin-Brittain 1999). It is also known that 
the ratchet effect can act upon religious costs, increasing the intensity of costs over time (Sterelny 2007).

\subsubsection{The ratchet effect and supernatural expertise}

There are two ways in which the ratchet effect may have enhanced the cognitive capacities necessary for supernatural expertise. The first assumes that the human potential to acquire supernatural knowledge is the product of sexual selection for intelligence, memory, and problem solving skills. Once a population finds these traits attractive, selection will target them. When these traits are common throughout the population, those individuals that possess them to a slightly greater degree than their peers will have a greater chance of winning a mate; resulting in a second generation with a greater potential to acquire supernatural knowledge. As the figurative evolutionary ratchet turns, intelligence and memory for supernatural knowledge would increase.

However, this is an example of sexual selection acting upon the cognitive potential for a person to acquire supernatural knowledge. Sexual selection cannot act upon the content of supernatural belief systems, as this content is transmitted culturally, not biologically. If the supernatural knowledge base utilised by a religious group is sufficiently complex, a person will be able to judge the desired cognitive capacities of prospective mates by assessing the degree to which they've been able to familiarise themselves with the complex canon of supernatural concepts. 
One objection to this application of sexual selection theory is that an increase in the human potential to manage complex supernatural knowledge may not be a sufficient cause for an increase in the complexity of supernatural belief systems. Without a reasonable level of complexity in supernatural concepts to illustrate the difference between those with strong cognitive capacities for the acquisition of complex supernatural knowledge and those without, there is no way a person can accurately judge a partner's cognitive potential for acquiring complex supernatural knowledge. Thus, there is nothing for sexual selection to target. Therefore, the application of sexual selection theory to supernatural expertise requires an explanation of the origin and sustainability of the complexity of supernatural belief systems.

My second application of the ratchet effect assumes that the expression of supernatural knowledge is a costly signal of commitment to supernatural causation. Those engaging in the acquisition and expression of supernatural knowledge meet the criteria for inclusion in a reciprocally altruistic community. Once everybody is engaging in this practice, those few who are able to express a greater degree of supernatural knowledge will earn a greater degree of prestige in their community. This will create an incentive for others to likewise acquire more supernatural knowledge.

One objection to the second application is that the handicap principle maintains that, for a signal to be reliable, a person's ability to display the signal must be contextually linked to the trait that the signal represents. If supernatural expertise is to function as a signal of cooperative commitment, it must be configured so that only the genuinely committed will engage in the acquisition and expression of supernatural knowledge. 
Thus, only some people will be capable of participating in the act of acquiring and expressing supernatural knowledge, with the strongly committed displaying a high level of knowledge and the weakly committed displaying a low level of knowledge. Therefore, the costly signalling theory of supernatural expertise predicts that the complexity of one's supernatural beliefs will increase or decrease proportionately with one's cooperative intent.

This is not a valid application of the ratchet effect for two reasons. First, an evolutionary ratchet will only move in one direction, with the effect typically referring to an increase in a trait's intensity. Second, the ratchet effect is used to describe situations in which a trait increases in intensity without any connection to another trait. For example, peacocks' long tails are not connected to any biological utility such as the ability to run faster or glide further. However, the costly signalling theory of supernatural expertise predicts that the complexity of one's supernatural knowledge will change in proportion with one's overall cooperative intent. Therefore supernatural knowledge is strictly dependent upon another trait. The ratchet effect cannot be applied to a costly signalling model of supernatural expertise without considerable revision of the model.

\subsubsection{Conclusion}

Sexual selection is useful for understanding the cognitive capacities necessary for supernatural expertise, and in understanding how these cognitive capacities may have become elaborated over time. However, it does not help to explain the complexity of supernatural belief systems. Further, the ratchet effect cannot be directly applied to 
the costly signalling model of supernatural expertise. Therefore, if the costly signalling model is to be used to account for the complexity of supernatural belief systems, a reconciliation between the sexual selectionist and costly signalling models is necessary. 


\section{Chapter 3. Spandrelism}

\subsection{Introduction}

A spandrel is the horizontal moulding between two archways. In cathedrals and elsewhere, spandrels are often decorated with artwork. An architectural layperson, admiring the artwork, may assume that the architect designed the spandrel and placed it deliberately for artistic purposes. This layperson would be wrong. A spandrel may appear to be a part of a building's design, but it is actually a side effect caused when two archways are placed side by side. It is an accidental byproduct of a structure with a purposeful design (Gould \& Lewontin 1979).

In biology, a spandrel is any physiological or psychological trait, the design for which has not been targeted by natural selection, but which is a byproduct of adaptations that are the product of natural selection. To illustrate, human beings today have almost the exact same genes as our ancestors did one hundred years ago, yet we behave in radically different ways. There is much evidence to suggest that human religiosity may be a spandrel instead of an adaptation (see Atran 2002; Boyer 2001; Kirkpatrick 1999, 2005, 2006; Whitehouse 2004). It is unlikely that religion is the byproduct of a single psychological mechanism (Kirkpatrick 2005). It is more likely the byproduct of several mechanisms which evolved prior to the origin of religion (Boyer 2001; Kirkpatrick 2004, 2006; Mithen 1996). 


\subsection{Cognitively optimal theory}

Originally theorised by Pascal Boyer (1993), cognitively optimal theory focuses primarily on why people believe in supernatural agents (Barrett \& Keil 1996). The theory maintains that religion is a byproduct of cognitive mechanisms that endow humans with innate knowledge about the world. It opens by identifying the kinds of information that are easiest for human beings to recall, known as cognitively optimal information (Boyer 2001; Whitehouse 2004) or minimally counter intuitive information (Boyer 2001). This form of information possesses a greater appeal than other forms because of the manner in which it is contrastable to our innate knowledge. The theory is supported by data collected in several empirical experiments (Barrett \& Nyhof 2001; Boyer \& Ramble 2001; Norenzayan, Atran, Faulkner, \& Schaller 2006). This section overviews the theory before concluding with a discussion about the extent to which cognitively optimal theory is helpful in explaining supernatural expertise.

\subsubsection{Evolved intuitions}

There are numerous examples of animals that are born with innate intuitions about the world. One example is Monarch butterflies. In August, before winter besets the Northern hemisphere, Monarchs begin to migrate south, arriving in central Mexico by November. Monarchs will hibernate in Mexico before breeding in February so that their offspring can migrate north for the spring. As an active adult Monarch will normally live three or four weeks, this nearly three month migration cannot be undertaken by a single individual. As a species, Monarchs never fail to make this 
migration. However, given that their migration is completed four generations after it began, they cannot learn where and when to travel by following a parent. Additionally, as there is no contact between parent and child, no information regarding the migration process can be intergenerationally transmitted. This knowledge must be inherited. Monarchs are born with an innate intuition about where and when to travel to ensure the survival of their offspring.

Experiments conducted on young children confirm that humans are also born with innate intuitions. For example, children as young as three understand that every cow in the world will have the same internal properties, that even a cow disguised as a horse still has the same internal properties as a cow, but that computers do not necessarily have the same internal properties (Boyer 2001). This latter statement is surprisingly more accurate than the assumption that many adults may make, as two computers that are externally identical can be comprised of different internal components; a fact some adults may not intuit. Additionally, six month old infants display surprise when they witness magic tricks in which objects disappear, or in which multiple solid objects combine into one (Boyer 2001).

Humans are born with an innate understanding of the biological and physical laws that govern our environment. This adaptation makes good evolutionary sense. The more innate universal knowledge an organism is born with, the less the organism has to learn. Humans are born only with innate knowledge that was universal to most of the environments that our Pleistocene ancestors would have occupied. 
Innate human intuitions have been grouped into broad categories (Atran 1995). For instance, folk physics is the common understanding of how physical objects behave. Humans display an innate knowledge of gravity and the fact that one object can only be in one place at one time. Folk biology provides us with an understanding of how living things behave. For example, humans are instinctively aware that there are specific and fixed types of living things, and that a cow cannot become a horse for instance (Boyer 2001). Folk psychology (Atran 2002; Boyer 1994) endows us with the knowledge that other agents are driven by their own desires and motivations, or essentially that other agents have minds.

This understanding that everything in the environment belongs to a different kind or type is known as essentialism (Spinosa \& Dreyfus 1996). Essentialist thinking is an example of a human universal (Bloom 2004). From a young age, people possess an intuitive understanding of the basic essences possessed by different concepts (Medin \& Ortony 1989) within the biological and social domains (Haslam 1998; Hirschfeld 1994). Humans acquire knowledge about the world via essentialist thinking (Hirschfeld 1998), and the same universal understanding of essences are possessed by persons of different cultures (Atran 1990). For example, different cultures often share the same taxonomic knowledge (Berlin 1992).

From a young age, essentialist thinking motivates children to identify possible functions of objects. Children will interpret animals, clouds, rocks and other objects as existing for a purpose (Kelemen 2004). This skill endows even young children with an ability to engage in teleological reasoning (Kelemen \& DiYanni 2005). This 
predisposition toward teleology can motivate particular religious beliefs, such as a belief in creationism (Evans 2001; Kelemen 2004).

One experiment designed to test for essentialist thinking found that participants would refuse to eat chocolate which looked like dog faeces (Rozin, Haidt, \& McCauley 2000). This result illustrates that, like other animals, humans identify objects via their surface properties (Medin \& Ortony 1989). We ascribe essences to objects based on these properties, such as feeling disgust when looking at chocolate merely because this particular chocolate possesses the surface properties of a disgusting object.

Our innate knowledge of categories and their essential elements endows humans with the ability to distinguish between objects that move on their own accord and objects that are moved by an external force (Rochat, Morgan, \& Carpenter 1997). This skill endows people with the ability to differentiate between agents and objects from five months of age (Karmiloff-Smith 1992; Kuhlmeier, Bloom, \& Wynn 2004). One experiment involved participants being asked to describe the movement of dots on a computer screen. Participants spoke about the movement by referring to the dots using human pronouns and other anthropomorphic descriptions (Wegner 2005).

Once we have detected an agent, our innate knowledge of folk psychology endows us with the ability to ascribe minds to other agents. This skill is known as theory of mind (Fodor 1983), an ability that is fully developed in humans by age three (Schjodt 2005). It is of interest to note that autistic people have trouble attributing beliefs and emotions to others (Frith 1989), indicating that their theory of mind is somehow impaired. Of relevance to religion is the fact that our theory of mind endows us with 
the ability to believe in the existence of supernatural agents (Lawson \& McCauley 1990).

We attribute mental states to these agents. For example, children will ascribe omniscience to God (Barrett, Richert, \& Driesenga 2001; Bering \& Bjorklund 2004; Kelemen 2004). Our theory of mind allows us to differentiate between the mind and the body. Thus humans are intuitive dualists (Bloom 2004, 2007), this may help to explain a belief in a soul. Even young children will presume that a soul survives death, this presumption occurs due to the human inability to represent the absence of mental states (Bering 2002, 2006a; Bering \& Bjorklund 2004; Gilbert 2001; Nichols 2007). Empirical work has shown that priming participants with thoughts of death will increase their supernatural belief (Norenzayan \& Hansen 2006).

The problem with believing in an afterlife is that, if one prefers the next world to this world, one might be a little too keen to get to the next world. Thus, evolution must endow people with the desire to remain within this world, in spite of the belief that the afterlife may be better. Interestingly, people regard corpses to be more dangerous than they really are (Fisher 2005; Morgan \& Fisher 2004; PAHO 2003; Wisner \& Adams, Eds. 2002), which helps to foster a fear of dying. This reaction to corpses is cross culturally universal (Metcalf \& Huntington 1991). Looking forward to an afterlife is a product of our theory of mind, whereas a fear of death prevents us from wanting to go there too soon. This is an example of the notion that people can possess different skills relevant to contradictory worldviews (Spinosa \& Dreyfus 1996). 


\subsubsection{Counter intuitive information}

The bulk of the information humans encounter conforms to our intuitive understanding of the world. If I were to tell you that "I jumped in the ocean and went for a swim," this would be a wholly intuitive statement. The statement conforms to your intuitive understanding of folk physics, in that a low-density body (such as myself) should float in water; as well as your understanding of folk biology, in that swimming is what you would expect an animal to do if they voluntarily jumped in the ocean; and also folk psychology, in that swimming is the most likely motivation for my jumping into water. This statement makes perfect sense, there is nothing surprising or unusual about it. Most people hearing this would take the obviousness of the statement for granted, and never give it a second thought.

A small proportion of the information that we encounter violates our intuitive understandings (Boyer 2001). If I were to tell you that "I jumped in the ocean, landed on Venus, walked around inside my kidneys where I conjured a blue rose that turned into a dead yeti who later became the monarch of the New American Republic," this would be a maximally counter intuitive statement. It does not in anyway conform to any of the behaviours or outcomes that you would expect to result when a body, animal, or conscious being jumps into water. The statement is confusing, to say the least, and very cognitively difficult to comprehend and remember. Maximally counter intuitive statements are cognitively difficult to process (Boyer 2001) and quickly forgotten. 
However, if I were to tell you that "I jumped in the ocean and held my breath for twenty four hours," this is an example of a minimally counter intuitive statement. It conforms to your understanding of folk physics in that I am underwater, the very place that you would expect me to be if I jumped into the ocean. Further, it largely conforms to your understanding of folk biology, in that a land animal cannot breathe underwater. It even conforms to folk psychology, in that anyone who is underwater without a breathing apparatus would be motivated to hold their breath. The statement does, however, violate one minor folk biological intuition; no land mammal can hold their breath for twenty four hours. The statement is largely intuitive, therefore it is comprehensible; but as it is not entirely intuitive, it is not taken for granted. It is a fully comprehensible statement which raises an eyebrow. Of the three statements discussed, this statement is the most likely to be remembered and hence the most likely to be retold. Minimally counter intuitive information is easy to recall (Boyer 2001). We can therefore say it is cognitively optimal (Barrett 2004b).

According to the cognitively optimal theory of religion, religious belief consists of minimally counter intuitive information (Atran 2002; Barrett 2004b; Boyer 2001). This makes religious information easy to remember (Whitehouse 2000), so religious beliefs spread in populations (Boyer 2001; McCauley \& Lawson 2002). For example, counter intuitive agent concepts are memorable and spread easily (Barrett 2000, 2004b; Pyysiäinen 2003). 


\subsubsection{Supernatural knowledge as cognitively optimal}

The ability to represent supernatural beings requires theory of mind (Boyer 1999;

Mithen 1996). Cognitively optimal theory predicts that a belief in such beings results from the human tendency to acquire minimally counter intuitive information (Boyer 1994, 2001). These tendencies are obvious from a young age. Children detect what they believe to be invisible agents by age 4 , and this contributes to the intuitive theistic knowledge that children possess (Kelemen 2004). This may also contribute to the intuitive teleology that children possess (Kelemen \& DiYanni 2005), in that they perceive all objects as serving a purpose (Kelemen 2004). This inference of an order in reality is motivated by the same psychology that motivates many to conclude that the world is the product of an intelligent creator (Bering 2003; Kelemen 2004; Pyysiäinen 2005). Supernatural beliefs are counter intuitive. I now turn to a discussion as to whether cognitively optimal theory can explain the supernatural knowledge associated with such beings.

There are three main problems associated with employing cognitively optimal theory to explain complex supernatural knowledge. First, the theory would suggest that a given supernatural concept will become a component within a supernatural belief system if it is memorable. However, there are countless memorable concepts, including numerous supernatural concepts, which are not found in any supernatural belief system. One example would be Santa Claus (Barrett 2008; Johnson 2005). Santa can fly and is familiar with the quality of your overall behaviour. These are counter intuitive properties that have been attributed to him. Yet, very young children will quite rationally and independently determine that Santa's existence is impossible 
without making the same determination about God. Thus there must be other conditions surrounding the nature of God that are beyond His counter intuitiveness, which prompt people to believe in Him.

Another example of a supernatural concept no one believes in is the Flying Spaghetti Monster. The concept of the Flying Spaghetti Monster was conceived by Bobby Henderson as a means to illustrate his view regarding the Kansas School Board's decision to teach intelligent design along with evolution. He argued that they should also teach the view that the Flying Spaghetti Monster created the universe after an all day drinking session, and that the imperfections in creation are a result of his drunkenness. This is of course a joke. The notion that spaghetti created the world is counter intuitive, but unbelievable. Thus it would appear that the minimally counter intuitive nature of many supernatural concepts is a necessary, but insufficient, cause for their becoming supernatural concepts.

My second objection to cognitively optimal theory is that even successful supernatural concepts are only accepted by a select group. It is counter intuitive that Buddha was a bodhisattva in a past life, and it is evidently believable as so many people do believe this. However, most people do not. It is counter intuitive and evidently believable that Jesus survived crucifixion but most people disbelieve this also. A complete theory of supernatural expertise must entail an explanation of the sufficient causes for supernatural belief, as well as the reasons as to why concepts meeting these criteria are not universally accepted. 
Third, the notion that all supernatural knowledge is minimally counter intuitive is actually wrong. Some supernatural concepts are moderately or even maximally counter intuitive, and therefore difficult to understand and recall (Boyer 1994, 2001). A lot of the information used to describe supernatural beings is likewise difficult to remember (Barrett 2004b; Boyer 2003). The modern Abrahamic perception of God as an omnipotent, omnipresent, omniscient and omnibenevolent being violates numerous folk intuitions. For example, God's omnipotence counters our intuitive understanding of folk biology which suggests that agents will be limited in the actions that they can perform. The concept of an omnipotent God can only be comprehended with much time consuming conscious thought (Barrett \& Keil 1996). God's omnipresence is contrary to our understanding of folk physics which informs us that an agent can only exist in one place at one time. God's omniscience violates our understanding of folk psychology which suggests that an agent will be limited in the information it has access to. Folk psychology also suggests that agents will, at least sometimes, be motivated by selfish intentions, but this is violated by the notion of God's omnibenevolence. In spite of the maximally counter intuitive nature of God, this deity is the primary subject of worship for over half the world's population.

Furthermore, there is evidence to suggest that humans cannot cognitively represent the counter intuitive properties of the gods that they believe in, but instead will possess two concepts of god, an intuitive one and a theologically correct one. For example, people have difficulty processing their belief that God is able to help two people simultaneously (Barrett \& Keil 1996). Furthermore, 63\% of Americans have experienced anger toward God (Davis, Smith, \& Marsden 2005), indicating that they do not always take a belief in God's omnibenevolence seriously. 
These are examples of a difference between explicit and implicit belief. Other empirical data has also been collected to demonstrate this (Shariff \& Norenzayam 2007). Whereas psychological surveys typically only measure people's theologically correct representations of God (Barrett \& Keil 1996), intuitive concepts of God can sometimes differ (Pyysiäinen 2004b). Cognitively optimal theory cannot account for this. A complete treatment of supernatural expertise must resolve this objection by explaining why so many religionists possess knowledge that is moderately to maximally counter intuitive.

\subsubsection{Conclusion}

Cognitively optimal theory is useful in explaining supernatural expertise insofar as the content of supernatural belief systems consists of minimally counter intuitive information. However, not all supernatural information is minimally counter intuitive, with some supernatural information being moderately or maximally counter intuitive. Further, humans reject most of the counter intuitive information that they encounter in two ways. First, many memorable concepts are not found in supernatural belief systems. Second, humans possess a bias toward the counter intuitive beliefs of their immediate religious group.

\subsection{The modes theory}

The modes theory of religion was developed by Harvey Whitehouse to explain the cognitive basis for the cultural transmission of religions (Whitehouse 1995, 2000, 
2004). Central to the modes theory is the ritual form hypothesis (Barrett 2004a;

Barrett \& Lawson 2001; McCauley \& Lawson 2002). This hypothesis begins with the notion that our ability to conceive of supernatural beings is a product of our theory of mind. This enables us to conceive of a supernatural being as either an actor or a patient within a religious ritual (Lawson \& McCauley 1990), that is, we can understand them to be effecting a change through the ritual, or to be changing because of the ritual. The ritual form hypothesis has been applied to the Pomio Kivung movement (McCauley \& Lawson 2002), and is supported by data collected through observing the wedding rituals of monotheistic religions (Malley \& Barrett 2003).

The modes theory explains religion in terms of the cognitive memory systems (Klein, Cosmides, Tooby, \& Chance 2002) and the social arrangements that human beings develop to facilitate the transmission of religious ideas (Boyer 2001; McCauley \& Lawson 2002; Whitehouse 2000) such as experiential recollections which are remembered episodically (in the imagistic mode) or doctrinal information which is recalled semantically (in the doctrinal mode) (Whitehouse 2002). The doctrinal and imagistic modes, as well as the acquisition and spread of cognitively optimal concepts, all heavily influence one another (Whitehouse 2004). This section overviews the doctrinal mode. It concludes by identifying the necessary revisions that must be applied to the modes theory before a complete account of supernatural expertise can be developed.

Essential to the modes theory are the six different forms of memory identified by Endel Tulving (1972). First, implicit memory refers to information we recall subconsciously, such as how to express our thoughts in our native language. Second, 
explicit memory refers to conscious knowledge which can be either short or long term. Third, short term memory refers to information retained momentarily, such as a limerick. Fourth is long term memory, which retains information for extended periods of time, and can be either semantic or episodic. Fifth, semantic memory consists of information that we are aware of, but cannot recall where or how we learnt it, such as a religious doctrines. Sixth, episodic memory is the recollection of information we can remember learning. Episodic memory typically consists of recollections of particular events or episodes, such as a baptism.

\subsubsection{The doctrinal mode of religiosity}

As his starting point for the doctrinal mode of religion, Whitehouse (2004) observes that within doctrinal religions, religionists often engage in the frequent repetition of religious teachings. This may take the form of the recitation of scripture, creeds, or religious lyrics. Many ritual practices are also repeated, examples include saying grace before eating, meditating, or performing salat. The frequency with which such practices are repeated has been likened to obsessive compulsive disorder (Boyer 2003, 2005; Boyer \& Lienard 2006).

Whitehouse (2004) observes that frequent repetition causes two effects. First, doctrinal information is remembered semantically. That is, although specific doctrines are stored in memory, the precise occasion upon which those details were learnt becomes lost in a sea of the many memories for the occasions on which the information was recited. After a religionist has recited a canonised creed one hundred times, there is no way he could identify which specific recitation resulted in that creed 


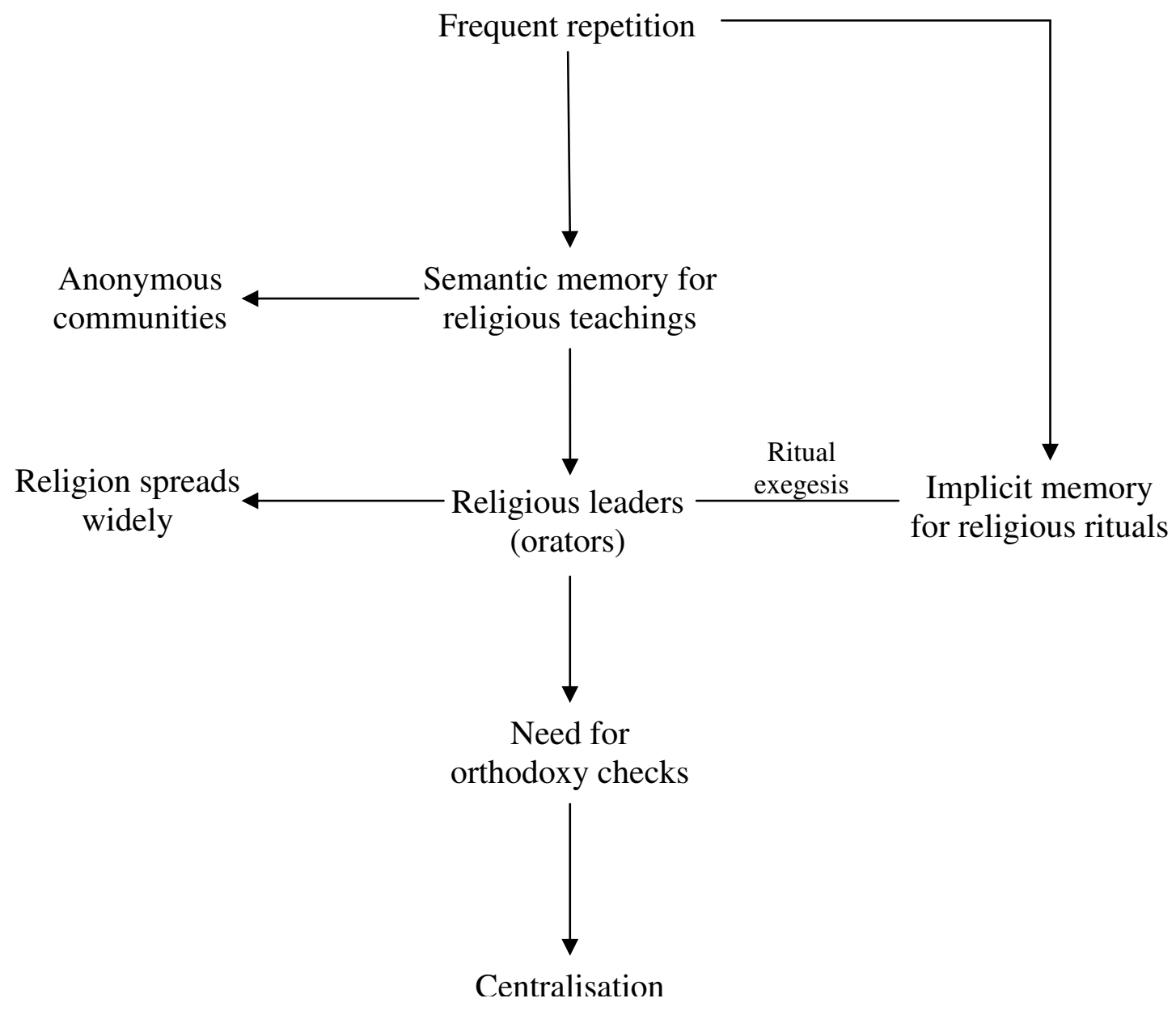

Figure 1: The doctrinal mode

Source: derived from fig 4.2 in Whitehouse (2004)

being stored in his long term memory. Second, the frequent repetition of rituals results in an implicit memory for ritual procedures. That is, ritual procedures are recalled subconsciously without the participant being aware that any recollections are taking place. A Catholic does not have to consciously concentrate on the precise manner in which she should position her hands when receiving a communion wafer from her priest. However, this is no doubt information she frequently recalls as she holds her hands in the exact same position every time. If she were to ever fail to 
adopt the accurate hand position, her priest may discriminate against her on this basis. $^{6}$

Further, Whitehouse (2004) observes that the fact that religious teachings are semantically remembered results in three effects. First, some individuals will emerge as religious leaders. Whitehouse describes these individuals as orators. He speculates that the most charismatic individuals will assume leadership roles because their ability to articulate the religious teachings will exceed that of their peers. Second, religious leaders are in a position to dictate a canonised body of doctrinal knowledge. Examples include the doctrine of the trinity or the Talmudic interpretations of the Torah. Whitehouse observes that religious leaders perform orthodoxy checks to ensure that their teachings are universally accepted throughout the group. Such orthodoxy checks require leaders to identify and suppress unauthorised innovation. Whitehouse speculates that these checks function to ensure the credibility of the religious tradition. Third, as a means to quell innovation leaders must establish a canonised body of knowledge. Thus leaders will perform the function of exegeting ritual procedures. As rituals are performed automatically, having been stored in implicit memory, religionists will be unaware as to the reasons for their ritual behaviour. Religious leaders are in a position to provide an interpretation for this behaviour.

Whitehouse (2004) concludes that the doctrinal mode of religiosity creates three different social conditions. First, the necessity for orthodoxy checks inevitably results in the centralisation of religion. Heterodoxy is much easier to police if there is a

\footnotetext{
${ }^{6}$ Indeed, the author has a Protestant friend who once attended Catholic mass but was denied communion on the basis that their hands were positioned incorrectly.
} 
single authority from which all innovation is understood to originate. This authority can then enforce the established doctrine and police unauthorised innovation. One classic historical example was the council of Nicea, a fourth century Christian body that was established to determine an official belief system for the Christian church, which led to the persecution and ultimate annihilation of innovatory Gnostic movements. Second, the semantic memory for religious teachings results in anonymous communities; that is, communities in which any one member will not know the majority of others. As these memories are not episodic, the exact time, place, and people that a practitioner sat next to while learning the teachings is unimportant. What is important is that the religious knowledge is common among a vast community of believers; resulting in communities whose members are largely unknown to one another. Third, some religious leaders assume roles as missionaries or evangelists who travel for the sole purpose of spreading the religion to other regions and localities. Thus the doctrinal mode of religiosity creates widespread anonymous communities with a centralised hierarchy.

\subsubsection{Discussion of the doctrinal mode}

I have four main concerns about Whitehouse's model of the doctrinal mode. First, Whitehouse's initial observation is the fact that religionists engage in the frequent repetition of religious teachings. It is correct that frequent repetition occurs and that it leads to the semantic memory for supernatural information which ultimately results in the social conditions elaborated above, but Whitehouse does not account for why frequent repetition occurs in the first place. A complete explanation of the doctrinal 
mode must explain both how frequent repetition began, and why it continues to persist as a central practice in doctrinal traditions.

Second, by employing frequent repetition as his starting point, Whitehouse does not examine the content of supernatural belief systems as a separate category. It is supernatural information that is subject to frequent repetition. Thus, such information must exist before frequent repetition occurs. In this respect, the content of supernatural belief systems could equally be considered the starting point for the doctrinal mode as opposed to the frequent repetition of that content. However, this consideration would be problematic, as supernatural information is dictated by religious leaders. Whitehouse himself observes that leaders dictate the belief system as well as performing the function of exegeting ritual procedure. Therefore, religious leaders must come before supernatural information. However, leaders cannot be considered a starting point for the model, as Whitehouse argues that leaders exist because semantic memory for religious teachings creates a social condition whereby some persons will be understood to possess a mastery over those teachings, thereby emerging as leaders. Hence we observe that frequent repetition leads to the semantic memory for religious teachings, which causes leaders to emerge who dictate the supernatural information that is then frequently recited. This is a purely cyclical process which has no starting point. We find ourselves with a classic chicken/egg scenario. A complete treatment of the doctrinal mode of religion must explain how this cyclical process began in the first place.

Third, Whitehouse arbitrarily describes religious leaders as the orators. For Whitehouse, the leaders are the persons who can articulate religious teachings the 
best. One need not look too far to identify counter examples of this assumption. In Hinduism, religious leadership is predominantly hereditary. Brahman priests inherit their elite positions from their parents. In Tibetan Buddhism, new lamas are chosen on the basis of psychic intuition, astrological analysis, and testing procedures that, from the perspective of an outsider, produce seemingly insignificant results. In both of these examples, communication skills have little or nothing to do with the selection process. Clearly it is insufficient to explain religious leaders as the best orators. This does not mean that semantic memory for religious teachings does not create a condition in which religious leaders will emerge. However, it does mean that the personal and familial qualities which determine whether someone will hold a leadership position are more complex than Whitehouse proposes. A better treatment of the doctrinal mode must provide a more complete analysis of the variety of conditions under which religious leaders will emerge. These conditions may be as numerous as the many religions, if not more so. However, a more complete analysis is possible.

Fourth, the model does not address the issue of any social functionalities that may be performed by the doctrinal mode. Whitehouse has suggested that, "the doctrinal mode ... emerged when relatively large-scale patterns of cooperation became routinised, probably as a result of the seasonal rhythms associated with the domestication of animals and plants and the establishment of the first townships" (Whitehouse 2008). However, Whitehouse only observes that a relationship exists between the necessity for large-scale cooperation and religious doctrine. A complete examination of the doctrinal mode must arrive at an explanation as to the nature of this relationship. Specifically, the link must be established between (a) the three 
social conditions created by the doctrinal mode, these being centralisation, anonymous community, and widespread religion, and (b) the manner in which religious groups and societies solve large-scale cooperation problems.

\subsubsection{Conclusion}

The doctrinal model is incomplete because it does not account for the origin of frequent repetition, nor does it account for the origin of the cyclical process between the repetition of supernatural information and the religious leaders that dictate that information. Whitehouse's description of religious leaders as the best orators is insufficient and requires revision. Lastly, although Whitehouse asserts that the doctrinal mode emerged alongside large-scale cooperation, an exploration as to the link between these two phenomena is required. 


\section{Chapter 4. Towards a reconciliation of the adaptationist and spandrelist paradigms}

\subsection{Introduction}

In this chapter I argue for an innovative theory of supernatural expertise that is consistent with the theories previously discussed. However, my theory expands upon the theories previously discussed by addressing the many difficulties with each theory that are identified above. I open by addressing the manner in which supernatural expertise can be more costly for non-religionists than religionists; I turn to cognitively optimal theory to provide this explanation. I then demonstrate how the ratchet effect acting upon sexual selection has enhanced the quality and quantity of expressions of complex supernatural knowledge. Lastly, I address the doctrinal mode of religiosity, demonstrating how cognitively optimal theory can better explain the cyclical process that is left unexplained by Whitehouse's model. In doing so I argue for a theory of supernatural expertise that is consistent with a variety of research in the fields of the cognitive science of religion and the evolutionary psychology of religion.

\subsection{The cost of complex supernatural knowledge}

As established in section 2.2, supernatural expertise appears costly in terms of the effort that is required to acquire complex supernatural knowledge. In this regard, supernatural expertise conforms to the first criterion for a hard to fake signal.

Likewise, it conforms to the second criterion in that there is a contextual association between religious commitment and the acquisition of supernatural beliefs surrounding 
that commitment. The third criterion requires that a signal is more costly for a genuine communicator than a false communicator. Whether or not supernatural expertise conforms to this criterion remains to be identified.

It is easy to understand how the examples of costly signals previously discussed conform to this criterion. An unfit gazelle cannot stot and if it tried its physical weakness would be apparent in its poor stotting performance. A peacock cannot display a perfect tail if it has had a brush with a predator. So both stotting and peacocks' tails are configured to prevent false communicators from imitating the signal. However, as regards one's familiarity with supernatural knowledge this does not appear to be the case. For instance, even I am familiar with the supernatural beliefs of many religious systems that I don't believe in.

Given the highly competitive environment in which our species evolved, humans have developed a preference for information that improves our chance of survival (Tooby \& Cosmides 1992). Accordingly, our minds are designed to formulate explanations about the world which will benefit our survival potential (Stark 1999; Stark \& Bainbridge 1987). Nevertheless, many people seem to be interested in religious information, even if such information is not readily available. For example, in religions where a particular form of prayer is required, people tend to pray in the same manner even if procedural instructions about how to pray are not made available (Barrett 2001). This indicates an interest in religious information which is so strong that people will aspire to acquire even unspoken information. The key to explaining the human interest in supernatural information is to understand how this information is useful in enhancing our chance of survival. Humans possess a preference to 
acquire only relevant information (Sperber 1985, 1996; Sperber \& Wilson 1986), thus the relevance of supernatural information must be identified.

I now turn to the cognitively optimal theory of religion and apply it to the third criterion for a Zahavian handicap. This theory states that minimally counter intuitive (MCI) ideas are best configured to be memorable, thus the content of supernatural belief systems should consist of minimally counter intuitive information. The difficulties with this theory are that the content of supernatural belief systems is sometimes maximally counter intuitive and that humans do not believe in every counter intuitive concept they encounter.

Further, Justin Barrett (2004b) has noted that "some theological beliefs, more typically held by clergy than regular folk, do have a large number of counter intuitive features and do not fit the MCI label" and "if a person believes in an MCI god, through rigorous theological instruction they may be led to accept additional counter intuitive properties of the god." Barrett observes these facts merely because they are true. However, he does not attempt to reconcile cognitively optimal theory with the fact that he observes supernatural experts to be more concerned with maximally counter intuitive supernatural information than lay persons.

What is more perplexing is the observation, not only that supernatural experts memorise maximally counter intuitive information, but that they concern themselves with specific pieces of counter intuitive information. A supernatural expert expressing the example belief suggested in section 2.2.9, that the Dalai Lama is the thirteenth incarnation of Avalokitesvara, when the Dalai Lama is in fact believed to be 
the fourteenth, has expressed a theologically incorrect belief. Both of these statements are counter intuitive, but only one is theologically correct. Theological incorrectness (Slone 2004) can be a problem in some religious traditions, where practitioners are expected to hold theologically correct beliefs.

This leads to a dilemma in which the beliefs that religionists often explicitly express do not correspond to the implicit beliefs they display. For example, non-theist Buddhists sometimes behave in a way that is consistent with a theistic belief system (Slone 2004), and people who verbally deny a belief in magic and superstition will sometimes act as if they do believe in magic (Subbotsky \& Quinteros 2005). These apparent contradictions are possible in that humans have the ability to simultaneously possess different skills that can be applied to multiple worldviews (Spinosa \& Dreyfus 1996). It has been shown that linguistically based supernatural beliefs are fundamental to the acquisition of religion (Bering 2004) as religious beliefs are often maintained because people feel obligated to express specific beliefs (Burris \& Navara 2002; Greenwald, Banaji, Rudman, Farnham, Nosek, \& Mellott 2002). This indicates that explicit beliefs are an essential part of religion even though they sometimes contradict implicit beliefs evidenced through behaviour. Any explanation of supernatural expertise requires an account of both its maximally counter intuitive nature, and the fact that this counter intuitive information is not always evidenced in the behaviours of some supernatural experts.

I have previously demonstrated that complex supernatural knowledge is costly to acquire in terms of the time and effort that must be invested into its acquisition. The proposition I now advance is that the reason complex supernatural knowledge 
requires so much time and effort is because it is not minimally counter intuitive. I accept that our minds are configured to find minimally counter intuitive information memorable. I also accept that maximally counter intuitive information is not memorable in this respect. I likewise accept that the acquisition of maximally counter intuitive supernatural beliefs requires considerable effort. Given that much supernatural knowledge is maximally counter intuitive, this analysis clarifies precisely how the acquisition of complex supernatural knowledge is costly.

This analysis resolves the three difficulties with the application of cognitively optimal theory and costly signalling theory to supernatural expertise. First, so much supernatural knowledge is maximally counter intuitive because if this were not so, supernatural expertise would not perform a costly signalling function. The presence of maximally counter intuitive systems of supernatural belief secures cooperation via the costly signalling function performed by the expression of complex supernatural knowledge.

Second, this analysis finally allows us to apply the third criterion for a Zahavian handicap to supernatural expertise, which requires that a signal be more costly for a dishonest communicator. As discussed in section 2.2.7, the cost of ritual investment is perceived differently by a believer and a sceptic, preventing the uncommitted from achieving the same quality of ritual performance as believers. When the acquisition of complex supernatural knowledge is understood in terms of a private ritual for the acquisition of maximally counter intuitive information, we can understand why complex supernatural knowledge is more costly for sceptics than religionists. Sceptics perceive a greater cost (and ultimately a net loss) associated with the 
acquisition of knowledge that they recognise as being false and non-strategic, whereas believers perceive a net gain associated with the acquisition of information they perceive as being accurate strategic information about the universe. The greater cost to a non-believer is a perceptual one. Thus religionists will experience a greater motivation to acquire supernatural knowledge than sceptics.

Third, we recognise why humans do not believe in every counter intuitive concept they encounter. It is in our immediate biological interest to invest in the acquisition of the systems of supernatural knowledge belonging to the religious group of which we are a member. If we were to believe in all counter intuitive concepts, we would be motivated to acquire all supernatural knowledge, an impossible task that would significantly detract from opportunity costs that could be invested into acquiring the systems of supernatural knowledge possessed by one's immediate religious group. Thus it is advantageous for humans to be sceptical concerning the beliefs of other groups.

Further, given that the beliefs that people claim to hold do not always correspond with their implicit beliefs (Barrett 1998, 1999; Barrett \& VanOrman 1996), supernatural expertise is costly in another respect. It requires further effort for a person to act as if their supernatural beliefs are true. For example, the belief that God can perform two acts simultaneously is an intellectual belief, but not one that affects the manner in which people implicitly think about God (Barrett \& Keil 1996). Humans possess two meaning subsystems which correspond to intellectual and affective belief (Barnard \& Teasdale 1991). I suggest that these correspond to two different forms of knowledge that human beings can possess, this being schematic knowledge and experiential 
knowledge (James 1890). For a supernatural expert to implicitly behave as if God can perform two acts simultaneously, her experience of her concept of God must be consistent with her intellectual beliefs about God so that her experience will affect her behaviour. This requires a very high level of familiarity with the maximally counter intuitive beliefs of one's religion.

The expression of complex supernatural knowledge evidences the costly commitment that one has invested into the acquisition of that knowledge. Costly signalling theory predicts that this functions as a signal of commitment to one's religious group through the ideal of supernatural causation. This requires that supernatural experts be motivated to acquire and express information which is theologically correct within the context of their religious beliefs. Therefore, humans possess the motivation to minimise religious doubt (Edwards \& Hall 2003).

In addition to signalling commitment, supernatural expertise functions as what I call an epistemological adornment. That is, supernatural experts adorn their knowledge base with complex supernatural information. Adornment signalling is common, even among our own species. For example, humans grow much longer hair than other primates. Those of us who possess the time and the resources to invest in grooming, signal that we possess a surplus of resources (Zahavi \& Zahavi 1997). Accordingly, those able to express complex supernatural information evidence that they have the time to waste on the acquisition of that information.

It should also be noted that some supernatural experts will express their supernatural knowledge in front of a large audience of witnesses. Examples include a Catholic 
priest delivering a sermon or a Buddhist monk giving a dharma talk. If the supernatural expert were to express a theologically incorrect statement, this would be witnessed by the entire audience, incurring a huge cost to the reputation of the expert. This risky behaviour may seem perplexing, however, it is worthwhile to note that signalling to a group is a stronger signal precisely because the signaller incurs a larger cost if the signal is false (Zahavi \& Zahavi 1997). By incurring this greater risk, the supernatural expert signals confidence in his mastery over his group's system of supernatural belief. Members of his group can infer his mastery from the confidence evidenced and can accordingly deduce his high degree of commitment to the group. This explains why some supernatural experts are motivated to express their beliefs to large groups.

\subsection{Sexual selection for the cognitive capacities necessary for supernatural expertise}

Sexual selection is the process by which traits are selected because they are attractive to a mate and not necessarily because they serve a utilitarian function. The ratchet effect is the process by which sexually selected traits are enhanced over time. Although there is evidence that hard-to-acquire aspects of religion can be caused by the ratchet effect (Tomasello 1999), we established in section 2.3.4 that a sexual selectionist account for supernatural expertise is problematic in that sexual selection theory cannot account for the complexity of supernatural belief systems. Thus, without complexity in supernatural beliefs, sexual selection for the cognitive ability to manage that complexity cannot occur. Likewise, the ratchet effect cannot be applied directly to the costly signalling model of supernatural expertise because it is only 
applicable to situations in which a trait continually increases in intensity. By way of contrast, the costly signalling model discussed in section 2.2 predicts that the complexity of a religionist's supernatural knowledge will increase or decrease in rough proportion to their cooperative intent.

However, for the sake of conjecture, let us assume both theories to be true. The individuals in a religious community who express the most supernatural knowledge would be engaging in a signal that communicates two very different traits. First, they communicate their cooperative intent. Second, they communicate that they possess genes which code for a high intelligence, good memory and problem solving skills; abilities which are necessary to manage complex supernatural information. The former message is beneficial in that it ensures their membership in a reciprocally altruistic community. The latter message is beneficial in that it increases their sexual attractiveness. This model predicts that, at least historically, supernatural experts would have won mates more easily than their peers. ${ }^{7}$

I now present an example of sexual selection for the cognitive capacities for supernatural knowledge that can perform a costly signalling function. Assume at generation $n$, there are a variety of cognitive capacities within a population, which endow individuals with varying levels of the ability to acquire supernatural knowledge. Assume each individual in the population inherits the cognitive capacities of their parent with only minor variation. Assume that the majority of individuals in the population acquire some degree of supernatural knowledge in an attempt to signal cooperative intent. Those with elite cognitive capacities may or may

\footnotetext{
${ }^{7}$ Note that the cultural invention of celibacy may or may not hinder this process in some societies. See section 2.3.2 for a discussion of celibacy.
} 
not acquire a complex level of supernatural knowledge depending upon the degree of their cooperative intent. Those that do acquire a complex level of supernatural knowledge exhibit a higher degree of sexual attractiveness. Therefore, at generation $n+1$ the number of individuals who have inherited elite cognitive capacities is higher than the number of individuals who inherited non-elite capacities. Thus the average cognitive capacities of the population have increased. Further, minor variations in the inherited capacities would result in some children of supernatural experts possessing greater cognitive capacities than their parents. Hence the spread of cognitive variability at generation $n+1$ is about the same as it was at generation $n$. Persons attempting to signal cooperative intent now have the potential to acquire a greater degree of supernatural knowledge than their forebears. Thus, in order to remain one step ahead of the masses, the most altruistic individuals must compensate for the population's increased cognitive potential by expressing a more complex level of supernatural knowledge than would have been necessary had they lived at generation n. Again, the supernatural experts signal not only their cooperative intent, but also certain genetic qualities. This increases their sexual attractiveness, resulting in higher average cognitive capacities at generation $n+2$.

We see that the ratchet effect can be applied to supernatural expertise by utilising costly signalling theory to account for the complexity of supernatural belief systems. This model resolves the difficulty associated with applying sexual selection theory to supernatural expertise in that the necessary cause for the complexity of supernatural belief is the costly signalling function it performs. The model likewise resolves the difficulty of applying the ratchet effect to a costly signalling model in that the variations in expressions of supernatural knowledge that are predicted by the model 
are necessary to highlight variability in cognitive capacities so that sexual selection can occur. We see that costly signalling theory and the ratchet effect acting upon sexual selection can complement one another; and indeed must complement each other if the origin of the complexity in supernatural belief is to be understood.

\subsection{The functionality of the doctrinal mode}

Here I employ my previous critiques of costly signalling theory, cognitively optimal theory, and sexual selection theory as a means to resolve my three concerns with Whitehouse's model of the doctrinal mode (2004). First, I examine the question of what came first: religious leaders who acquire complex supernatural information or the supernatural information that is dictated by religious leaders. Second, I address the fact that Whitehouse employs the frequent repetition of supernatural information as his starting point without discussing how frequent repetition began. Third, I discuss how the need for "large-scale patterns of cooperation" can create a requirement for the social conditions generated by the doctrinal mode.

Whitehouse's doctrinal model (2004) leaves unanswered a classic chicken/egg scenario. Although Whitehouse does not identify the content of supernatural belief systems as a separate category, it is this content which is the subject of frequent repetition. Therefore, frequent repetition leads to semantic memory for religious teachings which leads to some religionists emerging as leaders who dictate the content of the belief system which is the subject of frequent repetition. Thus Whitehouse's doctrinal mode has no beginning. For this cyclical process to begin, at least one of these four processes would need to have originated independently of the model. 
Max CI concepts, linked to supernatural

Preference for

causation

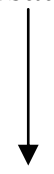

Supernatural

knowledge functions

as a costly signal

of altruistic intent

altruistic mates

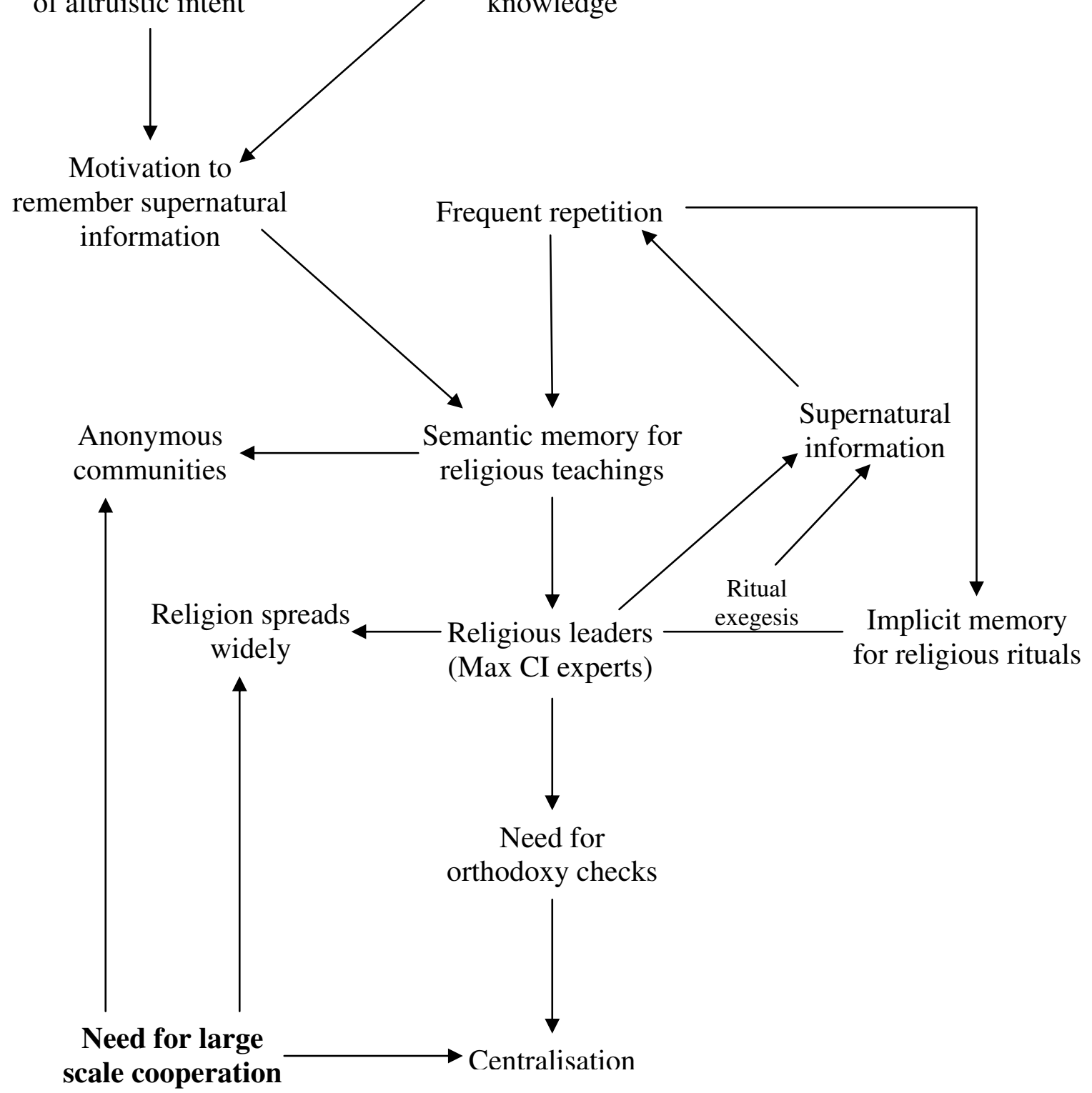

Figure 2: How the doctrinal mode began; and how the doctrinal mode resolves the need for large scale cooperation. 
During my discussion of costly signalling theory in section 2.2, I demonstrated how supernatural expertise can perform a costly signalling function if the acquisition and expression of supernatural knowledge is linked to supernatural causation. Further, in my application of the ratchet effect to sexual selection in section 4.3, I argued that the ratchet effect acting upon cognitive capacities for the acquisition of supernatural information can increase the complexity of supernatural belief systems if a costly signalling function is being performed. In this scenario, supernatural knowledge represents one factor which determines a person's sexual attractiveness as well as their suitability as an exchange partner. Thus, although the most altruistic individuals will likely acquire more supernatural knowledge than their peers, many people will be attempting to acquire supernatural knowledge in an attempt to gain the same advantages that it brings to those individuals. This results in memory for supernatural information.

Thus supernatural information begins with the semantic memory for religious teachings. These memories originate when sexual selection acts upon the cognitive capacities for the acquisition of supernatural knowledge in an environment where complex supernatural knowledge can perform a costly signalling function. Semantic memory then leads to the emergence of religious leaders. ${ }^{8}$ The leaders are in a position to contribute to the increasingly complex pool of supernatural knowledge by exegeting ritual procedures and constructing new analyses of supernatural information. These behaviours allow supernatural experts to assert their prowess as

\footnotetext{
${ }^{8}$ For the purposes of this thesis, religious leaders are assumed to be those who are best at acquiring complex supernatural knowledge. While this assumption is more helpful than Whitehouse's arbitrary assertion that the religious leaders are the "orators", it is by no means a complete analysis of the emergence of religious leadership. Religious leaders are appointed for a variety of reasons, such as the social status of their family. A more complete treatment of religious leadership is required.
} 
acquirers of supernatural knowledge and ultimately maintain their elite social positions. A prestige bias, that is, the motivation to imitate successful individuals (Richerson \& Boyd 2005), prompts lay religionists to familiarise themselves with the canon of supernatural concepts dictated by the leaders. Established and new doctrines are frequently repeated by many religionists as a means to increase their status as acquirers of supernatural knowledge. Frequent repetition then acts as a low arousal ritual which further encapsulates supernatural information in semantic memory and increases the willingness of religionists to accept the orthodoxy dictated by religious leaders (Whitehouse 2004). The doctrinal mode has begun.

This analysis resolves the first two objections that I intended to address. First, it is neither religious leadership nor supernatural information that came first. Rather, it was semantic memory for maximally counter intuitive information. Second, the doctrinal mode does not begin with frequent repetition; rather, the doctrinal mode began with semantic memory for supernatural information which resulted in the social conditions that led to frequent repetition.

Lastly, I wish to address the issue of why the doctrinal mode emerged alongside large-scale patterns of cooperation. Although Whitehouse (2008) identifies that this is the case, he does not address the relationship between the doctrinal mode and the need for large-scale cooperation. It may be the case that one caused the other, or that both conditions are symbiotically dependent.

Cooperative techniques are required to solve competition problems. Competition increases for a variety of reasons, such as resource depletion or population increase. 
An increase in population density will typically result in a need for more advanced cooperation techniques. For example, imagine a group of nomadic tribes who only consume plants and animals which thrive naturally within the environment. If the tribes' populations continue to increase, they will eventually reach a point at which there will not be a sufficient quantity of food for the tribes to consume. This will result in greater competition, both inter- and intra-tribally. This competition can be resolved if the nomadic tribes adopt agricultural techniques to extract a greater quantity of resource from their environment. Agriculture comes at a great cost in that (a) it requires more organisation and cooperation between individuals, (b) those practising it are more susceptible to repetitive strain injuries, and (c) switching from a nomadic to an agricultural lifestyle entails a reduction in the variety of one's diet. In spite of these disadvantages, agriculture was adopted around 12,000 years ago, quite possibly to solve competition problems associated with an increasing human population.

Whitehouse likewise identifies that the doctrinal mode emerged alongside conditions of population increase, specifically "as a result of the seasonal rhythms associated with the domestication of animals and plants and the establishment of the first townships" (Whitehouse 2008). Increasing population would have undoubtedly resulted in increased competition. Yet religions which have spread throughout multiple towns, cities, and even nations have been successful in promoting wide scale cooperation (Wilson 2002). While it has been argued that religious change led to the origins of agriculture (Cauvin 2000), I suggest that it was agriculture which led to the origins of the doctrinal mode. Here I discuss the three social conditions which result 
from the doctrinal mode and explore whether supernatural expertise is a cultural technology which, at least historically, resolved competition problems.

First, as established in section 2.2, complex supernatural knowledge can perform a costly signalling function. However, this analysis alone did not address the extent to which this costly signalling function can spread. Complex supernatural knowledge may not be sufficient to resolve the competition problems that would result from "the establishment of the first townships." However, as part of the doctrinal mode, Whitehouse (2004) observes that the semantic memory for religious teachings produces anonymous communities. That is, communities which are not formed on the basis of the common association of their members, but are bound by a common sense of identity which is ground in a common system of supernatural knowledge. A member belonging to an anonymous community, in which complex supernatural knowledge performs the function of costly signalling cooperative intent, can judge a stranger's reliability as an exchange partner by assessing the extent of her supernatural knowledge. Ordinarily, one would have to rely upon their knowledge of another's reputation to make this judgement. However, in large settlements in which it is not possible to track the behaviour of each individual, a shared system of supernatural knowledge provides a means for individuals to solve this problem.

Therefore, supernatural expertise functions via the assessment of cultural capital (see Bourdieu 1986). Fellow supernatural experts, who are able to assess each other's familiarity with the relevant non-utilitarian cultural information, will be able to determine the quantity of time and resource that each has invested into the acquisition of this cultural capital. Where the acquisition of such information is contextually 
dependent upon a belief in supernatural causation, the altruistic intent of a fellow supernatural expert can be inferred via the expression of their supernatural knowledge. The most devout experts will semantically store the correct cultural capital in a theologically correct manner. For example, one belief that is central in evangelical Christianity is the notion of a personal relationship with God.

Experiments involving evangelical Christians have found that participants store supernatural information about God in a manner consistent with such a relationship (Gibson 2005). My explanation of supernatural expertise predicts that such Christians should be able to express their supernatural knowledge in a manner that is consistent with this fundamental belief. This prediction is confirmed by the results of an experiment in which evangelical Christians were able to produce faster reaction times than non-evangelicals when attributing traits to God (Gibson 2006). This is an example in which a consistency has been achieved in both one's intellectual and experiential knowledge, a feat of perfection in supernatural expertise that requires a great deal of effort as explained in section 4.1. The strive toward perfection can be adaptive (Flett \& Hewitt, Eds. 2002), because perfection earns prestige for those striving to familiarise themselves with the complex supernatural knowledge of their religious leaders and because the degree of prestige that an individual possesses can perform a costly signalling function (Zahavi \& Zahavi 1997).

Second, Whitehouse (2004) further observes that the presence of religious leaders causes religions to become widespread as some of the leaders assume missionary roles. This increases the size of the anonymous community. A religionist may be able to traverse a large geographical area and still regularly encounter persons 
belonging to his own religion, enabling him to find reliable exchange partners as he travels. This can facilitate trade and communication between settlements.

Third, Whitehouse (2004) notes that the necessity for orthodoxy checks results in the centralisation of religions. These centralised authorities perform the function of policing innovation. Novelty results from creativity (Reuter, Panksepp, Schnabel, Kellerhoff, Kempel, \& Hennig 2005) and revelation which is often stimulated by high arousal religious activities (Richert, Whitehouse, \& Stewart 2005), thus creating the need for orthodoxy checks. For example, ethnographic studies of the Pomio Kivung movement demonstrate that high arousal rituals prompt conscious reflection as to the significance of the rituals which generate exegetical knowledge (Whitehouse 1995, 2000; Whitehouse \& Laidlow 2004).

Another example is the practice of firewalking which often begins as a costly ritual without a supernatural justification (Xygalatas, in press). Prior to the introduction of an official supernatural explanation for firewalking, any exegetical innovation would need to be carefully policed via the use of orthodoxy checks to ensure that it is theologically correct. A central religious authority enables the possibility of orthodoxy checks by establishing a canon of supernatural concepts. This aids religionists in their assessment of each other's supernatural knowledge. Dedicated religionists, who are familiar with the official canon, can compare the supernatural knowledge base of potential exchange partners against that canon. 


\subsection{Conclusion}

I opened this thesis by proposing the question, "Why do people have religion?" I identified the acquisition and expression of complex supernatural knowledge as a particular area of interest. In this chapter I have argued for an innovative theory for supernatural expertise. I have shown that the acquisition of maximally counter intuitive knowledge will perform a costly signalling function where that knowledge is contextually linked to a belief in supernatural causation. It does this because of the cognitive difficulty associated with the acquisition of complex supernatural knowledge. The complexity of supernatural belief systems increases over time to compensate for an average increase in cognitive capacities for the acquisition of supernatural knowledge which are targeted by sexual selection. Supernatural expertise enables the construction of widespread anonymous communities with canonised supernatural belief systems. These systems enable religionists to identify each other's cooperative intent, thereby providing a solution to cooperation problems in dense human settlements. In this regard, we can view complex supernatural knowledge as an adaptive technology, selected because of the social conditions that it generates which aided human organisation and cooperation. This is the reason why supernatural expertise evolved, and this is part of the reason why people have religion.

As discussed in section 1.12, the value of this thesis is in its critique of the body of literature within the evolutionary psychology of religion for purposes of developing a general model to account for the acquisition and expression of complex supernatural knowledge. This thesis was limited to the development of this model alone, without 
applying the model to any specific case studies of supernatural experts or examples of complex supernatural belief. As explained in section 1.12, arguing for the model by applying it to selected examples would have confounded the thesis due to the possibility of bias in the selection of examples. It was therefore necessary to argue for the model with a critique of the literature within the field of the evolutionary psychology of religion, without reference to specific examples. Despite this limitation, this thesis is valuable in that the model which it argues for is confirmed through its critique of the literature.

Nevertheless, now that the model has been developed, scope for future research via empirical testing of the model is now possible. For the reasons discussed, testing the model via its application to examples is problematic. Examples or case studies which are found to confirm the model would only weakly support it, as the possibility of selectivity in examples exists. However, if examples or case studies could be found which disconfirm the model this would constitute strong confounding evidence.

One method of overcoming the objection of selectivity when choosing examples would be to select examples randomly. David Wilson (2005) has used this method by selecting page numbers at random from an encyclopaedia, and assigning undergraduate students the task of assessing whether the religions described on the random pages support his theory of group selection. Should other researchers wish to adopt this method to test the model developed herein, they would have to overcome the problem that the model maintains that complex supernatural knowledge is configured in such a way so as to only be acquirable by the genuinely committed. 
To illustrate, if a researcher was to randomly select a religious system that they don't personally believe in, this thesis predicts that he could neither acquire nor express the complex supernatural concepts which perform a costly signalling function within that religious system. Therefore, he would not be able to assess how specific supernatural concepts are precisely configured so that only the genuinely committed can acquire them. Indeed, during the research for this thesis the author spent a great deal of time attempting to study randomly selected examples as a means of testing the model. After three months of researching twentieth century American Jewish theology, a religious tradition that had been selected using the random method explained above, the author found he could say little other than that he could not understand the complexities of the supernatural belief system being studied. This outcome is predicted by the theory advanced here.

Although it was not appropriate, in this thesis, to argue for the model through the use of examples for the reasons explained, the door remains open for future researchers to further test the model by applying it to examples. These researchers would have to overcome the difficulties associated with the possibility of selectivity in choosing their examples, perhaps through the use of the same method employed by Wilson (2005). They would also have to overcome the problem that the very theory they are testing predicts they should not be capable of acquiring complex supernatural concepts to the level that would be necessary to test the model. I leave the development of a method to overcome this latter difficulty to future research.

To summarise, this thesis has contributed the following advancements to the field of the evolutionary psychology of religion: 
- I have identified a gap in the literature in that, prior to the completion of this thesis, no specific account for supernatural expertise had been developed.

- I have shown that, at face value, supernatural expertise has no apparent utility; therefore a major critique of the literature was required to develop an evolutionary model to account for its continued existence.

- I have advanced costly signalling theory by demonstrating that the acquisition of supernatural expertise involves the investment of time and opportunity costs, providing a framework through which expressions of supernatural knowledge can be accurately identified as reliable signals of commitment; a fact that had previously been dismissed.

- I have controversially combined cognitively optimal theory and costly signalling theory, explaining the cost of acquiring supernatural knowledge in terms of the maximally counter intuitive nature of complex supernatural concepts; demonstrating that adaptationist and spandrelist theories of religion can complement each other.

- I have combined costly signalling theory and sexual selection theory to account for the emerging complexity of supernatural belief systems, in that the motivation for individuals to employ more costly signals necessitates the development of more complex supernatural concepts, which are necessary to continually highlight variation in cognitive capacities.

- I have resolved the paradox associated with the cyclical perpetuation of the doctrinal mode of religion by identifying that the doctrinal mode originated as a result of maximally counter intuitive concepts becoming linked to supernatural causation, and of their ability to signal the presence of genes which code for cognitive capacities desirable in offspring. 
- Lastly, I have demonstrated that the doctrinal mode can be recognised as an adaptive technology in that the social conditions which result from the doctrinal mode aid in enabling large scale cooperation. 


\section{Bibliography}

Agid, Y., Javoy-Agid, M., \& Ruberg, M. 1987. Biochemistry of neurotransmitters in

Parkinson's disease. In C.D.M.S. Fahn, Ed., Movement disorders 2, 166-230. London, UK: Butterworth.

Aiello, L., \& Wheeler, P. 1995. The expensive-tissue hypothesis: The brain and the digestive system in human and primate evolution. Current Anthropology, 36, 199221

Alcorta, C., \& Sosis, R. 2005. Ritual, emotion, and sacred symbols: The evolution of religion as an adaptive complex. Human Nature, 16 (4), 323-359.

Alexander, R. 1987. The biology of moral systems. New York, NY: Aldine de Gruyter.

Andrews, P.W., Gangestad, S.W., \& Matthews, D. 2002. Adaptationism - how to carry out an exaptationist program. Behavioral \& Brain Sciences, 25, 489-553.

Appleton, J. 1975. The experience of landscape. London, UK: John Wiley \& Sons.

Atran, S. 1990. Cognitive foundations of natural history: Towards an anthropology of science. Cambridge, UK: Cambridge University Press. 
Atran, S. 1995. Causal constraints on categories and categorical constraints on biological reasoning. In D. Sperber, D. Premack, \& A.J. Premack, Eds., Causal cognition: A multidisciplinary debate, 205-233. New York, NY: Oxford University Press.

Atran, S. 2002. In gods we trust: The evolutionary landscape of religion. New York, NY: Oxford University Press.

Atran, S. 2006. The cognitive and evolutionary roots of religion. In P. McNamara, Ed., Where God and science meet: How brain and evolutionary studies alter our understanding of religion, Vol. 1, 181-207. Westport, CT and London: Praeger Publishers.

Atran, S., \& Norenzayan, A. 2004. Religion's evolutionary landscape:

Counterintuition, commitment, compassion, communion. Behavioral \& Brain Sciences, 27 (6), 730-70.

Azari, N.P., Nickel, J.P., Wunderlich, G., Niedeggen, M., Hefter, H., Tellmann, L., et al. 2001. Neural correlates of religious experience. European Journal of Neuroscience, 13, 1649-1652.

Balling, J.D., \& Falk, J.H. 1982. Development of visual preference for natural environments. Environment \& Behavior, 14, 5-28. 
Barnard, P.J., \& Teasdale, J.D. 1991. Interacting cognitive subsystems: A systematic approach to cognitive-affective interaction and change. Cognition \& Emotion, 5 (1), $1-39$.

Baron-Cohen, S. 2003. The essential difference: The truth about the male and female brain. New York, NY: Basic Books.

Barrett, H.C. 2005. Adaptations to predators and prey. In D.M. Buss, Ed., The handbook of evolutionary psychology, 200-223. New York, NY: Wiley.

Barrett, J.L. 1998. Cognitive constraints on Hindu concepts of the divine. Journal for the Scientific Study of Religion, 37, 608-619.

Barrett, J.L. 1999. Theological correctness: Cognitive constraint and the study of religion. Method \& Theory in the Study of Religion, 11, 325-339.

Barrett, J.L. 2000. Exploring the natural foundations of religion. Trends in Cognitive Sciences, 4 (1), 29-34.

Barrett, J.L. 2001. How ordinary cognition informs petitionary prayer. Journal of Cognition \& Culture, 1 (3), 259-269.

Barrett, J.L. 2004a. Bringing data to mind: Empirical claims of Lawson and McCauley's theory of religious ritual. In B.C. Wilson \& T. Light, Eds., Religion as a 
human capacity: A festschrift in honor of E. Thomas Lawson, 265-288. Leiden, Netherlands: Brill.

Barrett, J.L. 2004b. Why would anybody believe in God? Walnut Creek, CA: AltaMira Press.

Barrett, J.L. 2008. Why Santa Claus Is Not a God. Journal of Cognition and Culture, $8(1), 149-161$.

Barrett, J.L., \& Keil, F.C. 1996. Conceptualizing a non-natural entity: Anthropomorphism in God concepts. Cognitive Psychology, 31, 219-247.

Barrett, J.L., \& Lawson, E.T. 2001. Ritual intuitions: Cognitive contributions to judgments of ritual efficacy. Journal of Cognition and Culture, 1 (2), 183-201.

Barrett, J.L., \& Nyhof, M. 2001. Spreading non-natural concepts: The role of intuitive conceptual structures in memory and transmission of cultural materials. Journal of Cognition \& Culture, 1 (1), 69-100.

Barrett, J.L., \& VanOrman, B. 1996. The effects of image use in worship on God concepts. Journal of Psychology \& Christianity, 15 (1), 38-45.

Barrett, J.L., Richert, R.A., \& Driesenga, A. 2001. God's beliefs versus mother's: The development of nonhuman agent concepts. Child Development, 72 (1), 50-65. 
Beauregard, M., \& Paquette, V. 2006. Neural correlates of a mystical experience in Carmelite nuns. Neuroscience Letters, 405, 186-190.

Benson, H. 1976. The relaxation response. New York, NY: William Morrow \& Company, Inc.

Bering, J.M. 2002. Intuitive conceptions of dead agents' minds: The natural foundations of afterlife beliefs as phenomenological boundary. Journal of Cognition \& Culture, 2, 263-308.

Bering, J.M. 2003. Towards a cognitive theory of existential meaning. New Ideas in Psychology, 21, 101-120.

Bering, J.M. 2005. The evolutionary history of an illusion: Religious causal beliefs in children and adults. In B.J. Ellis \& D.F. Bjorklund, Eds., Origins of the social mind: Evolutionary psychology and child development, 411-437. New York, NY: Guilford Press.

Bering, J.M. 2006a. The cognitive psychology of belief in the supernatural: A byproduct of the ability to reason about the minds of others may offer evolutionary advantage. American Scientist, 94, 2, 142-149.

Bering, J.M. 2006b. The folk psychology of souls. Behavioural \& Brain Sciences, 29, 453-498. 
Bering, J.M., \& Bjorklund, D.F. 2004. The natural emergence of reasoning about the afterlife as a developmental regularity. Developmental Psychology, 40 (2), 217-233.

Bering, J.M., \& Johnson, D.D.P. 2005. 'Oh Lord, you perceive my thoughts from afar': Recursiveness in the cognitive evolution of supernatural agency. Journal of Cognition \& Culture, 5, 118-142.

Bering, J.M., McLeod, K.A., \& Shackelford, T.K. 2005. Reasoning about dead agents reveals possible adaptive trends. Human Nature, 16, 360-381.

Berlin, B. 1992. Ethnobiological classification: Principles of categorization of plants and animals in traditional societies. Princeton, NJ: Princeton University Press.

Berridge, K., \& Robinson, T. 1998. What is the role of dopamine in reward? Brain Research Reviews, 28, 309-369.

Bloom, P. 2004. Descartes' baby: How the science of child development explains what makes us human. New York, NY: Basic Books.

Bloom, P. 2007. Religion is natural. Developmental Science, 10, 147-151.

Boehm, C. 1999. Hierarchy in the forest. Cambridge, MA: Harvard University Press.

Boehm, C. 2000. Conflict and the evolution of social control. Journal of Consciousness Studies, 7, 79-183. 
Bookstein, F., Fieder, M., \& Huber, S. 2008. Spouses age at the same rate: reply to H. Kokko, 'Human parental age difference and offspring count: a comment on Fieder et al.'. Biology Letters, 4, 261.

Bourdieu, P. 1986. The form of capital. In J. Richardson, Ed., Handbook of theory and research in education, 241-258. Westport, CT: Greenwood Press.

Boyd, R., \& Richerson, P.J. 1992. Punishment allows the evolution of cooperation (or anything else) in sizable groups. Ethology \& Sociology, 13, 171-195.

Boyd, R., Gintis, H., Bowles, S., \& Richerson, P.J. 2003. The evolution of altruistic punishment. Proceedings of the National Academy of Sciences, USA, 100 (6), 35313535.

Boyer, P. 1993. Cognitive aspects of religious symbolism. In P. Boyer, Ed., Cognitive aspects of religious symbolism, 4-47. Cambridge, UK: Cambridge University Press.

Boyer, P. 1994. The naturalness of religious ideas: A cognitive theory of religion.

Berkeley, CA: University of California Press.

Boyer, P. 2001. Religion explained: Evolutionary origins of religious thought. New York, NY: Basic Books. 
Boyer, P. 2003. Religious thought and behavior as by-products of brain function. Trends in Cognitive Sciences, 7, 119-124.

Boyer, P. 2005. A reductionist model of distinct modes of religious transmission. In H. Whitehouse \& R.N. McCauley., Eds., Mind and religion: Psychological and cognitive foundations of religiosity, 3-29. Walnut Creek, CA: AltaMira Press.

Boyer, P., \& Liénard, P. 2006. Why ritualized behaviour? Precaution systems and action-parsing in developmental, pathological and cultural rituals. Behavioral \& Brain Sciences, 29 (6), 595-650.

Boyer, P., \& Ramble, C. 2001. Cognitive templates for religious concepts: Crosscultural evidence for recall of counter-intuitive representations. Cognitive Science, 25, $535-564$.

Brown, D.E. 1991. Human universals. New York, NY: McGraw-Hill.

Bulbulia, J. 2004a. Religious costs as adaptations that signal altruistic intention. Evolution \& Cognition, 10, 19-39.

Bulbulia, J. 2004b. The cognitive and evolutionary psychology of religion. Biology \& Philosophy, 18, 655-686.

Bulbulia, J. 2007. Evolution and religion. In R. I. Dunbar \& L. Barrett, Eds., Oxford handbook of evolutionary psychology. New York, NY: Oxford University Press. 
Bulbulia, J. 2009. Religiosity as mental time travel: cognitive adaptations for religious behavior. In J. Schloss \& M. Murray, Eds., The Believing Primate: Scientific, Philosophical and Theological Perspectives on the Evolution of Religion. New York, NY: Oxford University Press.

Bulbulia, J., \& Frean, M. (in press). Coordination by sacred cues. Journal of the Study of Religion, Nature, \& Culture.

Bulbulia, J., \& Mahoney, A. 2008. Religious Solidarity: The Hand Grenade Experiment. Journal of Cognition and Culture, 8 (3), 295-320.

Bulbulia, J., Sosis. R., Harris, E., Genet, R., Genet, C., \& Wyman, K. 2008. The evolution of religion: Studies, theories, \& critiques. Santa Margarita, CA: Collins Foundation Press.

Buss, D. 2002. Human mate guarding. Neuroendocrinology Letters, 23, Suppl. 4, 23 29.

Buss, D. 2003. The evolution of desire: Strategies of human mating, Reprint ed. New York, NY: Basic Books.

Cauvin, J. 2000. The birth of the gods and the origins of agriculture. T. Watkins, Trans. Cambridge, UK: Cambridge University Press. Original work published 1994. 
Chen, D. 2003. Economic distress and religious intensity: Evidence from Islamic resurgence during the Indonesian financial crisis. MIT: Mimeo.

Chesswas, A. (unpublished). Evaluating the case for meta-atheism: Evolutionary psychology, religion \& the narrow path. Retrieved April 26, 2011, from $<$ http://reocities.com/SouthBeach/keys/8485/Evaluatingthecaseformetaatheism.doc>

Clark, A. 1997. Being there: Putting brain, body, and world together again. Cambridge, MA: The MIT Press.

Clark, A., \& Chalmers, D.J. 1998. The extended mind. Analysis, 58, 10-23.

Colman, A. 2006. The puzzle of cooperation. Nature, 44, 744-745.

Comings, D.E., Gonzales, N., Saucier, G., Johnson, J.P., \& MacMurray, J.P. 2000. The DRD4 gene and the spiritual transcendence scale of the character temperament index. Psychiatric Genetics, 10 (4), 185-189.

Covey, S.R., Merrill, A.R., \& Merrill, R.R. 1994. First things first. New York, NY: Simon and Schuster.

Cronk, L. 1994. Evolutionary theories of morality and the manipulative use of signals. Zygon: Journal of Religion \& Science, 29, 81-101. 
Crook, J.H., \& Crook, S.J. 1988. Tibetan polyandry: Problems of adaptation and fitness. In L. Betzig, M. Borgerhoff-Mulder, \& P. Turke, Eds., Human reproductive behaviour: A Darwinian perspective, 97-114. Cambridge, UK: Cambridge University Press.

D’Onofrio, B.M., Eaves, L.J., Murrelle, L., Maes, H.H., \& Spilka, B. 1999. Understanding biological and social influences on religious affiliation, attitudes, and behaviors: A behaviour genetic perspective. Journal of Personality, 67 (6), 953-984.

Damasio, A. R. 1999. The feeling of what happens: Body, emotion and the making of consciousness. London, UK: Vintage.

Darwin, C. 1871. The descent of man, Vol. 1. New York, NY: Penguin Classics.

Darwin, C. 1965. The expression of the emotions in man and animals. Chicago, IL: University of Chicago Press. Original work published 1872.

Darwin, C. 1968. The origin of species. London, UK: Penguin Books. Original work published 1859 .

Davis, J.A., Smith, T.W., \& Marsden, P.V. 2005. General Social Surveys, 1972-2004. [CUMULATIVE FILE] [Computer file]. Chicago, IL: National Opinion Research Center. Retrieved April 26, 2011, from <http://sda.berkeley.edu/D3/GSS04/Doc/gs040048.htm> 
Dawkins, R. 2006. The god delusion. London, UK: Bantam Press.

Deacon, T. 1997. The symbolic species: The co-evolution of language and the human brain. London, UK: Penguin: Allen Lane.

Dennett, D.C. 1995. Darwin's dangerous idea: Evolution and the meanings of life. New York, NY: Simon \& Schuster.

Dennett, D.C. 2006. Breaking the spell: Religion as a natural phenomenon. New York, NY: Viking.

Dow, J.W. 2006. The evolution of religion: Three anthropological approaches. Method \& Theory in the Study of Religion, 18, 67-91.

Dunbar, R. 2004. The human story: A new history of mankind's evolution. London, UK: Faber and Faber Ltd.

Durham, W.H. 1991. Coevolution: Genes, culture, and human diversity. Stanford, CA: Stanford University Press.

Durkheim, E. 1995. The elementary forms of religious life. New York, NY: Free Press. Original work published 1915.

Edis, T. 2002. The ghost in the universe: God in light of modern science. Amherst: Prometheus. 
Edis, T. 2004. Chance and necessity - And intelligent design? In M. Young \& T. Edis, Eds., Why intelligent design fails: A scientific critique of the new creationism, 139-152. New Brunswick, NJ: Rutgers University Press.

Edwards, J. 1982. A treatise concerning religious affections. Grand Rapids, MI: Baker Books. Original work published 1746.

Edwards, J. 2007. The distinguishing marks of a work of the spirit of God, applied to that uncommon operation that has lately appeared on the minds of the people of New England: With a particular consideration of the extraordinary circumstances with which this work is attended. Cornwall, UK: Diggory Press. Original work published 1741.

Edwards, K.J., \& Hall, T.W. 2003. Illusory spiritual health: The role of defensiveness in understanding and assessing spiritual health. In T.W. Hall \& M. R. McMinn, Eds., Spiritual formation, counselling, and psychotherapy, 261-275. Hauppauge, NY: Nova Science Publishers.

Epstein, S. 1994. Integration of the cognitive and the psychodynamic unconscious. American Psychologist, 49 (8), 709-724.

Escalas, J.E., \& Stern, B.B. 2003. Sympathy and empathy: Emotional responses to advertising dramas. Journal of Consumer Research, 29, 566-578. 
Evans, E. M. 2001. Cognitive and contextual factors in the emergence of diverse belief systems: Creation versus evolution. Cognitive Psychology, 42, (3), 217-266.

Fehr, E., \& Gächter, S. 2002. Altruistic punishment in humans. Nature, 415, 137-140.

Fessler, D. 2006. A burning desire: Steps toward an evolutionary psychology of fire learning. Journal of Cognition \& Culture, 6, 429-451.

Fieder, M., \& Huber, S. 2007. Parental age difference and offspring count in humans. Biology Letters, 3, 689-691.

Fieder, M., Huber, S., Bookstein, F. 2008. Reply to Lindqvist et al. 'Does parental age difference affect offspring count in humans: comment on Fieder and Huber'. Biology Letters, 4, 80-81.

Fisher, J. 2005. Disposal of dead bodies in emergency conditions. World Health Organization Technical Notes for Emergencies No.8.

Flett, G., \& Hewitt, P., Eds. 2002. Perfectionism: Theory, research, and treatment. Washington, D.C.: American Psychological Association.

Fodor, J. 1983. The modular theory of mind. Cambridge, MA: The MIT Press.

Foley, R. 1995. Humans before humanity. Oxford, UK: Blackwell Publishers Ltd. 
Foster, K., \& Kokko, H. 2009. The evolution of superstitious and superstition-like behaviour. Proceedings of the Royal Society of London B., 276, 31-37.

Fowler, J. 2005. Human cooperation: Second-order free-riding problem solved? Nature, 437, E8.

Frank, R.H. 1988. Passions within reason: The strategic role of the emotions. New York, NY: Norton and Company.

Frank, R.H. 2001. Cooperation through emotional commitment. In R.M. Nesse, Ed., Evolution and the capacity for commitment, 57-77. New York, NY: Russel Sage Foundation.

Frazer, G. 1994. The golden bough Abridged ed. New York, NY: Oxford University Press.

Frecska, E., \& Kulcsar, Z. 1989. Social bonding in the modulation of the physiology of ritual trance. Ethos, 17, 70-87.

Freud, S. 1938. Totem and taboo. A.A. Brill, Trans. Harmondsworth, UK: Penguin Books. Original work published 1913.

Freud, S. 1964. The future of an illusion. In J. Strachey, Ed. and Trans. New York, NY: Norton and Company. Original work published 1927. 
Frith, U. 1989. Autism: Explaining the Enigma. Oxford: Blackwell.

Gibson, N.J.S. 2005. The experimental investigation of religious cognition.

Unpublished doctorial dissertation. Cambridge University, Cambridge, England.

Gibson, N.J.S. 2006. The experimental investigation of religious cognition.

Unpublished doctoral dissertation, University of Cambridge, UK. Retrieved April 26, 2011, from

$<$ http://www.prrg.org/prrg/people/staff/staff.acds?context=1609849\&instanceid=1609 $850>$

Giedd, J., Blumenthal, J., Jeffries, N.O., Catellanos, F.X., Liu, H., Zijdenbos, A., et al. 1999. Brain development during childhood and adolescence: A longitudinal MRI study. Nature Neuroscience, 2, 861-863.

Gilbert, D.T. 2001. Why economists are not afraid to die. Paper presented at the First International Conference on Experimental Existential Psychology, Amsterdam, The Netherlands, August 2-4, 2001.

Gintis, H., Smith, E., \& Bowles, S. 2001. Costly signalling and cooperation. Journal of Theoretical Biology, 213, 103-119.

Gobbini, M. I., Leibenluft, E., Santiago, N., \& Haxby, J. V. 2004. Social and emotional attachment in the neural representation of faces. NeuroImage, 22, 16281635. 
Goldstein, J. 2003. War and gender: How gender shapes the war system and viceversa, New ed. Cambridge, UK: Cambridge University Press.

Gould, S.J., \& Lewontin, R.C. 1979. The spandrels of San Marco and the panglossian paradigm: A critique of the adaptationist program. Proceedings of the Royal Society of London, Series B, 205 (1161), 581-598.

Grafen, A. 1990. Biological signals as handicaps. Journal of Theoretical Biology, $144,517-546$.

Greenfield, S. 2000. The private life of the brain. London, UK: Penguin.

Greenwald, A.G., Banaji, M.R., Rudman, L.A., Farnham, S.D., Nosek, B.A., \& Mellott, D.S. 2002. A unified theory of implicit attitudes, stereotypes, self-esteem, and self-concept. Psychological Review, 109, 3-25.

Hamer, D. 2004. The God gene. How faith is hardwired into our genes. New York, NY: Anchor Books.

Hare, R. 1999. Without conscious: The disturbing world of psychopaths among us. New York, NY: Guilford Press. 
Harrar, G., \& Harrar, H. 1977. Music, emotion, and autonomic function. In M.

Critchley \& R. A. Henson, Eds., Music and the brain: Studies in the neurology of music, 202-216. Springfield, IL: Charles C. Thomas.

Harrison, J.E. 1909. The influence of Darwinism on the study of religion. In A.C.

Seward, Ed., Darwin and modern science: Essays in commemoration of the centenary of the birth of Charles Darwin and of the fiftieth anniversary of the publication of the origin of species, 494-511. Cambridge, UK: Cambridge University Press.

Haselton, M.G., \& Miller, G.F. 2006. Women's fertility across the cycle increases the short-term attractiveness of creative intelligence. Human Nature, 17 (1), 50-73.

Haslam, N.O. 1998. Natural kinds, human kinds, and essentialism. Social Research, $65(2), 291-314$.

Hattfield, E., Cacioppo, J.T., \& Rapson, R.L. 1994. Emotional contagion. Cambridge, UK: Cambridge University Press.

Hauert, C., Traulsen, A., Brandt, H., Nowak, M.A., \& Sigmund, K. 2007. Via freedom to coercion: The emergence of costly punishment. Science, 316 (5833), 1905-1907.

Henrich, J., \& Boyd, R. 2001. Why people punish defectors: Weak conformist transmission can stabilize costly enforcement of norms in cooperative dilemmas. Journal of Theoretical Biology, 208 (1), 79-89. 
Henry, J.L. 1982. Possible involvement of endorphins in altered states of consciousness. Ethos, 104, 394-408.

Herzog, T.R., Herbert, E.J., Kaplan, R., \& Crooks, C.L. 2000. Cultural and developmental comparisons of landscape perceptions and preferences. Environment \& Behavior, 32, 323-346.

Hill P.C. 1995. Affective theory and religious experience. In R.W. Hood, Jr., Ed., Handbook of religious experience, 353-377. Birmingham, AL: Religious Education Press.

Hill, P.C. 2005. Measurement assessment and issues in the psychology of religion and spirituality. In R.F. Paloutzian \& C.L. Park, Eds., Handbook of the psychology of religion, 43-79. New York, NY: Guilford Press.

Hill, P.C., \& Hood, R.W., Jr. Eds. 1999a. Measures of religiosity. Birmingham, AL: Religious Education Press.

Hill, P.C., \& Hood, R.W., Jr. 1999b. Affect, religion, and unconscious processes. Journal of Personality, 67, 1015-1046.

Hill, P.C., \& Pargament, K.I. 2003. Advances in the conceptualization and measurement of religion and spirituality: Implications for physical and mental health research. American Psychologist, 58, 64-74. 
Hirschfeld, L.A. 1994. Is the acquisition of social categories based on domain specific competence or on knowledge transfer? In L.A. Hirschfeld \& S. A. Gelman, Eds., Mapping the mind: Domain specifity in cognition and culture, pp. 201-233. New York, NY: Cambridge University Press.

Hirschfeld, L.A. 1998. Natural assumptions: Race, essence, and taxonomies of human kinds. Social Research, 65 (2), 331-349.

Hirschleifer, J. 1987. On the emotions as guarantors of threats and promises. In J. Dupré, Ed., The latest on the best: Essays in evolution and optimality, 307-326. Cambridge, MA: The MIT Press.

Hirstein, W. 2005. Brain fiction: Self-deception and the riddle of confabulation. Cambridge, MA: The MIT Press.

Horvitz, J. 2000. Mesolimbocortical and nigrostriatal dopamine responses to salient non-reward events. Neuroscience, 96, 651-656.

Hume, D. 1776. Dialogues concerning natural religion. London, UK: Penguin Classics.

Hutchins, E. 1995. Cognition in the wild. Cambridge, MA: The MIT Press. 
Iannaccone, L.R. 1994. Why strict churches are strong. American Journal of Sociology, 99 (5), 1180-1211.

Irons, W. 1996a. In our own self image: The evolution of morality, deception, and religion. Skeptic, 4, 50-61.

Irons, W. 1996b. Morality, religion, and evolution. In W.W.W.M. Richardson, Ed., Religion and science: History, method, and dialogue, 375-399. New York, NY:

Routledge.

Irons, W. 2001. Religion as a hard-to-fake sign of commitment. In R.M. Nesse, Ed., Evolution and the capacity for commitment, 292-309. New York, NY: Russel Sage Foundation.

James, W., 1890. Principles of psychology, Vol. 1. New York, NY: Henry Holt. James, W. 2003. Pragmatism. New York, NY: Barnes and Noble. Original work published 1907.

Johnson D.D.P., \& Bering, J.M. 2006. Hand of God, mind of man: Punishment and cognition in the evolution of cooperation. Evolutionary Psychology, 4, 219-233.

Johnson, D.D.P., \& Krüger, O. 2004. The good of wrath: Supernatural punishment and the evolution of cooperation. Political Theology, 52, 159-176. 
Johnson, D.D.P. 2005. God's punishment and public goods. A test of the supernatural punishment hypothesis in 186 world cultures. Human Nature, 16 (4), 410-446.

Kaplan, R., \& Kaplan, S. 1989. The experience of nature: A psychological perspective. New York, NY: Cambridge University Press.

Kaplan, S. 1992. Environmental preference in a knowledge-seeking, knowledge-using organism. In J.H. Barkow, L. Cosmides \& J. Tooby, Eds., The adapted mind: Evolutionary psychology and the generation of culture, 581-598. New York, NY: Oxford University Press.

Kapur, S. 2003. Psychosis as a state of aberrant salience. American Journal of Psychiatry, 160, 13-23.

Karmiloff-Smith, A. 1992. Beyond modularity: A developmental perspective on cognitive science. Cambridge, MA: The MIT Press.

Kelemen, D. 2004. Are children "intuitive theists"? Reasoning about purpose and design in nature. Psychological Science, 15 (5), 295-301.

Kelemen, D., \& DiYanni, C. 2005. Intuitions about origins. Journal of Cognition \& Development, 6 (1), 3-31. 
Kenrick, D.T., Maner, J.K., Butner, J., Li, N.P., Becker, D.V., \& Schaller, M. 2002. Dynamic evolutionary psychology: Mapping the domains of the new interactionist paradigm. Personality \& Social Psychology Review, 6, 347-356.

Kirkpatrick, L.A. 1999. Toward an evolutionary psychology of religion and personality. Journal of Personality, 67, 921-952.

Kirkpatrick, L.A. 2004. Attachment, evolution, and the psychology of religion. New York, NY: Guilford Press.

Kirkpatrick, L.A. 2006. Religion is not an adaptation. In P. McNamara, Ed., Where God and science meet: How brain and evolutionary studies alter our understanding of religion, Vol. 1, 159-179. Westport, CT and London: Praeger Perspectives.

Klein, S., Cosmides, L., Tooby, J., \& Chance, S. 2002. Decisions and the evolution of memory: Multiple systems, multiple functions. Psychological Review, 109, 306-329.

Koenig, L.B., \& Bouchard, T.J., Jr. 2006. Genetic and environment influences on the traditional moral values triad - authoritarianism, conservatism, and religiousness - as assessed by quantitative behaviour generic methods. In P. McNamara, Ed., Where God and science meet: How brain and evolutionary studies alter our understanding of religion, Vol. 1, 31-60. Westport, CT and London: Praeger Perspectives.

Kokko, H. 2008a. Males, females and the value of toy models: a commentary on Bookstein et al. (2008). Biology Letters, 4, 349-350. 
Kokko, H. 2008b. Human parental age differences and offspring count: and we still don't know what men or women want. Biology Letters, 4, 259-260.

Kokko, H., Brooks, R., \& Jennions, M.D. 2003. The evolution of mate choice and mating biases. Proceedings of the Royal Society of London, Series B, 270, 653-664.

Kokko, H., Jennions, M.D., \& Brooks, R. 2006. Unifying and testing models of sexual selection. Annual Review of Ecology, Evolution, \& Systematics, 37, 43-66.

Kolb, B., Forgie, M., Gibb, R., Gorny, G., \& Rontree, S. 1998. Age, experience and the changing brain. Neuroscience \& Biobehavioral Reviews, 22, 143-159.

Korpela, K.M., Klemettilä, T., \& Hietanen, J.K. 2002. Evidence for rapid affective evaluation of environmental scenes. Environment \& Behavior, 34, 634-650.

Kotiaho, J.S., Simmons, L.W., \& Tomkins, J. 2001. Towards a resolution of the lek paradox. Nature, 410, 684-686.

Kuhlmeier, V., Bloom, P., \& Wynn, K. 2004. Do 5-month-old infants see humans as material objects? Cognition, 94 (1), 95-103.

Kunda, Z. 1999. Social cognition: Making sense of people. Cambridge, MA: The MIT Press. 
Lawson, E.T., \& McCauley, R.N. 1990. Rethinking religion: Connecting cognition and culture. Cambridge, UK: Cambridge University Press.

Lazar, S.W., Bush, G., Gollub, R.L., Fricchione, G.L., Khalsa, G., \& Benson, H. 2000. Functional brain mapping of the relaxation response and meditation.

NeuroReport, 11 (7), 581-1585.

Lazarus, R. 1991. Emotion and adaptation. New York, NY: Oxford University Press.

Leary, M.R. 1999. Making sense of self-esteem. Current Directions in Psychological Science, 8, 32-35.

Leslie, A.M., German, T.P., \& Polizzi, P. 2005. Belief-desire reasoning as a process of selection. Cognitive Psychology, 50, 45-85.

Levenson, R.W. 1999. The intrapersonal functions of emotion. Cognition \& Emotion, $13(5), 481-504$.

Levenson, R.W. 2003. Blood, sweat and fears: the autonomic architecture of emotions. In P. Ekman, J.J. Campos, R.J. Davidson, \& F.B.M. de Waal, Eds., Emotions inside out, 348-366. Annals of the New York Academy of Sciences, Vol. 1000. New York: New York Academy of Sciences.

Levinson, S. 2003. Space in language and cognition. Cambridge, UK: Cambridge University Press. 
Lindqvist, E., Cesarini, D., \& Wallace, B. Does parental age difference affect offspring count in humans? Comment on Fieder and Huber. Biology Letters, 4, 78-79.

Lutkehaus, N.C., \& Roscoe, P.B., Eds. 1995. Gender rituals: Female initiation in Melanesia. London, UK: Routledge.

Macalister, A. 1882. Evolution in church history. Dublin, Ireland: Hodges, Figgis.

Mahoney, A. 2008. Theological expressions as costly signals of religious commitment. In Bulbulia, J., Sosis. R., Harris, E., Genet, R., Genet, C., \& Wyman, K., The evolution of religion: Studies, theories, \& critiques, 161-166. Santa Margarita, CA: Collins Foundation Press.

Malley, B. 2004. How the Bible works: An anthropological study of American Biblicism. Walnut Creek, CA: AltaMira Press.

Malley, B., \& Barrett, J.L. 2003. Does myth inform ritual? A test of the LawsonMcCauley hypothesis. Journal of Ritual Studies, 17 (2), 1-14.

Marangella, J. 1998. Announcement to the Baha'i world from the guardian of the faith. Retrieved April 26, 2011, from

$<$ http://members.iinet.net.au/ guardian/announcement.html>

Marett, R.R. 1909. The threshold of religion. London, UK: Methuen \& Co. 
Marett, R.R. 1912. Anthropology. London, UK: Williams \& Norgate.

Marx, K., \& Engels, F. 1976. Manifesto of the Communist party. In K. Marx \& F. Engels, Eds., Collected works. Vol. 6, 476-519. New York, NY: International Publishers. Original work published 1888.

Maynard Smith, J. 1982. Evolution and the theory of games. New York, NY:

Cambridge University Press.

Maynard Smith, J., \& Harper, D. 1995. Animal signals: Models and terminology. Journal of Theoretical Biology, 177, 305-311.

Maynard Smith, J., \& Harper, D. 2003. Animal signals. Oxford, UK: Oxford University Press.

Mayr, E. 2001. What evolution is. New York, NY: Basic Books.

McCauley, R.N., \& Lawson, E.T. 2002. Bringing ritual to mind: Psychological foundations of religious forms. Cambridge, UK: Cambridge University Press.

McNamara, P., Durso, R., Brown, A., \& Harris, E. 2006. The chemistry of religiosity: Evidence from patients with Parkinson's disease. In P. McNamara, Ed., Where God and science meet: How brain and evolutionary studies alter our understanding of religion, Vol. 2, 1-14. Westport, CT and London: Praeger Perspectives. 
Medin, D., \& Ortony, A. 1989. Psychological essentialism. In S. Vosniadou \& A.

Ortony, Eds., Similarity and analogical reasoning, 179-195. Cambridge, UK:

Cambridge University Press.

Metcalf, P., \& Huntington, R. 1991. Celebrations of death: The anthropology of mortuary ritual, $2^{\text {nd }}$ ed. Cambridge, England and New York: Cambridge University Press.

Miller, G. 2000. Evolution of human music through sexual selection. In N.L. Wallin, B. Merker, \& S. Brown, Eds., The origins of music, 329-360. Cambridge, MA: MIT Press.

Miller, G. 2001. The mating mind: How sexual choice shaped the evolution of human nature. New York, NY: Anchor Books.

Miller, G. 2007. Sexual selection for moral virtues. Quarterly Review of Biology, 82 (2), 97-126.

Mithen, S. 1996. The prehistory of the mind. London, UK: Phoenix.

Monod, J. 1971. Chance and necessity: An essay on the natural philosophy of modern biology. New York, NY: Knopf. 
Morewedge, C.K. 2009. Negativity bias in attribution of external agency. Journal of Experimental Psychology: General.

Morgan, O., \& Fisher, J. 2004. Infectious disease risk from dead bodies following natural disasters. Revista Panamericana Salud Pública / Pan American Journal of Public Health, 15 (5), 307-312.

Morris, P. 2010. Personal communication.

Murdock, G.P. 1965. Culture and society. Pittsburgh, PA: University of Pittsburgh Press.

Murdock, G.P., \& White, D.R. 1969. Standard cross-cultural sample. Ethnology, 8, 329-369.

Nesse, R. M. Ed. 2001. Evolution and the capacity for commitment. New York, NY: The Russel Sage Foundation.

Newberg, A.B., \& d'Aquili, E. 1998. The neuropsychology of spiritual experience. In H.G. Koenig, Ed., Handbook of religion and mental health, pp. 75-94. San Diego, CA: Academic Press.

Newberg, A.B., Alavi, A., Baime, M., Pourdehnad, M., Santanna, J., \& d'Aquili, E. 2001. The measurement of regional cerebral blood flow during the complex cognitive 
task of meditation: A preliminary SPECT study. Psychiatric Research, Neuroimaging, 106, 113-122.

Nichols, D.E., \& Chemel, B.R. 2006. The neuropharmacology of religious experience: Hallucinogens and the experience of the divine. In P. McNamara, Ed., Where God and science meet: How brain and evolutionary studies alter our understanding of religion, Vol. 3, 1-33. Westport, CT and London: Praeger Perspectives.

Nichols, S. 2007. Imagination and immortality: Thinking of me. Synthese, 159 (2), $215-233$

Norenzayan, A., \& Hansen, I. 2006. Belief in supernatural agents in the face of death. Personality \& Social Psychology Bulletin, 32, 174-187.

Norenzayan, A., \& Heine, S.J. 2005. Psychological universals: What are they and how can we know? Psychological Bulletin, 131, 763-784.

Norenzayan, A., \& Shariff, A. 2008. The origin and evolution of religious prosociality. Science, 322 (58), 58-62.

Norenzayan, A., Atran, S., Faulkner, J., \& Schaller, M. 2006. Memory and mystery: The cultural selection of minimally counterintuitive narratives. Cognitive Science, 30, $531-553$ 
Olsen, S. 2006. Teens and media: a full-time job. Retrieved April 26, 2011, from <http://news.com.com/2100-1041_3-6141920.html>

Orians, G.H. 1969. On the evolution of mating systems in bird and mammals. American Naturalist, 103, 589-603.

Orians, G.H., \& Heerwagen, J.H. 1992. Evolved responses to landscapes. In J. H. Barkow, L. Cosmides, \& J. Tooby, Eds., The adapted mind: Evolutionary psychology and the generation of culture, 555-579. New York, NY: Oxford University Press.

Pan American Health Organization. PAHO. 2003. Unseating the myths surrounding the management of cadavers, Disaster Newsletter, NO. 93, October 2003. PAHO, USA.

Paller, K. A., Ranganath, C., Gonsalves, B., LaBar, K.S., Parrish, T.B., Gitelman, D.R., et al. 2003. Neural correlates of person recognition. Learning \& Memory, 10, 253-260.

Paloutzian, R.F., \& Kirkpatrick, L.A., Eds. 1995. Religious influences on personal and societal well-being. Journal of Social Issues, 512.

Panchanathan, K., \& Boyd, R. 2004. Indirect reciprocity can stabilize cooperation without the second-order free rider problem. Nature, 432, 499-502. 
Pargament, K.I., Koenig, H.G., Tarakeshwar, N., \& Hahn, J. 2001. Religious struggle as a predictor of mortality among medically ill elderly patients. Archives of Internal Medicine, 161 (10), 1881-1884.

Persinger, M.A. 1987. Neuropsychological bases of God beliefs. New York, NY: Praeger Publishers.

Pew. 2006. Spirit and power: A 10-country survey of Pentecostals. The Pew Forum on Religion and Public Life.

Pinel, E.C., Long, A.E., Landau, M.J., Alexander, K., \& Pyszczynski, T. 2006.

Seeing I to I: A pathway to interpersonal connectedness. Journal of Personality \& Social Psychology, 90, 243-257.

Pinker, S. 1995. The Language Instinct. New York, NY: HarperPerennial.

Pinker, S., \& Bloom, P. 1990. Natural language and natural selection. Behavioral \& Brain Sciences, 13, 707-727.

Post, S. 2007. Altruism and health: Perspectives from empirical research. New York, NY: Oxford University Press.

Prince, R. 1982. Shamans and endorphins: Hypothesis for a synthesis. Ethos, 104, 409-423. 
Pyysiäinen, I. 2001. Cognition, emotion, and religious experience. In J. Andresen, Ed., Religion in mind: Cognitive, perspectives on religious belief, ritual, and experience, 70-93. Cambridge, UK: Cambridge University Press.

Pyysiäinen, I. 2003. How religion works: Towards a new cognitive science of religion. Leiden, Netherlands: Brill.

Pyysiäinen, I. 2004a. Magic, miracles, and religion: A scientist's perspective. Walnut Creek, CA: AltaMira Press.

Pyysiäinen, I. 2004b. Intuitive and explicit in religious thought. Journal of Cognition \& Culture, 4 (1), 123-150.

Pyysiäinen, I. 2005. God: A brief history with a cognitive explanation of the concept. Temenos, 41 (1), 77-128.

Ramachandran, V. 1997. The evolutionary biology of self-deception, laughter, dreaming and depression: Some clues from anosognosia. Medical Hypotheses, 47, $347-362$.

Reuter, M., Panksepp, J., Schnabel, N., Kellerhoff, N., Kempel, P., \& Hennig, J. 2005. Personality and biological markers of creativity. European Journal of Personality, 19, 83-95. 
Reynolds, V., \& Tanner, R. 1985. The effects of religion on human biology. In J. Durant, Ed., Darwinism and divinity, 131-153. Oxford, UK: Basil Blackwell.

Richerson, P.J., \& Boyd, R. 2005. Not by genes alone: How culture transformed human evolution. Chicago, IL: University of Chicago Press.

Richert, R.A., Whitehouse, H., \& Stewart, E. 2005. Memory and analogical thinking in high-arousal rituals. In H. Whitehouse \& R.N. McCauley, Eds., Mind and religion: Psychological and cognitive foundations of religiosity, 127-145. Walnut Creek, CA: AltaMira Press.

Robinson, J., Ed. 1990. The Nag Hammadi Library. New York, NY: HarperCollins.

Rochat, P., Morgan, R., \& Carpenter, M. 1997. Young infants’ sensitivity to movement information specifying social causality. Cognitive Development, 12, 441465.

Roes, F.L., \& Raymond, M. 2003. Belief in moralizing gods. Evolution \& Human Behavior, 24, 126-135.

Rowlands, M. 2003. Externalism: Putting mind and world back together again. Chesham, Buckinghamshire: Acumen Publishing Ltd. 
Rozin, P., Haidt, J., \& McCauley, C. 2000. Disgust: The body and soul emotion. In M. Lewis \& J.M. Haviland-Jones, Eds., Handbook of emotions, $2^{\text {nd }}$ ed., 637-653. New York, NY: Guilford Press.

Rozin, P., Kurzer, N., \& Cohen, A.B. 2002. Free associations to "food": The effects of gender, generation, and culture. Journal of Research in Personality, 36, 419-441.

Sachser, N., Durschlag, M., \& Hirzel, D. 1998. Social relationships and the management of stress. Psychoneuroendocrinology, 23, 891-904.

Sapolsky, R.M. 2006. Social cultures among nonhuman primates. Current Anthropology, 47 (4), 641-656.

Schelling, T. 1960. The strategy of conflict. Cambridge, MA: Harvard University Press.

Schjødt, U. 2005. Homøostasis \& religiøs adfoerd: Om kognitivismens begroensninger og simulationsteoriens forklaringskraft i et religionsvidenskabeligt perspektiv "Homeostasis and Religious Behavior: on the Limits of Cognitivism and the Explanatory Power of Simulation Theory from the Perspective of the Study of Religion”. Master's thesis, University of Aarhus, Aarhus, Denmark.

Schloss, J. P. 2004. Evolutionary ethics and Christian morality: Surveying the issues. In P. Clayton \& J. Schloss, Eds., Evolution and ethics: Human morality in biological and religious perspective, 1-24. Grand Rapids, MI: Eerdmans. 
Schloss, J. P. 2005. Hath Darwin suffered a prophet's scorn? Evolutionary theory and the scandal of unconditional love. In C. Harper, Ed., Spiritual information, 291-299. Philadelphia, PA: Templeton Press.

Schloss, J. P. 2008. He who laughs best: Involuntary religious affect as a solution to recursive cooperation defection. In Bulbulia, J., Sosis. R., Harris, E., Genet, R., Genet, C., \& Wyman, K., The evolution of religion: Studies, theories, \& critiques, 197-207. Santa Margarita, CA: Collins Foundation Press.

Schuster, M., Stein, B., Jaycox. L., Collins, R., Marshall. G., Elliot, M., et al. 2001. A national survey of stress reactions after the September 11, 2001 terrorist attacks. New England Journal of Medicine, 345, 1507-1512.

Shah, N., Marshall, J.C., Zafiris, O., Schwab, A., Zilles. K., Markowitsch, H.J., et al. 2001. The neural correlates of person familiarity: A functional magnetic resonance imaging study with clinical implications. Brain, 124, 804-815.

Shaner, A., Miller, G., \& Mintz, J. 2004. Schizophrenia as one extreme of a sexually selected fitness indicator. Schizophrenia Research, 70, 101-109.

Shariff, A.F., \& Norenzayan, A. 2007. God is watching you: Supernatural agent concepts increase prosocial behavior in an anonymous economic game. Psychological Science, 18, 803-809. 
Sharpe, E.J. 1986. Comparative religion: A history. London, UK: Duckworth Press. Original work published 1975.

Silverman, I., \& Choi, J. 2005. Locating places. In D. M. Buss, Ed., The handbook of evolutionary psychology, 177-199. Hoboken, NJ: John Wiley \& Sons.

Slone, D.J. 2004. Theological incorrectness: Why religious people believe what they shouldn't. Oxford, UK: Oxford University Press.

Smith, J.Z. 1982. Imagining religion. Chicago, IL: University of Chicago Press.

Sosis, R. 2000. Religion and intragroup cooperation: Preliminary results of a comparative analysis of utopian communities. Cross-Cultural Research, 34 (1), 77 88.

Sosis, R. 2003. Why aren't we all Hutterites? Costly signaling theory and religious behavior. Human nature, 14 (2), 91-127.

Sosis, R. 2004. The adaptive value of religious ritual. American Scientist, 92, 166172.

Sosis, R. 2005. Does religion promote trust? The role of signaling, reputation, and punishment. Interdisciplinary Journal of Research and Religion, 1, 1-30. 
Sosis, R. 2007. Psalms for safety: Magico-religious response to threats of terror. Current Anthropology, 48 (6), 903-911.

Sosis, R., \& Alcorta, C. 2003. Signaling, solidarity, and the sacred: The evolution of religious behavior. Evolutionary Anthropology, 12, 264-274.

Sosis, R., \& Bressler, E. 2003. Co-operation and commune longevity: A test of the costly signaling theory of religion. Cross-Cultural Research, 372, 11-39.

Sosis, R., \& Ruffle, B.J. 2003. Religious ritual and cooperation: Testing for a relationship on Israeli religious and secular kibbutzim. Current Anthropology, 44, 713-722.

Sosis, R., \& Ruffle, B.J. 2004. Ideology, religion and the evolution of cooperation: Field tests on Israel kibbutzim. Research in Economic Anthropology, 23, 89-117.

Sosis, R., Kress, H., \& Boster, J. 2007. Scars for war: Evaluating alternative signalling explanations for cross-cultural variance in ritual costs. Evolution \& Human Behavior, 28, 234-247.

Spear, L.P. 2000. The adolescent brain and age-related behavioral manifestations. Neuroscience \& Biobehavioral Reviews, 24, 417-463.

Sperber, D. 1985. Anthropology and psychology: Towards an epidemiology of representations. The Malinowski Memorial Lecture, 1984. Man N.S., 20, 73-89. 
Sperber, D. 1996. Explaining culture: A naturalistic approach. Oxford, UK:

Blackwell Publishers.

Sperber, D., \& Wilson, D. 1986. Relevance: Communication and cognition. Oxford, UK: Basil Blackwell.

Spinosa, C., \& Dreyfus, H.L. 1996. Two kinds of antiessentialism and their consequences. Critical Inquiry, 22 (4), 735-763.

Stark, R., \& Bainbridge, W.S. 1987. A theory of religion. New Brunswick, NJ:

Rutgers University Press.

Stark, R. 1999. Micro foundations of religion: A revised theory. Sociological Theory, $17,264-289$.

Steadman, L.B., \& Palmer, C.T. 1995. Religion as an identifiable traditional behavior subject to natural selection. Journal of Social \& Evolutionary Systems, 18 (2), 149164.

Steadman, L.B., Palmer, C.T., \& Tilley, C.F. 1996. The universality of ancestor worship. Ethnology, 35 (1), 63-76.

Sterelny, K. 2007. SNAFUS: An evolutionary perspective. Biological Theory, 2 (3), $1-11$. 
Strier, K.B. 2002. Beyond the apes: Reasons to consider the entire primate order. In F.B.M. de Waal, Ed., Tree of origin: What primate behavior can tell us about human social evolution, $2^{\text {nd }}$ ed., 69-93. Cambridge, MA: Harvard University Press.

Subbotsky, E., \& Quinteros, G. 2005. Do cultural factors affect causal beliefs? Rational and magical thinking in Britain and Mexico. British Journal of Psychology, 93, 519-543.

Tiele, C.P. 1897. Elements of the science of religion. 2 volumes. Edinburgh, Scotland: William Blackwood and Sons.

Tomasello, M., \& Carpenter, M. 2005. Intention reading and imitative learning. In S. Hurley \& N. Chater, Eds., Perspectives on imitation: From neuroscience to social science, Vol. 2, 133-148. Cambridge, MA: The MIT Press.

Tomasello, M. 1999. The cultural origins of human cognition. Cambridge, MA: Harvard University Press.

Tomkins, J.L., Radwan, J., Kotiaho, J.S., \& Tregenza, T. 2004. Genic capture and resolving the lek paradox. Trends in Ecology \& Evolution, 19 (6), 323-328.

Tooby, J., \& Cosmides. L. 1988. The evolution of war and its cognitive foundations. Institute for Evolutionary Studies Technical Report No. 88-1. Presented at the Evolution and Human Behavior Meetings, Ann Arbor, Michigan, April 1988. 
Tooby, J., \& Cosmides, L. 1990. On the universality of human nature and the uniqueness of the individual: The role of genetics and adaptation. Journal of Personality, 58, 17-67.

Tooby, J., \& Cosmides, L. 1992. The psychological foundations of culture. In J. H. Barkow, L. Cosmides, \& J. Tooby, Eds., The adapted mind: Evolutionary psychology and the generation of culture, 19-136. New York, NY: Oxford University Press.

Tooby, J., \& Cosmides, L. 2001. Does beauty build adapted minds? SubStance, 94, 625.

Tooby, J., \& Cosmides, L. 2005. Conceptual foundations of evolutionary psychology. In D.M. Buss, Ed., The handbook of evolutionary psychology, 5-67. Hoboken, NJ: John Wiley \& Sons.

Tremlin, T. 2006. Minds and gods: The cognitive foundations of religion. New York, NY: Oxford University Press.

Trivers, R.L. 1971. The evolution of reciprocal altruism. Quarterly Review of Biology, $46,35-57$.

Trivers, R.L. 2000. The elements of a scientific theory of self-deception. Annals of the New York Academy of Sciences, 907 (1), 114-131. 
Turner, V.W. 1990. Drama, fields, and metaphors: Symbolic action in human society. Ithaca, NY: Cornell University Press.

Tulving, E. 1972. Episodic and semantic memory. In Tulving, E. \& Donaldson, W., Eds. Organisation of memory, 382-402. New York, NY: Academic Press, Inc.

Tylor, E.B. 1871. Primitive culture. London, UK: John Murray.

Ulrich, R.S. 1983. Aesthetic and affective response to natural environment. In I. Altman \& J.F. Wohlwill, Eds., Behaviour and the natural environment, 85-125. New York, NY: Plenum Press.

de Waal, F.B.M. 1996. Good Natured: The origins of right and wrong in humans and other animals. Cambridge, MA: Harvard University Press.

Waitley, D. 1979. The psychology of winning. New York, NY: Berkley Books.

Wallace, A.F.C. 1966. Religion: An anthropological view. New York, NY: Random House.

Watts, F.N. 1996. Psychological and religious perspectives on emotion. International Journal for the Psychology of Religion, 6 (2), 71-87.

Watts, F.N., \& Williams, J.M.G. 1988. The psychology of religious knowing. Cambridge, UK: Cambridge University Press. 
Weber, M. 1978. Economy and society, Vol. 1, G. Roth \& C. Wittich, Trans.

Berkeley, CA: University of California Press. Original work published 1923.

Wegner, D. 2005. Who is the controller of controlled processes? In R. Hassin, J.

Uleman, \& J. Bargh, Eds., The new unconscious, 19-36. Oxford, UK: Oxford University Press.

Wellman, H.M., \& Miller, J.G. 2006. Developing conceptions if responsive intentional agents. Journal of Cognition \& Culture, 6 (1-2), 27-55.

Wesley, J. 2006. Plain account of Christian perfection. Peabody, MA: Hendrickson Publishers. Original work published 1766.

West-Eberhard, M.J. 2003. Developmental plasticity and evolution. Oxford, UK:

Oxford University Press.

Whitehouse, H. 1995. Inside the cult: Religious innovation and transmission in Papua New Guinea. Oxford, UK: Oxford University Press.

Whitehouse, H. 2000. Arguments and icons: Divergent modes of religiosity. Oxford, UK: Oxford University Press. 
Whitehouse, H. 2002. Modes of religiosity: Towards a cognitive explanation of the socio-political dynamics of religion. Method \& Theory in the Study of Religion, 14, 293-315.

Whitehouse, H. 2004. Modes of religiosity: A cognitive theory of religious transmission. Walnut Creek, CA: AltaMira Press.

Whitehouse, H. 2008. Cognitive evolution and religion; Cognition and religious evolution. In Bulbulia, J., Sosis. R., Harris, E., Genet, R., Genet, C., \& Wyman, K., The evolution of religion: Studies, theories, \& critiques, 31-42. Santa Margarita, CA: Collins Foundation Press.

Whitehouse, H., \& Laidlow, J. 2004. Ritual and memory: Toward a comparative anthropology of religion. Walnut Creek, CA: AltaMira Press.

Wilberforce, W. 1997. Real Christianity: Discerning true faith from false beliefs. Minneapolis, MN: Bethany House Publishers. Original work published 1797.

Williams, G.C. 1966. Adaptation and natural selection: A critique of some current evolutionary thought. Princeton, NJ: Princeton University Press.

Wilson, D.S. 2002. Darwin's cathedral: Evolution, religion, and the nature of society. Chicago, IL: University of Chicago Press. 
Wilson, D.S. 2005. Testing major evolutionary hypotheses about religion with a random sample. Human Nature, 16 (4), 382-409.

Wind, Y., Crook, C., \& Gunther, R. 2005. The power of impossible thinking. Philadelphia, PA: Wharton School Publishing.

Wisner, B., \& Adams, J., Eds. 2002. Environmental health in emergences and disasters. World Health Organization Technical Notes for Emergencies. WHO, Geneva.

Wispé, L. 1986. The distinction between sympathy and empathy: To call forth a concept, a word is needed. Journal of Personality \& Social Psychology, 50 (2), 314321.

Wood, J.M., Nezworski, M.T., \& Garb, H.N. 2003. What's wrong with the Rorschach? San Francisco, CA: Jossey-Bass.

Wrangham, R., \& Peterson, D. 1996. Demonic males: Apes and the origins of human violence. New York, NY: Houghton Mifflin Company.

Wrangham, R., Jones, J.H., Laden, G., Pilbeam, D., \& Conklin-Brittain, N. 1999. The raw and the stolen: Cooking and the ecology of human origins. Current Anthropology, $40,568-594$. 
Xygalatas, D. (in press). Firewalking in the Balkans: High arousal rituals and memory. In I. Czachesz, Ed., Changing minds: Religion and cognition through the ages. Leuven: Peeters.

Zahavi, A. 1975. Mate selection: A selection for a handicap. Journal of Theoretical Biology, 53, 205-214.

Zahavi, A., \& Zahavi, A. 1997. The handicap principle. New York, NY: Oxford University Press.

Zajonc, R.B. 1980. Feeling and thinking: Preferences need no inferences. American Psychologist, 35, 151-175. 